\title{
An evaluation of the Thai Tsunami Victim Identification DNA Operation
}

\author{
Kirsty Wright
}

Bachelor of Biomedical Science (Honours)

A thesis submitted in fulfilment of the requirements for the degree of Doctor of

Philosophy, February 2016

\section{LVIJUNIVERSITY}

School of Natural Sciences, Nathan Campus, Griffith University 



\title{
KEY WORDS
}

South-East Asia Tsunami, Disaster Victim Identification (DVI), mass fatalities, Forensic Biology, Forensic Dentistry, Fingerprinting, Thai Tsunami Victim Information (TTVI) operation, human identification

\begin{abstract}
On 26 December 2004, a 9.3 magnitude earthquake struck off the west of Sumatra, Indonesia triggering a tsunami that killed over 280,000 people in thirteen countries. The total energy released from the earthquake was equivalent to 550 million times that of the Hiroshima atomic bomb. It was one of the deadliest natural disasters in modern history, and, in terms of scale and number of victims, the largest ever disaster victim identification (DVI) operation. In response, teams of police and forensic experts from around the world united to form the Thai Tsunami Victim Identification (TTVI) operation in Phuket from 12 January 2005 in an unprecedented effort to identify 3,679 victims. Approximately half of the victims were foreign tourists who perished along the popular tourist strip in Thailand. Forensic evidence, including the primary identifiers dental, fingerprints and DNA, were used to compare ante-mortem (AM) and post-mortem (PM) data in accordance with INTERPOL DVI guidelines. The identification effort continues today at the Royal Thai Police Headquarters in Bangkok for approximately 370 unidentified victims.
\end{abstract}

Given the extraordinary scale and complexity of the operation, a number of unique challenges confronted the TTVI DNA Team. One significant obstacle was the lack of AM DNA reference samples to compare against PM samples. This included personal items swept away by the wave. There were also multiple victims from the same family, often limiting the source of suitable kinship references. The most extreme example encountered involved twenty-two victims killed from one family, including twelve children. 
Mass disasters occur through natural phenomena such as earthquakes and floods, accidents including aviation disasters, or through deliberate acts of terrorism such as the World Trade Centre attacks and the Bali Bombings. A rapid, reliable and efficient forensic response to mass fatalities is needed to identify the victims, which, in the last 10 to 15 years, has become a highly specialised field separate from routine criminal case work. This specialised DVI capability has evolved and progressed as a result of the lessons learnt from each major disaster.

Each disaster has its own set of challenges that require logistical, technical and procedural solutions. The DVI response is usually thoroughly evaluated at an operational debriefing to evaluate the effectiveness and success of the response, to determine what issues and impediments existed that limited the response, and identify any lessons learned and improvements for use in future disasters. To date, only a small number of limited evaluations have occurred for the TTVI DNA response to the 2004 South-East Asia Tsunami, and all but one paper were written by authors without forensic biology experience, and only one paper has been published from a member of the TTVI DNA Team. These papers report only on the early phase of the TTVI operation where DNA had little success, or report inaccurate DNA identification figures, or fail to recognise critical impediments that limited the DNA response. Some papers state that DNA had little impact overall on TTVI identifications and recommend that DNA should only be used when all other methods are exhausted. Given the inaccuracy of many of these earlier evaluations and recommendations, the question still remains: how effective was the TTVI DNA response to victim identification? This thesis focuses on answering this important question.

The first paper in this thesis reveals that all TTVI teams struggled to identify a large proportion of victims due to incomplete or poor quality AM and PM data. In response to these challenges, 
the TTVI implemented a new 'near-threshold' DVI management strategy to systematically target presumptive identifications and improve operational efficiency. DNA kinship matches that failed to reach the reporting threshold of $99.9 \%$ were prioritized under this strategy and progressively filtered through the Investigation, Dental, and Fingerprint Teams to either add evidence to strengthen the case for identification, or conclusively exclude the match. Using the near-threshold strategy over a five-month period, 111 victims from ten countries were identified. The new identifications comprised 87 adults, and 24 children, of whom 97 were Thai locals.

In the second paper, analysis was performed to determine whether there was a difference in identification rates between adults and children ( $\leq 16$ years old). The data show that during the first 100 days of the operation the percentage of adult identifications far outweighed child identifications. On a nationality basis, the percentages of adult compared to child victims identified were: $89.0 \%$ of Finnish adults compared to $29.4 \%$ of Finnish children; $84.4 \%$ of German adults compared to $28.6 \%$ of German children; and $91.5 \%$ of Swedish adults compared to $27.0 \%$ of Swedish children. Additionally, the younger the child, the longer the identification process $(p<0.0001)$, with children under the age of 1 taking an average of 195 days to identify, compared to 130 days for children aged 16 . Identification times increased an average of 4.3 days for each year the victim was younger than 16 .

Reasons for the slower identification of children revealed numerous deficiencies in AM and PM material for children which were largely present for adults. In an effort to overcome the challenging child cases, the TTVI implemented a number of targeted DNA strategies which resulted in a significant increase in identifications shortly after introduction. Specifically, the DNA strategies identified 214 children (48.4\% of the 442 children identified up to 12 December 2005), while fingerprints identified 152 (34.4\%), dental 73 (16.5\%) and physical 3 (0.7\%). 
The third paper evaluates the overall impact of the TTVI DNA operation, leveraging off issues and strategies reported in the first two papers. The data demonstrate that in the early phase of the operation (end of May 2005), only 15 identifications had been established using DNA analysis (compared to 307 by fingerprints, 1,266 by dental and 11 by physical) indicating that critical impediments were limiting the TTVI DNA response. While 2,358 AM cases and 4,325 PM cases (including duplicates and body parts) had been created by the end of May 2005, only 310 AM profiles (13\% of cases) and 180 PM profiles (4\% of cases) were available. Issues also existed with data management and automated DNA kinship matching. These issues were recognised and quickly addressed by the TTVI, resulting in larger numbers of DNA identifications in the middle and later stages of the operation.

To better understand the impact of DNA on the TTVI operation, identification methods based on victim age was analysed. DNA was used for $13 \%$ of 2,439 adult victims from all nationalities, and a large proportion of the 442 child identifications (33\% of 10 - 16 year olds, $43 \%$ of 5 - 9 year olds, and $73 \%$ of $0-4$ year olds). The younger the victim, a significantly greater reliance was placed on DNA to establish identification $(p<0.0001)$. When considering age and nationality, DNA was used least for European adults (only $2 \%$ of 988 adult victims identified from Finland, France, Germany and Sweden), though DNA was successful for 30\% of Thai adult identifications (266 out of 886 ). By 16 July 2008 , DNA had identified $24 \%$ of all victims (799), dental 40\% (1,337), fingerprints 35\% $(1,142)$, and physical $1 \%(30)$. These findings indicate that a better understanding of the impact of victim demography on identification methods is crucial and may assist in planning and resourcing for future mass fatalities.

Overall, this research provides an accurate record of the TTVI DNA operation, including the challenges involved in victim identification, the strategies that were devised to overcome these 
issues, and a measure of how effective these strategies were. From this analysis, recommendations are provided that may assist in future mass disasters. This research also forms part of an historical record of the TTVI DNA operation which can be used by the forensic community as a tool for continuous improvement in victim identification. 
STATEMENT OF ORIGNAL AUTHORSHIP 
This work has not previously been submitted for a degree or diploma in any university. To the best of my knowledge and belief, the thesis contains no material previously published or written by another person except where due reference is made in the thesis itself.

Kirsty Wright 
Title page

Key words 3

Abstract 3

$\begin{array}{ll}\text { Statement of original authorship } & 9\end{array}$

Table of contents 11

$\begin{array}{ll}\text { List of tables } & 14\end{array}$

$\begin{array}{ll}\text { List of figures } & 14\end{array}$

$\begin{array}{ll}\text { List of abbreviations } & 17\end{array}$

List of publications and manuscripts $\quad 19$

$\begin{array}{ll}\text { Contribution of candidate } & 21\end{array}$

$\begin{array}{ll}\text { Acknowledgements } & 23\end{array}$

$\begin{array}{lll}\text { CHAPTER } 1 \text { Introduction } & 27\end{array}$

1.1 The Boxing Day Tsunami $2004 \quad 28$

1.2 Initial response to the tsunami in Thailand 31

1.3 The Thai Tsunami Victim Identification Operation 33

1.4 Disaster Victim Identification 39

1.5 Use of DNA analysis for disaster victim identification 48

1.6 Specific aims of this study $\quad 54$

1.7 Progress of research linking the scientific papers 55

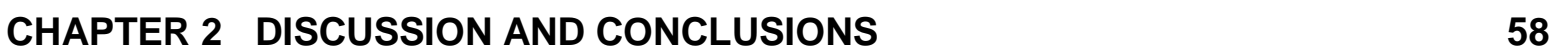

2.1 General Discussion and Conclusions $\quad 60$

2.2 Future Directions $\quad 69$

2.2.1 Improving Integration of DNA within the DVI Operation 70

2.2.2 Analysis of AM/PM TTVI Cases that Led to Mis-Identifications 75

2.2.3 Combined PM Kinship Analysis $\quad 77$

$\begin{array}{ll}2.3 \text { Recommendations } & 79\end{array}$ 


\section{APPENDIX}

This research is based on the following papers (referred to by the numbers 1 to 3 ).

PAPER 1 A new disaster victim identification management strategy targeting "near identification-threshold" cases: Experiences from the Boxing Day Tsunami

PAPER 2 DNA identification of child victims of the South-East Asia Tsunami in Thailand

PAPER 3 An evaluation of the Thai Tsunami victim identification DNA operation 


\section{CHAPTER 1}

Table 1: Number of missing persons by 15 December 2005 according to Plass Data entries.

\section{PAPER 1}

Table 1: Number of identifications assisted with the new strategy.

Table 2: Number of identifications assisted, by method, using the near-threshold strategy.

\section{PAPER 2}

Table 1: Adults and children identified in the first 50 and 100 days of the TTVI operation, by country.

\section{PAPER 3}

Table 1: Number of adults and children identified at 12 December 2005

\section{LIST OF FIGURES}

\section{CHAPTER 1}

Figure 1: Map of Boxing Day Tsunami 2004.

Figure 2: Thailand coastal areas affected by the 2005 Tsunami.

Figure 3: The INTERPOL DVI Process used at the TTVI

Figure 4: The TTVI International Command structure.

Figure 5: Thai Tsunami Victim Identification Command Structure.

\section{CHAPTER 2}

Figure 1: Incorporating the standard DVI method and the near-threshold method within a mass fatality operation.

Figure 2: Stages of a disaster management response that could include decision points on identification strategies.

\section{PAPER 1}


Figure 1: Percentage of total identifications each month achieved with stand-alone methods.

Figure 2: The near-threshold strategy used at the TTVI.

\section{PAPER 2}

Figure 1: Age distribution of 442 children who were victims of the South-East Asia Tsunami in Thailand (all nationalities).

Figure 2: A family with victims across three generations.

Figure 3: A local Thai family that lost twenty-two members in the tsunami.

Figure 4: Average days to identify children using all methods as a function of age.

Figure 5: Examples by country showing marked increases in child identifications following implementation of targeted child identification strategies at approximately 100 days into the operation, and near concordance between adult and child identification rates by day 300 .

Figure 6: Percentage of child and adult identifications established using DNA from percentage of total child and adult identifications throughout the first year of the TTVI operation (all nationalities and all methods).

Figure 7: The percentage of total child identifications, established each month by each method (all nationalities).

\section{PAPER 3}

Figure 1: Identifications by month and by method during the early, middle and late operational stages

Figure 2: Identification by method and age category.

Figure 3: Methods used to identify victims from Norway and Thailand in four age categories.

Figure 4: Percentage of victims identified with DNA between 0 to 16 years old across all nationalities. 


\section{LIST OF ABBREVIATIONS}

AFP

AFIS

AM

$\mathrm{Cl}$

DNA

DVI

GMT

ICMP

ID

IMC

INTERPOL

$\mathrm{km}$

kph

p

PM

SNP

STR

TTVI

WTC
Australian Federal Police

Automated Fingerprint Identification System

Ante-mortem

Confidence Interval

Deoxyribonucleic Acid

Disaster Victim Identification

Greenwich Mean Time

International Commission on Missing Persons

Identification

Information Management Centre

International Criminal Police Organisation

kilometres

kilometres per hour

Probability

Post-mortem

Single nucleotide polymorphism

Short Tandem Repeat

Thai Tsunami Victim Identification Centre

World Trade Centre 


\section{LIST OF PUBLICATIONS AND MANUSCRIPTS}

Included in this thesis are papers 1, 2 and 3 which are co-authored with other researchers. My contribution to each co-authored paper is outlined at the front of the relevant paper. The bibliographic details for these papers are:

1. K. Wright, A. Mundorff, J. Chaseling, A. Forrest, C. Maguire, D.I. Crane. A new disaster victim identification management strategy targeting "below identificationthreshold" cases: Experiences from the Boxing Day Tsunami. Forensic Science International 250 (2015) 91-97.

Accepted 10 March 2015

Copyright status: Copyright assigned to publisher.

2. K. Wright, J. Chaseling, A. Mundorff, C. Maguire, D.I. Crane. DNA identification of child victims of the South-East Asia Tsunami in Thailand.

Unpublished manuscript

Copyright status: Copyright status likely to be assigned to publisher.

3. K. Wright, A. Mundorff, J. Chaseling, C. Maguire, D.I. Crane. An evaluation of the Thai Tsunami victim identification DNA operation. Forensic Science Policy \& Management: An International Journal, (2015) 6:3-4, 69-78.

Accepted 30 June 2015

Copyright status: Copyright assigned to publisher.

Given copyright has been assigned to the publisher for papers 1 and 3, and is likely to be assigned to the publisher for paper 2 , I request that an embargo is placed on my thesis in order to restrict public access to the thesis once examination has been completed. 
Ethical clearance was granted for this research from the Griffith University Human Ethics Research Committee (GU Ref No: BPS/05/14/HREC) and was conducted in accordance with the approved protocol. Permission was granted to conduct this research by the Australian Federal Police (AFP). All manuscripts will be reviewed and endorsed by the AFP prior to journal submission. Permission was granted to use the TTVI Reconciliation data and the data was supplied by the Royal Thai Police. 


\section{CONTRIBUTION BY CANDIDATE}

I am a Forensic Biologist who has specialised in missing persons and disaster victim identification (DVI) for nearly 15 years. I have assisted in identifying thousands of victim murder, suicides, house fires, and drowning, accidental deaths, deaths in military combat, aviation disasters, terrorist bombings, and natural disasters. Between April and September 2005 I was seconded by the Australian Federal Police to lead the DNA team for the Thai Tsunami Victim Identification (TTVI) operation in Phuket. This was the largest DVI and forensic operation in history. As DNA Team Leader, I was responsible for approximately 150 police and scientists from over 30 countries, and my role was to devise procedures and policy for the TTVI for the fast and accurate identification of tsunami victims. I held this position for 5 months, so was in a unique position to see the DNA response unfold, from the early, middle and late stages of the TTVI operation.

The papers contained within this thesis describe first-hand accounts of the problems encountered by the TTVI DNA Team and include solutions that were successfully implemented to resolve them. I devised these solutions and was responsible for implementing and monitoring them with the assistance of the TTVI DNA Team. 


\section{ACKNOWLEDGEMENTS}

The TTVI DNA Team consisted of experts from around the world, and we worked under extreme circumstances trying to achieve the almost impossible. One of my motivations for writing these papers is to demonstrate what we collectively achieved. Despite the daily pressures we faced, we all smiled, treated each other with genuine respect and became true friends.

Thanks to my Supervisor Denis Crane for your support and advice and leading me through this process. Your humour and experience made this enjoyable.

Thanks to Janet Chaseling for your wise words, statistical assistance and friendship. I have always looked up to you.

Thanks to Amy Mundorff for your advice on how to present this work in a meaningful way. You left a lasting impression on me when I first met you in New York as you worked on the WTC Attacks. Your commitment and dedication to victim identification really inspired me and has strongly influenced my career. I consider you a real hero.

Thanks to Chris Maguire for your advice and time. Your work truly inspired me when I was an undergraduate and new to the forensic field. Your contribution to the DVI field is a legacy you should be proud.

To all the members of the Australian Federal Police and State agencies who deployed as part of Operation Cawdor, you are all amazing people. I have the utmost respect and admiration for you all. Being part of the Australian DVI Team and serving alongside you was a true honour. Thank you for your camaraderie, company at the bar each night, and the humorous conversation on the bus to and from the TTVI each day.

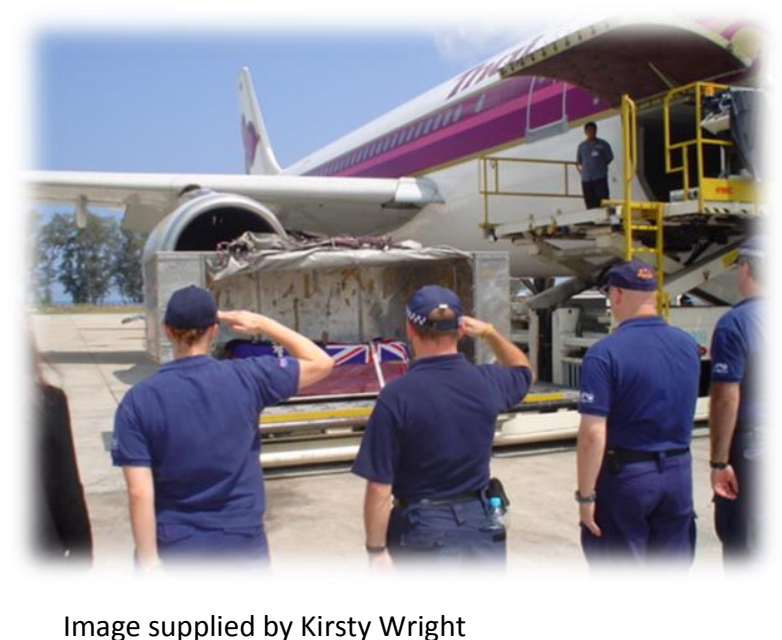


Thank you to the Royal Thai Police for giving me access to the TTVI Reconciliation data and for supporting this research. It was a great pleasure to work alongside all the men and women in the Royal Thai Police at the TTVI. Their total dedication to the operation and friendship during that period was invaluable, and they always made us feel welcome so far from home.

Lastly, special thanks to the families and friends who survived this tragedy for their strength and patience in assisting the TTVI to find their missing loved ones.
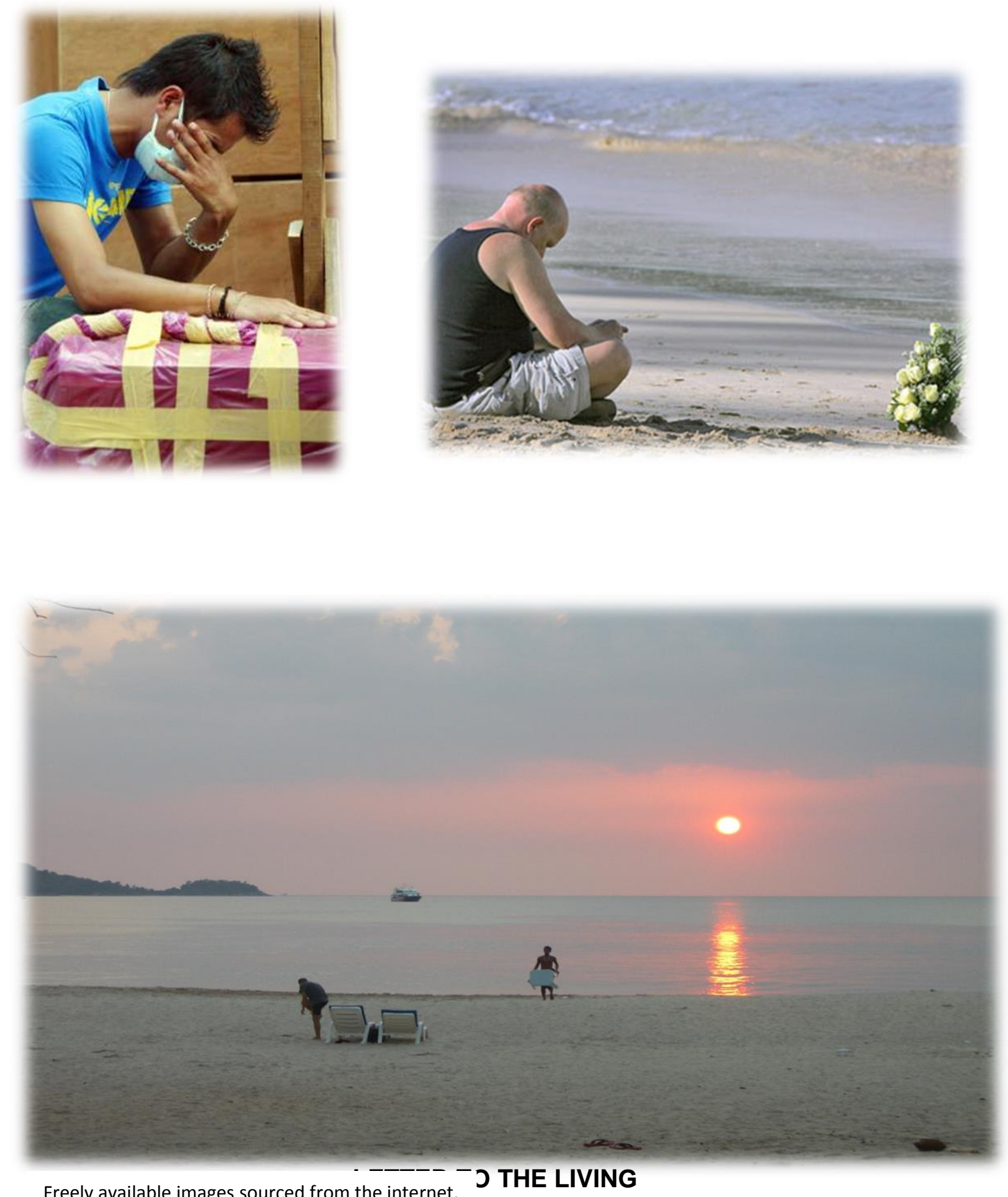
This poem was composed by an Australian interpreter after the tsunami and read at a memorial service for the victims at Patong Beach in 2005.

Hello my friend from distant lands.

I see you without my eyes and

Still you look upon my face as

Though I am watching you.

I feel your touch without my senses

And still you treat my body with

Unbridled kindness.

I hear you even though I am

Without ears, and still you speak

Softly to me as you do your work.

I know I am not what I used to be,

But please remember me as I was.

You may mourn my passing but

You must not be saddened by it.

As my life began, so must it end.

Know that your work for me,

My family and my country will

Never be forgotten.

Know that your smile throughout

Adversity lifts my spirits, as well as

Those of your friends and others

Around you. Always live your life

As though it may end at any time,

For it is then that you will truly live.

My eternal Love and Blessings.

The unknown dead.
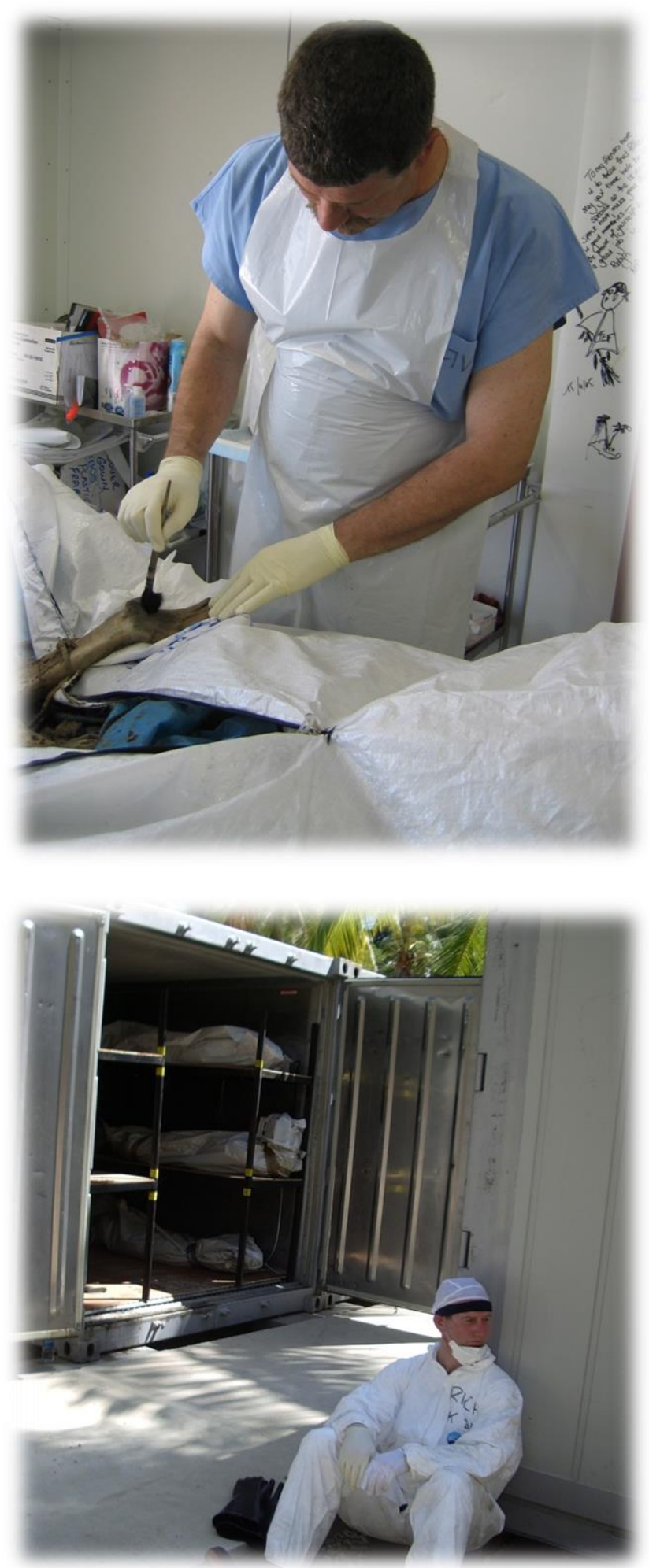

Freely available images sourced from the internet. 

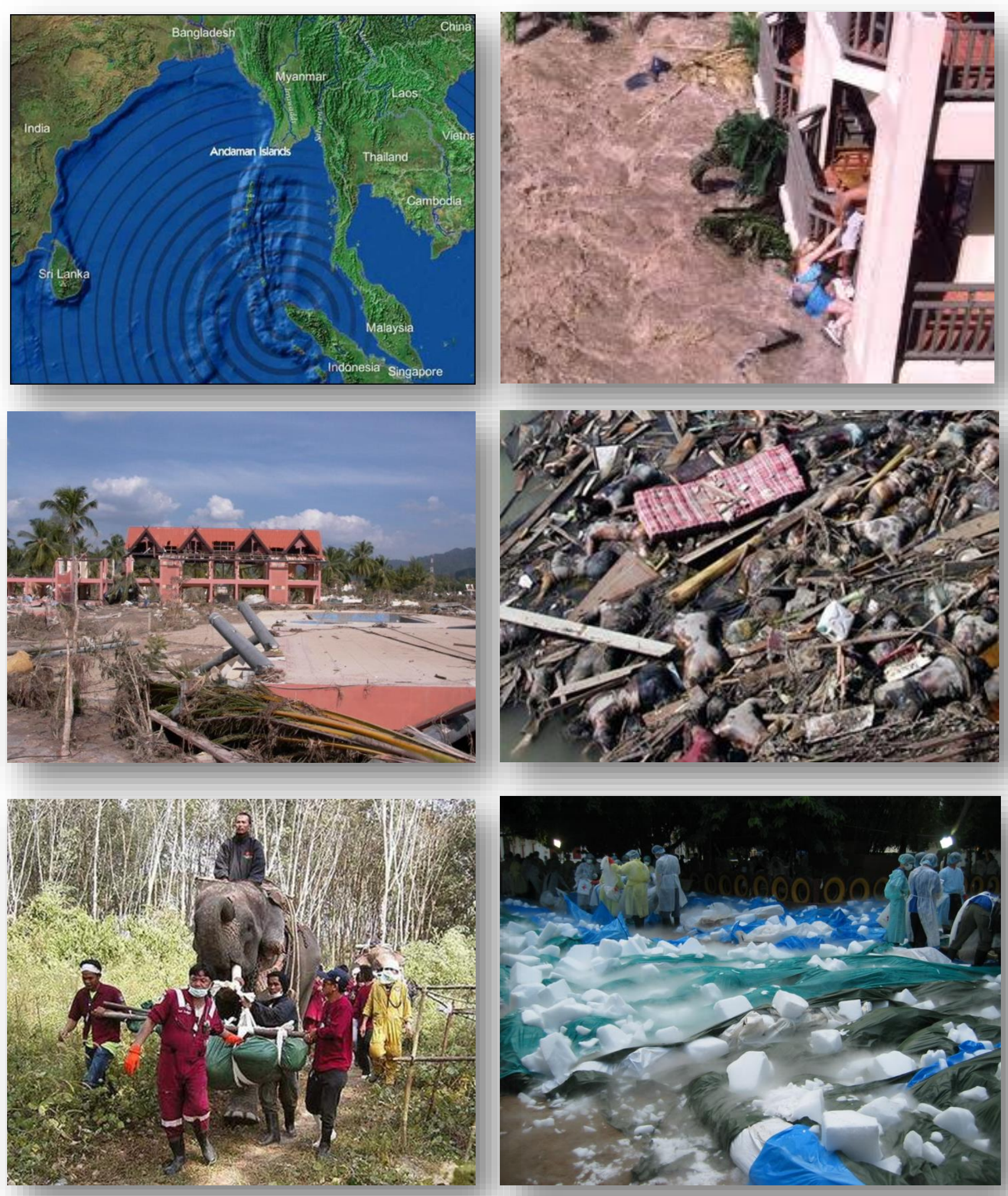

Freely available images sourced from the internet. 


\subsection{The Boxing Day Tsunami 2004}

At 00:58 GMT (07:58 Thai local time) on 26 December 2004 an earthquake measuring 9.3 on the Richter scale struck in the Indian Ocean approximately $250 \mathrm{~km}$ off the west coast of Sumatra creating a rupture up to $1,300 \mathrm{~km}$ long (Figure 1) (INTERPOL Tsunami Evaluation Working Group; Nalbant et al, 2011). It was the largest earthquake recorded in 40 years and the third largest earthquake ever recorded on a seismograph, and was so strong it caused the Earth to wobble on its axis by 1 centimetre (Paris et al, 2007). The massive displacement of water caused by the shifting tectonic plates created a series of waves travelling approximately 800kph towards thirteen countries, causing one of the world's deadliest natural disasters and killing an estimated 280,000 people (INTERPOL Tsunami Evaluation Working Group; Paris et al, 2007). Indonesia was the worst affected nation with an estimated 160,000 dead or missing, Sri Lanka second with 35,000 dead or missing, India third with 8,850 dead or missing, and then Thailand with 8,195 dead or missing, followed by the Andaman and Nicobar Islands (7,450 dead or missing). The other affected nations were Somalia (200 dead), Maldives (81 dead), Malaysia (68 dead), Myanmar (61 dead), Tanzania (10 dead), Bangladesh (2 dead), Kenya (1 dead), and Seychelles (1 dead) (INTERPOL Tsunami Evaluation Working Group).

Figure 1: Map of Boxing Day Tsunami 2004.

Source: http://www.bbc.co.uk/schools/gcsebitesize/geography/natural_hazards/tsunamis_rev2.shtml

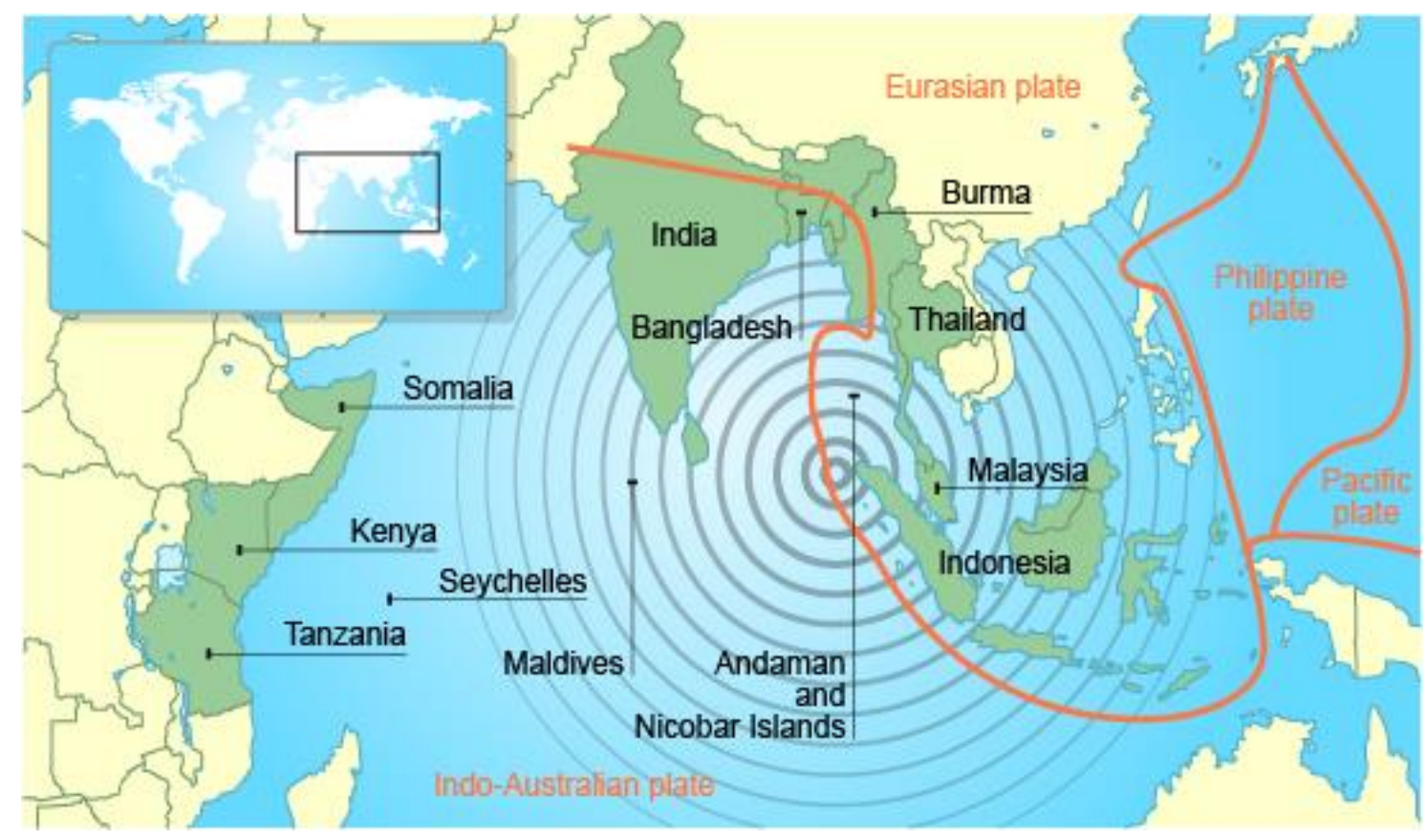


Within 90 minutes of the earthquake occurring, approximately $380 \mathrm{~km}$ of Thailand's coastline and outlying islands were struck by waves reaching 10 to 30 meters high (INTERPOL Tsunami Evaluation Working Group). The Thai Meteorological Department did not issue a tsunami warning, so locals and tourists were unaware of the impending disaster, and this contributed to the high death toll (Cohen, 2007). The tsunami hit the western coast of Thailand, with the most severe damage to Krabi, Trang, Phang-Nga, Phuket, Ranong and Satun provinces, an area containing 407 villages and a large number of tourist resorts (Figure 2) (Rosa). Rosa reported that the tsunami destroyed $52 \%$ of residential constructions in Phang-Na, $21 \%$ in Phuket and $14 \%$ in Krabi.

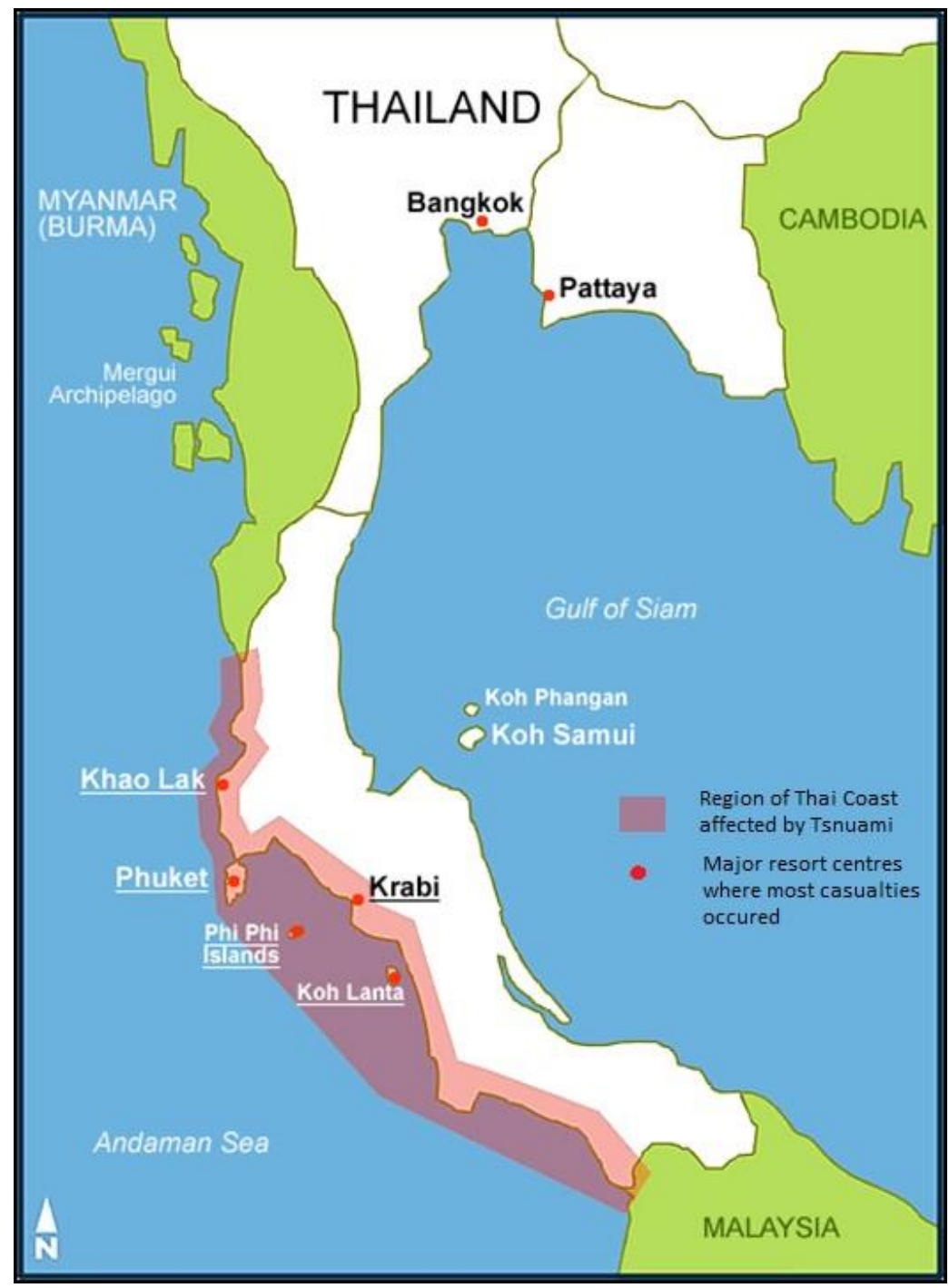

Figure 2: Thailand coastal areas affected by the 2005 Tsunami.

Source: www.linkedin.com/pulse/20140722221403-187701030-thai-tsunami-disaster-victim-identification-reporta-fingerprint-perspective 
Phang-Nga, Phuket and Krabi attract large numbers of foreign tourists and local workers. In total, there were 5,395 fatalities, representing 42 nationalities (INTERPOL Tsunami Evaluation Working Group). The foreign tourists who lost their lives in these regions were from 41 different countries and all major continents. Table 1 provides data on the number of missing persons for each nation (INTERPOL Tsunami Evaluation Working Group; De Valk, 2006). The Europeans were the most affected tourists, comprising over $80 \%$ of the foreign national deaths (De Valk, 2006). Ranong (on the northern coast), Trang and Satun (both on the southern coast) are more rural, and less populated with tourists. Phuket and Ranong are the fifth and seventh highest ranked provinces for the number of documented migrant labourers from Myanmar (the number of illegal Myanmar labourers in these regions at the time of the tsunami was unknown) (Fujita et al, 2006). Given the provinces affected, large numbers of Thai locals (of varying socio-economic backgrounds in both populated and rural districts), foreign tourists and both legal and illegal Myanmar labourers from a lower socio-economic background were the three main victim groups from a national and socio-economic perspective. The scale, location and timing of the disaster had a significant impact on victim demography, creating large numbers of victims of varying ages, nationalities, cultural, and socio-economic differences. This victim demography in turn created challenges for the DVI operation and led to certain groups being easier to identify, while other groups were more difficult, which made their identifications substantially slower. Victims' age, country of origin, and socio-economic status would inevitably impact on the type, accuracy, completeness, and speed that antemortem (AM) evidence was made available to the Thai Tsunami Victim Identification operation (TTVI) to achieve identifications. 
Table 1: Number of missing persons at 15 December 2005 according to Plass Data entries.

\begin{tabular}{|lc|lc|lc|}
\hline Country & Victims & Country & Victims & Country & Victims \\
Australia & 13 & Italy & 24 & Spain & 2 \\
Austria & 71 & Japan & 15 & Sweden & 519 \\
Belgium & 5 & Kazakhstan & 3 & Switzerland & 91 \\
Canada & 17 & Laos & 1 & Russia & 6 \\
China & 3 & Malaysia & 1 & Thailand & 1582 \\
Czech Republic & 5 & Myanmar & 131 & The Netherlands & 26 \\
Denmark & 38 & Nepal & 4 & Turkey & 1 \\
Estonia & 3 & New Zealand & 3 & Ukraine & 2 \\
Finland & 167 & Norway & 77 & United Kingdom & 82 \\
France & 72 & Philippines & 6 & USA & 17 \\
Germany & 495 & Poland & 6 & Yugoslavia & 1 \\
Greece & 1 & Portugal & 5 & Zimbabwe & 1 \\
Hong Kong & 9 & Singapore & 13 & & \\
Ireland & 3 & South Africa & 4 & & 3538 \\
Israel & 5 & South Korea & 8 & Total & \\
\hline
\end{tabular}

Source: De Valck (2006). Note: This figure is based on AM records rather than number of bodies. Thai authorities suspected that many illegal Myanmar labourers were not reported missing by their families for fear of persecution.

\subsection{Initial Response to the Tsunami in Thailand}

Given the scale of the disaster in terms of geographical area and number of deceased, it was unrealistic to expect a single agency or country to have the experience or resources to adequately perform victim identification. To the credit of the Thai authorities, body recovery and management commenced quickly, with a combined effort from the military, police, Thai non-government organisations (including the Po-Tek-Tung Foundation and the Ruam-KaTan-Yu Foundation), local volunteers and foreign tourists (Morgan et al, 2006). The largescale body retrieval effort continued for 10 days (until 5 January 2005) with nearly 5,000 bodies recovered in that period. However, bodies were still being discovered months after this date among debris or in the sea (Cohen, 2007). The bodies were taken to a temporary morgue at Wat Yanyao, a Buddhist temple in Takua-Pa Province, established by Dr Pornthip Rojanasuan 
(Deputy Directory of the Central Institute of Forensic Science, part of the Thai Ministry of Justice). Temporary storage facilities were also established in Buddhist temples at Wat Ban Muang, Mai Khoa and at Krabi. Dr Pornthip and her team of Forensic Scientists from Bangkok arrived in the affected area the afternoon of the disaster and commenced establishing the make-shift identification centre at Wat Yanyao (James, 2005). The temples, however, lacked refrigeration, so bodies rapidly decomposed in the hot sun, leading to loss of vital information that could assist in the identification process. The Thais immediately started taking photographs and collecting PM evidence from the decomposing bodies, including internal and external examination, recording property, collection of fingerprints where possible (decomposition prevented collection of approximately 3,000 fingerprints), and collection of DNA samples (initially hair and soft tissue) (Cohen, 2007). The Thai forensic teams completed examination of approximately 3,600 bodies within the first 7 to 10 days. During this period approximately 1,100 bodies were released to families and another 500 bodies were released to police and local physicians without the support of forensic evidence (Morgan, 2006).

International authorities wanted to ensure legally correct identifications, and were under pressure from victims' families to expedite repatriation. Concerns were raised by many nations over the accuracy of the initial identifications, fearing that bodies of foreigners were being incorrectly repatriated (Scanlon, 2008). In response, Thai authorities accepted assistance from international forensic identification teams and authorised classification of the deceased into two groups, 'Asian' and 'European' or 'Foreign' (Cohen, 2007). Within a week, international teams started working in the Thai make-shift mortuaries on the bodies classified as 'Foreign'; however, there was tension over some nations prioritising the identification of their own citizens, and further concerns over the accuracy of the classification of Asian and Foreign bodies. The fragmented approach of identifying the deceased was clearly not working. The Thai government decided on a joint effort between the Royal Thai Police, Thai 
forensic experts, INTERPOL, and international DVI teams, and on 12 January 2005 the TTVI was established. (Cohen, 2007; INTERPOL Tsunami Evaluation Working Group).

\subsection{The Thai Tsunami Victim Identification Operation}

The TTVI operation, the largest DVI in history, was launched on the island of Phuket and was comprised of police, forensic scientists and support staff from over 30 countries (Cohen, 2007; INTERPOL Tsunami Evaluation Working Group; Morgan 2006). Of the 5,395 fatalities, 1,716 bodies were repatriated prior to the TTVI operation, leaving 3,679 unidentified bodies (INTERPOL Tsunami Evaluation Working Group). All of the unidentified bodies underwent a second post-mortem in the hope of collecting more information and to ensure accuracy of the initial examination. The goal of the TTVI was to accurately identify the bodies as quickly as possible, while treating each victim equally, regardless of nationality, age, gender or background (INTERPOL Tsunami Evaluation Working Group). The TTVI mandate meant that the fragmented approach to victim identification would cease, and all local and international teams would work together to identify all victims equally. Dental, fingerprint, DNA and physical evidence was used to establish identification based on INTERPOL DVI Guide and processes. The INTERPOL DVI process, consisting of the recovery, PM collection, AM collection, reconciliation, and repatriation phases, was implemented into the TTVI as shown below (Figure 3). The bodies were recovered and sent to mortuaries where PM information (dental, fingerprints, DNA, and property) was collected. The PM information was sent to the Reconciliation Teams (dental, fingerprints, DNA, and property) to compare the same data categories for AM information. When a match between AM and PM data was found, the information was checked and sent to the Identification Board, who could then verify the match, which then led to repatriation. 


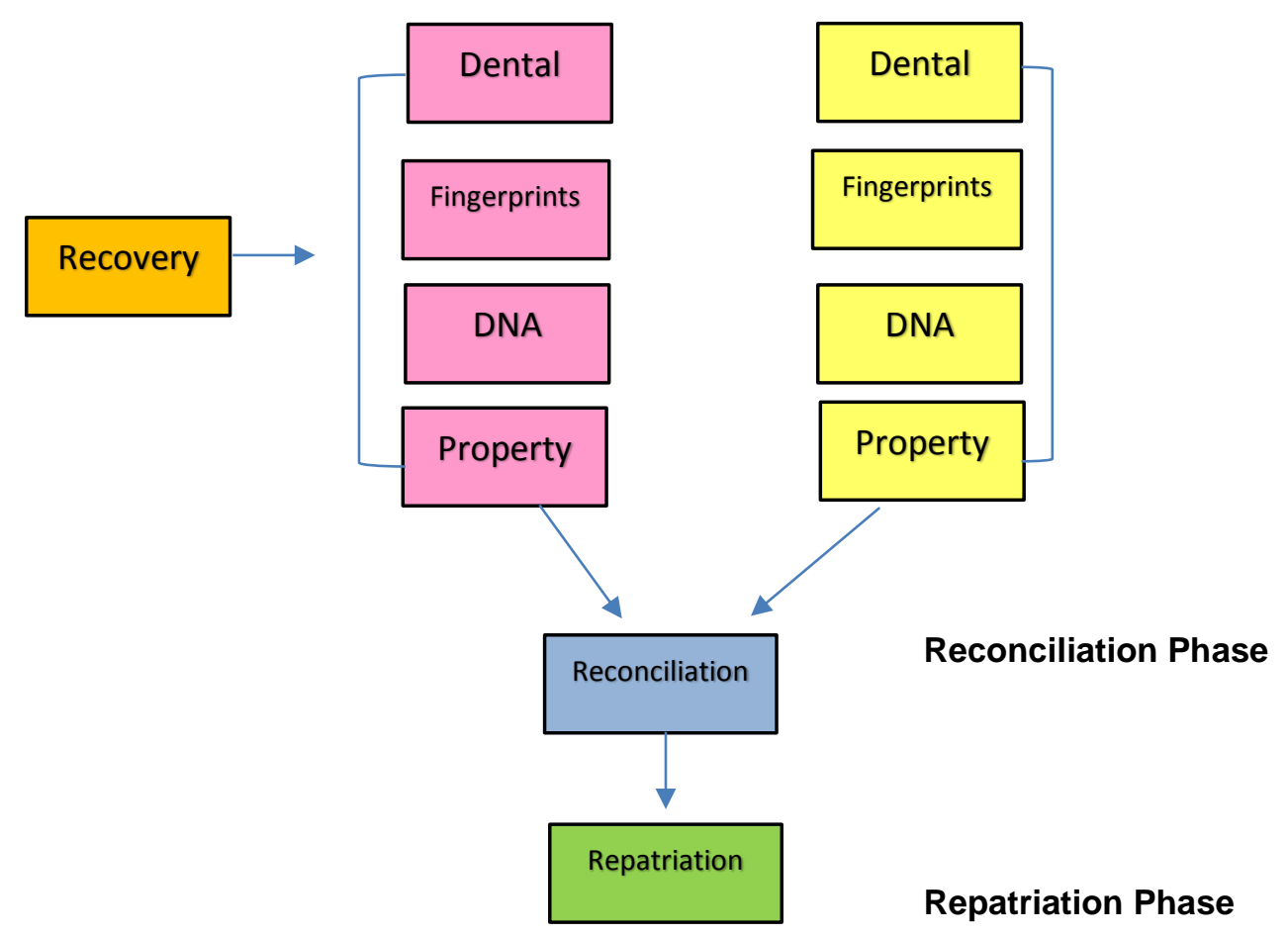

Figure 3: The INTERPOL DVI Process used at the TTVI.

The main stakeholders of the TTVI were families of the victims, all nations which incurred human losses, the Thai provincial governments, the Thai and foreign government departments, Thai and foreign law enforcement agencies, Thai and international health agencies, funding nations, INTERPOL, and National DVI teams (INTERPOL Tsunami Evaluation Working Group, p60-61). Partners of the TTVI included the Telecommunications Organisation of Thailand, Normeca, CrimTrac, Plass Data, The Bode Technology Group, the International Commission of Missing Persons, Beijing Genomics Institute, UK Forensic Alliance, the National Board of Forensic Medicine (Department of Forensic Genetics, Sweden), other international forensic laboratories, Barcode Data Systems, participating foreign government agencies, private practitioners, and other international aid agencies (INTERPOL Tsunami Evaluation Working Group, p61). 
An international command structure was established at the outset of the TTVI operation to enable a professional and standardised approach to management decisions and the running of the operation (Figure 4) (INTERPOL Tsunami Evaluation Working Group). The structure incorporated Thai government and police officials with international police and scientific experts. The aim of the command structure was to provide a fair and transparent system of management while leveraging off the combined experiences of all nations involved. The TTVI command structure was also established at the commencement of the operation with clearly defined roles and responsibilities documented for each position and team (Figure 5) (INTERPOL Tsunami Evaluation Working Group). The structure was effective for the daily running of the TTVI and only minor changes were made to the structure throughout the operation (mainly to consolidate teams where appropriate in the later stages of the operation to increase efficiency as workloads shifted throughout the DVI phases). 


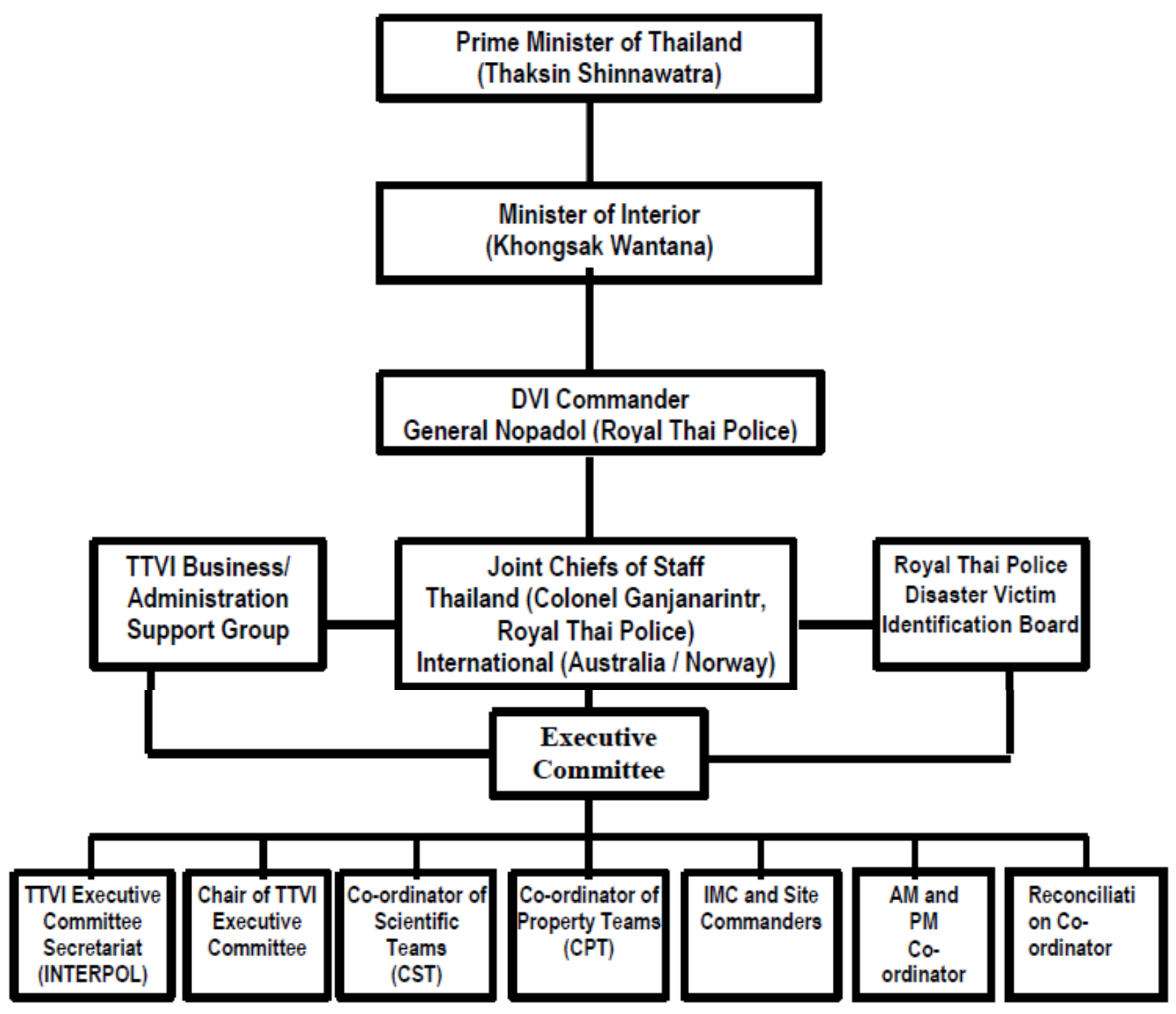

\begin{tabular}{|l|}
\hline \multicolumn{1}{|c|}{ TVI Executive Committee Members } \\
Representatives from all participating countries \\
currently directly involved in the TTVI DVI operation (at \\
12 September $2005-17$ countries) \\
Police Liaison (on rotation) \\
Joint Chiefs of Staff and IMC Commander \\
Diplomatic liaison officer/advisor \\
Financial advisor (IRL) \\
\hline
\end{tabular}

Figure 4: The TTVI International Command structure.

Source: INTERPOL Tsunami Evaluation Working Group, (p67). 


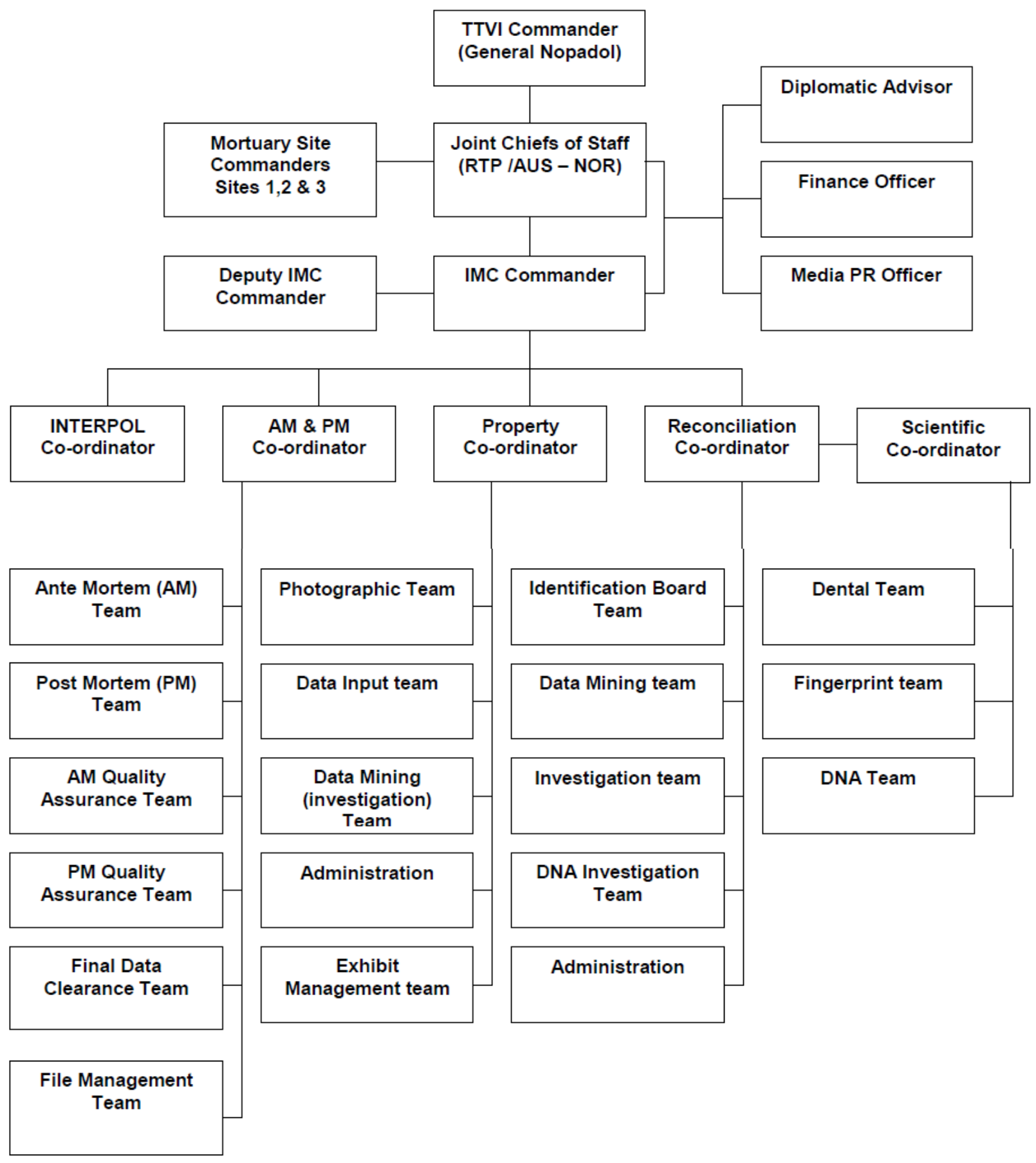

Figure 5: Thai Tsunami Victim Identification Command Structure.

Source: INTERPOL Tsunami Evaluation Working Group, (p84).

The DNA Team comprised the DNA Team Leader and, initially, two working teams, one at the mortuary collating DNA samples and preparing shipments to laboratories, and the other at the 
TTVI Information Management Centre (IMC). Initially the DNA Team at the IMC was under the command of the AM/PM Coordinator, but was moved to the command of the Reconciliation Coordinator in the mid-stage of the operation once a majority of AM and PM DNA profiles had been received for comparison. The DNA team was staffed by forensic biologists and police from approximately a dozen countries. Each national DVI team had a rotation policy of 3 to 5 weeks, so the composition of the team was constantly changing (there were exceptions, such as a scientist from the Beijing Genomics Institute who worked in the DNA Team for several months, and the author who was DNA Team Leader for five months). The author estimates at least 100 staff rotated through the DNA team between 12 January and 12 December 2005, with some staff performing multiple rotations during that period. The main roles of the DNA Team at the IMC were to develop protocols for accurate matching and reporting of DNA results consistent with international standards, manage information from DNA sample analysis and related information, perform quality assurance on DNA profiles and DNA reports, generate DNA matches using available DNA matching software, provide statistical calculations to support DNA matches, and compile and present DNA reports for the TTVI Identification Board.

A total of 3,679 victims required identification as part of the TTVI operation (INTERPOL Tsunami Evaluation Working Group). The DNA Team followed ISO/IEC 17025 guidelines to develop procedures and methods associated with the collection of DNA samples, analysis and reporting of results. Identifiler ${ }^{\mathrm{TM}}$ (15 STR loci) was used to analyse all AM and PM samples. DNA profiling was not performed by the TTVI. AM analysis was performed by laboratories in the country where the missing person resided, and PM analysis primarily by the International Commission on Missing Persons, Beijing Genomics Institute, and the National Board of Forensic Medicine, Sweden. On several cases Y-STR analysis was required to confirm sex when a suspected mutation occurred on the amelogenin gene preventing amplification of the Y-chromosome fragment. No cases were analysed with mitochondrial DNA. A posterior probability of $99.9 \%$ was used as a reporting threshold (which was determined by the author 
whilst DNA Team Leader), with cases reaching 95\% and above investigated further with a 'near identification-threshold strategy' (see paper 1). A combination of software was used to generate DNA matches and statistical probabilities, including Plass Data's DVI System Internationale (direct matches), DNA-View (perform calculations), in-house software from the International Commission of Missing Persons (direct and kinship matches) and in-house software from Queensland Health and Scientific Services (BRB Stats, direct and kinship match, and calculations). Allele frequencies from Asian, Caucasian, and Thai populations were reported for each case.

\subsection{Disaster victim identification}

The definition of a 'disaster' varies between organisations. The International Federation of the Red Cross defines a disaster as 'a sudden, calamitous event that seriously disrupts the functioning of a community or society and causes human, material, and economic or environmental losses that exceed the community's or society's ability to cope using its own resources'. Most countries and jurisdictions have legislative definitions of a 'disaster' or 'major incident' that trigger provisions and powers to enable an appropriate response. Identification of victims of disasters is considered a humanitarian response and the need for identity is a basic human right (James, 2005). The need to identify deceased individuals was stipulated in the 1949 Geneva Convention (I) for the Amelioration of the Condition of the Wounded and Sick in Armed Forces in the Field (Articles 16 and 17).

A disaster can be caused by natural events (such as earthquakes, floods, and bushfires), accidents (such as aviation accidents), or criminal actions (such as terrorist bombings or hijacking of planes). The terms 'closed' and 'open' disasters are used to characterise disaster events and can influence how a DVI operation is conducted. A 'closed' disaster is characterised by an event leading to a known number of victims whose identity is often known. 
For example, a plane crash in an unpopulated location would be considered a closed disaster, and the names of the passengers would be available on a flight manifest. Authorities can therefore quickly establish a list of victims (including their name and nationality) for collection of AM information and evidence. The finite number of victims in a closed disaster also enables a better estimation of resources required to conduct a DVI operation. Open disasters are characterised by events that lead to the death of an initially unknown number of people, without any confirmation of their identity. The Boxing Day tsunami was an open disaster, and encompassed the difficulties associated with open disasters, including a constantly fluctuating list of missing persons, uncertainty surrounding the completeness of body recovery and repatriation, and an initial uncertainty of what staffing and resources were required for the operation.

The scientific response to identification of disaster victims has developed slowly. Forensic odontology was the first of the three primary identifiers used for victim identification. It was used in 1878 to identify victims of a fire in the Vienna Opera House (Taylor, 2009). In 1940 the Federal Bureau of Investigation (FBI) established the FBI Disaster Squad, recognising the need for fingerprint methods for mass fatality incidents (Kaushal, 2009), and it wasn't until the 1993 Waco massacre that DNA profiling was used in a disaster operation (Clayton et al. 1995). The three primary identifiers (a method sufficient to establish identification as a stand-alone approach) are dental analysis, fingerprint comparison, and DNA analysis. Secondary identifiers are those that can support identification by a primary identification method, but are typically insufficient to establish identification alone (such as tattoos, personal property, and medical information) (INTERPOL DVI Guide). Taylor (2009) suggested that the modern era of forensic odontology commenced in response to a fire in the Paris Bazar de la Charité on 4 May 1897 where 126 people died. Barnes (2011) reported that the sinking of the USS Squalus in May 1939 was the first American disaster in which fingerprints were used to identify the 
victims. Short tandem repeat (STR) DNA analysis was first used in 1993 to assist in the identification of 76 victims of the Waco disaster (Clayton et al, 1995).

The application of international standards was seen as a necessity for the development of DVI, especially for consistency and uniformity in multinational disasters. To this end, the first INTERPOL DVI Guide, resulting from the work of the INTERPOL Standing Committee on DVI, was published in 1984. The DVI Guide is revised every seven years, with the most recent version released in 2014. The national DVI protocols of each member nation are based on the INTERPOL Guide to further enhance uniformity. The INTERPOL AM and PM forms are now used internationally as standard practice to record information about the missing person and unknown deceased respectively, to ensure a consistent and comprehensive approach to data collection, which facilitates subsequent comparison of forensic evidence and provides quality assurance. The use of the INTERPOL DVI Guide and AM and PM forms during the TTVI provided an enormous benefit considering the large number of nations involved in AM and PM data collection. Inconsistencies in evidence recording existed, however, this was due to differences between nations in terminology for description of clothing and other property (in response, the INTERPOL Standing Committee on DVI has established a list of standard terminology to be used for property fields on the AM and PM form).

A DVI response is a series of phases designed to give a structured and consistent approach to victim identification, with commanders designated as responsible for each phase. The structured approach to DVI operations can also assist with allocation of resources and personnel, with certain skill sets being required for each phase. The INTERPOL DVI Guide (2014) lists the four phases as: Scene (Phase 1), Post-mortem (Phase 2), Ante-mortem (Phase 3), and Reconciliation (Phase 4). Often a fifth phase, a 'debrief' or an 'evaluation' is unofficially included to discuss lessons learned and health and safety issues, and to provide 
recommendations for continuous improvement. In small DVI operations each of the four phases often occurs sequentially, while large disasters (characterised by number of victims or geographical area) usually lead to extended DVI phases, which therefore overlap or can progress concurrently.

The Scene Phase involves securing and searching the scene, recording, labelling, preservation, and collection of bodies, body parts, and packaging of property (INTERPOL DVI Guide). Depending on the nature of the disaster the Scene Phase can include recording and collection of other items by various specialists (for example, suspected bomb parts, or aircraft debris that may be analysed to determine the cause of an accident). INTERPOL 'DVI Recovery Forms' have been developed to assist with standardising recording and labelling of scene items (INTERPOL DVI Guide). Essentially, the scene should be handled like a crime scene to ensure preservation, integrity, and continuity of 'evidence' (depending on the disaster, the evidence could also be used in a criminal or civil court). Given the Boxing Day Tsunami was an open DVI that spanned many hundreds of kilometres along the Thai coast, it was not possible to secure the scene or prevent removal or destruction of evidence. Further to this, the INTERPOL Scene Phase guidelines were not followed, and body recovery was performed largely by untrained groups and volunteers. For example, the exact location of each body was not recorded, bodies were not labelled prior to removal, property not associated with bodies was not collected, preservation of the bodies was not possible due to lack of refrigeration, some bodies and body parts were not recognised as such and were overlooked, and the continuity of bodies and any property collected could not be guaranteed. After the initial chaos of body recovery, Thai and international experts searched areas thought to contain unrecovered bodies. In fact, months after the tsunami, bodies and body parts continued to arrive at the TTVI mortuary, discovered either by locals or search teams. Cohen (2009) reported that at least twenty bodies were recovered in the Phang Nga province by authorities in May 2005, five months after the disaster. 
The post-mortem phase involves the examination of bodies, body parts, and property at a designated mortuary site or sites, which provide secure storage and preservation. The aim of the post-mortem phase is to record, collect and analyse evidence that could lead to identification of the deceased by comparison with ante-mortem evidence (INTERPOL DVI Guide). Typically the following processes are performed by trained specialist during the postmortem phase: photography, processing of property found on the deceased, fingerprinting, odontology, DNA sampling (and subsequent analysis), internal and external examination and autopsy procedures (INTEROL DVI Guide). The INTERPOL DVI PM forms are used during this process to record the information either as a hard copy or electronic record. The accuracy, continuity, and integrity of the post-mortem phase are essential to obtain high quality evidence to establish identifications. Errors due to mis-labelling, transcription errors, sample mix-ups, inexperienced or unqualified personnel, fatigue, lack of appropriate equipment or resources, incomplete or inaccurate descriptions, and corruption of data can cause false exclusions or misidentifications which may not be discovered until well into the DVI operation.

There were numerous difficulties and issues associated with the post-mortem phase conducted during the initial response to the tsunami by Dr Pornthip and her team, as would be expected with a disaster of this magnitude. These included the initial lack of refrigeration which led to the rapid decomposition of bodies and loss of post-mortem evidence (it took about two weeks for approximately 100 containers to be delivered to store approximately 3,600 bodies), inadequate facilities to perform post-mortems (a make-shift examination room was constructed in the prayer area of the temple), small staff numbers with varying levels of experience, an inadequate body labelling system which led to multiple bodies being given the same PM number (PM labels were also originally written on paper and placed on the bodies, which perished as the body decomposed, preventing samples and records from being 
reassociated), a reliance on visual identification, and the INTERPOL DVI Guidelines not being implemented at this stage [Cohen, 2009; Morgan, 2006). After the formation of the TTVI, the DVI Commander authorised the re-examination of all unidentified bodies, in a process called the 'final inventory protocol', in an attempt to detect errors in the initial post-mortem phase, collect additional data, and validate existing information (completed in May 2005) (INTERPOL Tsunami Evaluation Working Group). Essentially, the completion of the post-mortem phase for the TTVI was delayed, which also delayed identifications and extended the operation.

From a DNA perspective, the samples removed from bodies during the final inventory protocol (5cm of femur and molars) were of good quality and provided up to a $95 \%$ success rate (complete 15 STR loci profiles) (Deng et al, 2005; Holmund et al, 2006). Initially, however, laboratories only obtained DNA profiles from a handful of samples. Some authors reported that the initial difficulties in obtaining complete STR profiles was due to the bodies being too decomposed, the effects of the bodies being exposed to salt water from the ocean, or due to invasion by microbes (Deng et al, 2005; Lessig et al, 2006). However, given the success of post-mortem DNA profiling of the samples obtained from the final inventory protocol it is more likely that sample and method selection, and laboratory inexperience with DNA profiling bone samples led to the initial poor results (INTERPOL Tsunami Evaluation Working Group). For example, in the initial post-mortem soft tissue, rib sections and teeth were collected (INTERPOL Tsunami Evaluation Working Group; Lessig et al, 2006). The DNA in the soft tissue would have been affected by the extreme temperatures and lack of refrigeration. Teeth are an excellent source of DNA, however at least two laboratories sampled the tooth pulp rather than the dentin. The tooth pulp failed to produce profiles because, similar to other soft tissue, it was too degraded. Laboratories also tried different DNA extraction methods for bones (often more suitable for soft tissue) before using an extraction method targeted for bone tissue (Deng et al, 2005). The initial difficulties associated with the DNA analysis of the bone samples delayed the progress of the TTVI DNA team and delayed identifications. Ideally, a 
Forensic Biologist with experience in analysis of bone samples should provide advice on sample selection and assist in the mortuary during the post-mortem phase. This is consistent with Recommendation 66 of the INTERPOL Tsunami Evaluation Working Group which states: 'It is recommended and important that persons with appropriate experience and skills of DNA analysis within laboratory work and DVI take part in the initial assessment of the disaster scene and be involved in the decisions taken after such an assessment' (INTERPOL Tsunami Evaluation Working Group, p130). Only laboratories with experience in DNA analysis of bone samples should be used to provide post-mortem DNA profiles, and where possible this experience should be shared with other laboratories to enable a surge capacity for large disasters. The INTERPOL Tsunami Evaluation Working Group also highlights the need for laboratory experience when processing PM samples from DVI operations in Recommendation 68: 'It is recommended that INTERPOL makes an inventory of accredited laboratories prepared and skilled to preform DNA analysis of post-mortem samples and deliver results according to the requirements stated' (INTERPOL Tsunami Evaluation Working Group, p136).

The ante-mortem phase involves generation of a list of possible victims and the recording, collecting, and preservation of information and items relating to those possible victims by police and specialists. Typical AM evidence collected for comparison against PM evidence includes fingerprints, (either latent from personal effects or ten prints from identity cards), palm prints and footprints, dental records and charts, DNA samples (from personal items, medical samples, or from close biological relatives), medical records and charts, photographs, descriptions of the missing person's physical appearance (including scars and tattoos), and descriptions of property (such as jewellery and clothing) (INTERPOL DVI Guide). The INTERPOL DVI AM form is used to record these descriptions, information, and note samples collected. Given victims of the tsunami were from 42 nations, the ante-mortem phase was a global event. Police and specialists from the missing person's country were responsible for the collection, documentation, analysis, and transmission of AM evidence to the TTVI. This 
created numerous issues including a preference of some AM evidence over others by some countries, issues with standard terminology between countries to describe property, data transmission issues which affected the quality or format of data being received, and in some cases a lack of appreciation of how much AM evidence was needed for the size of the disaster (for example some countries collected only one DNA sample from a relative) (INTERPOL Tsunami Evaluation Working Group, p21). Different national policies and legislation meant that some countries had access to better quality AM evidence. For example, Thailand require all citizens over 16 years to have an identity card containing ten prints, and Sweden temporarily changed legislation for the use of medical bio-bank cards allowing rapid access to 124 bio-bank samples (medical heal prick cards) within the first few weeks of the disaster (INTERPOL Tsunami Evaluation Working Group; Montelius \& Lindblom, 2012).

The lack of available AM DNA samples (the causes of this will be discussed in papers 1 to 3 ) was a major impediment to the TTVI DNA Team. Chaikunrat et al (2011) stated that only $58.1 \%$ of AM records contained DNA evidence by 9 January 2008 . In addition, family trees and pedigree analysis were not conducted by most countries prior to DNA samples being collected and submitted. This may have been due to lack of direction by the TTVI, no specific prompt on the INTERPOL AM DVI form for such information, and an initial lack of appreciation of why this information was necessary (the lack of this information may have led to the incorrect identification of siblings where parents were used as references). The TTVI later requested pedigrees to be supplied for $\mathrm{AM}$ cases involving two or more related victims, however, the initial absence of pedigree information caused delays in DNA identifications.

The Reconciliation Phase involves matching AM and PM data, and evaluation by the Reconciliation Team of $\mathrm{AM}$ and $\mathrm{PM}$ matches generated by each identification method to assess the strength and quality of the evidence and to determine that no inconsistencies exist 
(INTERPOL DVI Guide). The INTERPOL Comparison Report is used to record the collated evidence and scientific opinions of all methods involved in a case and record the outcome of the investigation. All cases that pass this evaluation are submitted to an Identification Board for presentation by experts and final assessment and acceptance of identification by a designated authority which then allows official release of the body for repatriation. Information and statistics on each confirmed case are usually generated by the Reconciliation Team for communication to the DVI Commander, which can be used to update families, governments, and media, and to assist in resource management.

Initially, thresholds were not set by the TTVI DNA Team to determine what statistical thresholds were required to be reached to allow a case to be forwarded to the Reconciliation Team for consideration. For example, if a kinship match was found a likelihood ratio calculation would be performed and included on the DNA report. The Reconciliation Team was staffed by police officers who could not appropriately weight the DNA evidence based on the likelihood ratio. Often if a DNA match report was forwarded to the Reconciliation Team it was accepted based on the Forensic Biologist's experience. This had the potential to create bias, confusion, and potentially mis-identifications. In April 2004 DNA reporting thresholds were developed using probabilities expressed as a percentage (to make it easier for the Reconciliation Team to understand and evaluate), with a threshold aligned to each INTERPOL reconciliation term (possible, probable, and established).

Overall, the use of standard INTERPOL DVI Guidelines, INTERPOL DVI forms, and the four structured DVI phases during the TTVI operation were enormously beneficial, particularly for standardisation, increased quality assurance, and overall management. DVI capability development, preparedness and training can assist a country or jurisdiction respond better to a disaster, however unexpected issues will often arise. The scale and complexity of the 
tsunami in Thailand was incomprehensible to even the most experienced DVI practitioners. The effort and achievements of all involved in the DVI response should be acknowledged, especially given the difficult operational environment and challenging circumstances. It should be emphasised that each disaster is different and the response to each disaster and DVI phase will therefore be unique. The DNA response to the Thai Tsunami was also unique compared to its use in other disasters which will be discussed in the following section.

\subsection{Use of DNA analysis for disaster victim identification}

Use of DNA analysis in a disaster can provide advantages over dental and fingerprint analysis, and the method has now been accepted as a standard tool in DVI. Bodies that are fragmented, highly decomposed, or incinerated often lack evidence required by dental and fingerprint methods to establish an identification. DNA is ubiquitous in all tissue, and highly resilient in bone and teeth, providing an opportunity to identify fragmented, and highly decomposed corpses. Prior to the use of DNA in such situations, for example an aviation disaster, fragmented remains that could not be reassociated with an identified body remained unidentified and were either respectfully disposed of, or interred in mass graves. Since the number of genetic loci used in DNA analysis has increased, it is considered the 'gold standard' in human identification, providing a high power of discrimination and an unbiased quantitative estimation of a victim's identity. The heredity of genetic material allows victims to be identified using the DNA of biological relatives as ante-mortem references. This additional source of ante-mortem evidence can be useful in disasters where victims do not have access to dental health services, or where a natural disaster has destroyed personal effects containing fingerprints or fingerprint records (floods, fires, tsunamis). The main limitations of using DNA over fingerprint and dental methods is the speed and cost of DNA analysis, and the requirement of appropriately experienced DNA laboratories and staff to generate AM and PM DNA profiles, which may be conducted some distance from the disaster site or DVI operation. For these reasons DNA is unlikely to replace the traditional DVI identification methods, but 
should be implemented in a way that either targets or supplements fingerprint and dental analysis where necessary. A strong understanding of the strengths and limitations of DNA analysis is therefore vital in understanding its role in future disasters. The following summary of the use of DNA in historical disasters highlights these characteristics, and is further explored in this thesis.

One of the first reported uses of DNA profiling in a mass disaster was in the 1990 Scandinavian Star ferry fire, where the earlier methods of restriction fragment length polymorphism (RFLP) and variable number of tandem repeats (VNTR) were used (Montelius \& Lindblom, 2012). The newly developed short tandem repeat (STR) method was first used in a DVI in 1993 after the Waco disaster near Texas where it assisted in the repatriation of 26 bodies (Clayton et al, 1995). Superior DNA methods have since been introduced, with these providing higher powers of discrimination and faster processing times, and have led to DNA profiling being recognised as a primary identification tool for DVI. DNA profiling is still a relatively new primary identification tool for DVI compared to dental and fingerprint methods (Kaushal, 2009; Taylor, 2009). Therefore, mass fatality operations often present new experiences and challenges for application of DNA methods. How DNA profiling is managed at an operational level, how DNA profiling can support fingerprint and dental methods or achieve identification when such evidence is unavailable, and determining what the real needs and limitations of DNA analysis are in each DVI situation are continuously evolving issues.

Major DVI operations that used DNA analysis for victim identification prior to the 2004 SouthEast Asia Tsunami include the 1992 Airbus A320 air crash, the 1996 Spitsbergen civil aircraft disaster, the 1998 Swissair flight 111, the 2000 Kaprun cable car fire disaster, the 2001 World Trade Centre attacks, and the 2002 Bali Bombings (Budimlija et al, 2003; Holland et al, 2003; Leclair et al, 2004, Meyer, 2003; Olaisen et al, 1997). At the time of the 1996 Spitsbergen disaster, DNA profiling was still not considered a standard tool in DVI. The Airbus A320 crash 
into Mount Ste-Odile (France) in 1992 involved 87 victims and was one of the first times DNA analysis was recognised as being able to resolve complex identifications in disaster operations (specifically fragmented remains) being successfully able to identify of 17 victims (Alonso et al, 2005; Ludes et al, 1994). A terrorist bombing in 1992 that destroyed the Argentine Israeli Embassy (Buenos Aires) killing 28 people was another early opportunity for DNA methods to assist with DVI. Ten sets of remains were analysed using a mixture of STRs (6 loci), VNTR (4 loci), a single locus min-satellite marker (YNH-24) and mitochondrial DNA sequencing of the hypervariable regions (I and II). This was also the first time that DNA analysis was adopted in Argentina by the Supreme Court of Justice in a criminal case, highlighting that the method was beginning to be accepted as both useful and reliable for human identification (Patrinos \& Ansorge, 2009). In the 1996 Spitsbergen aviation disaster 141 people perished and their bodies were highly fragmented. DNA analysis involved 3 STR markers and 5 VNTR markers and led to the reassociation of 257 body parts and identification of 139 victims, once again demonstrating the advantage of DNA profiling over traditional identification methods (Alonso et al, 2005; Olaisen et al, 1997). In 1998 three aviation disasters occurred that included the use of DNA analysis. The Taoyuan Airbus crash (Taiwan) killed 202 people, with DNA profiling used to analyse 685 body parts using Profiler Plus ${ }^{\circledR}$ kit (9 STR), the AmpIType HLA DQ-Alpha, and AmplType Polymarker, leading to the identification of 183 victims (Alonso et al, 2005; Hsu et al, 1999). An aircrash in the Philippines killed 104 people, with 187 body parts analysed with DNA (however, Alonso et al reports low success was achieved using STR markers) (Alonso et al, 2005). The Swissair flight 111 that crashed off the coast of Canada killing all 229 people on board involved the large scale analysis of 1,277 body parts using Profiler Plus $\AA$ and CoFiler® (Alonso et al, 2005). The scale of the DNA operation was one of the largest at that time, and was one of the first examples in a DVI operation of a purpose-built bioinformatics tool to assist with comparison of DNA profiles. DNA profiling identified 218 victims of the Swissair disaster and demonstrated how quickly DNA methods were being adapted and created for disaster victim identification (Alonso et al, 2005). In Austria, in November 2000, DNA profiling was again successfully used in the Kaprun cable car fire involving 155 victims 
(mostly incinerated and all bodies were intact). Incredibly, all 155 victims were identified using DNA method in just 19 days. The DNA response to the Kaprun cable car disaster was another dramatic advancement in the evolution of DNA as a tool in mass disasters (Meyer, 2003). The above successes of DNA analysis also started to create a benchmark for its use in future disasters, and an overall expectation that a DVI operation would eventually lead to the identification of all victims using a combination of scientific methods.

The 2001 World Trade Centre (WTC) attacks in New York can still be considered the most technically complex and challenging disaster operation. A total of 2,749 people were killed in an event that was unprecedented (Alonso et al, 2005). Due to the high impact of the planes, and the collapse of both buildings and subsequent fires, the victims' remains were mostly highly fragmented and affected by heat. Over 20,000 PM samples were sent for DNA analysis using a combination of Profiler Plus ${ }^{\circledR}$, Cofiler $\AA$, miniSTRs, and mitochondrial single nucleotide polymorphisms (SNPs) (Alonso et al, 2005). In addition to the 20,000 PM samples, approximately 11,000 AM samples (personal items and family samples) were analysed. Given the large volume of DNA comparisons (Alonso et al (2005) estimated 220 million) and calculations required, four different DNA software tools were used. The DNA operation in New York still continues today to complete the identification of all victims and body parts (by September 2014 a total of 1,639 victims and almost 12,000 body parts had been identified) (Daily Mail). This prolonged and concentrated DVI operation provided experience and numerous lessons, and led to innovation in DNA methodology, signalling another major advancement in the use of DNA profiling in mass disasters. The 2002 Bali Bombings was the second terrorist event in two years that required DNA methods to assist in the identification of fragmented remains. A total of 202 victims from 23 countries perished in the attacks, with DNA analysis assisting in the identification of 115 victims (Biotechnology Australia).

Each disaster (whether closed or open), presents its own set of challenges for successful DNA identification, such as the number of victims, limited recovery of remains, degree of body 
fragmentation and DNA degradation, and the type of DNA references available. In addition, consideration is needed for large-scale data management and DNA profile comparisons, coupled with stringent quality requirements, time pressures and availability of resources. The different combination of factors, therefore, necessitates very different approaches to management of DNA operations in different disasters, thus requiring managers to continuously adapt and problem-solve at the commencement of, and throughout, an operation.

The major challenges presented by the South-East Asia Tsunami for the Thai Tsunami Victim Identification (TTVI) DNA operation included:

- the number of unidentified victims $(3,679)$,

- the geographical extent of the disaster, which comprised hundreds of kilometres of the Thai coast,

- the number of nationalities represented as victims (42 different nationalities, with approximately half of the deceased being foreign tourists),

- the extent of relatedness among victims,

- the number of child victims,

- the lack of DNA references (personal items were destroyed by the tsunami and many close relatives perished limiting traditional kinship sources),

- the constantly rotating team of specialists from over 30 countries (national teams had a 2 to 6 week rotation policy, creating a lack of continuity at the TTVI, with staff constantly working with unfamiliar people, systems and protocols), and

- mass sample and data management issues caused by post-mortem (PM) samples being sent by the TTVI to several international laboratories, and ante-mortem (AM) profiles being received by the TTVI from 42 countries. 
However, unlike the Spitsbergen disaster, the Swissair flight 111 disaster, the Kaprun cable car fire, the World Trade Centre Attacks, and the 2002 Bali Bombings, the bodies of tsunami victims were relatively intact and provided good quality DNA profiles in over $99 \%$ of cases. This may be compared, for example, to the World Trade Centre Attack where the high degree of body fragmentation from the fire and building collapse required the DNA analysis of over 20,000 PM samples (Alonso et al, 2005).

The disaster closest in comparison, in terms of number of fatalities, prior to the South-East Asia Tsunami, was the World Trade Centre Attacks, which involved 2,749 victims (Alonso et al, 2005). This was similarly an open disaster, involving victims from different nationalities and requiring large-scale DNA comparisons (ante-mortem to post-mortem). However, compared to the South-East Asia Tsunami, the World Trade Centre attacks were geographically targeted, victims were mostly adult and unrelated, there was access to reference DNA (from either family members or personal effects from victims' homes), and the DNA operation was conducted at an existing forensic laboratory at the New York Office of the Chief Medical Examiner, by their team of ongoing staff. Therefore, the South-East Asia Tsunami resulted in a combination of operational complexities never before seen on such a large scale, and, considering DNA profiling was first used in a DVI only twelve years prior, provides a strong justification for a thorough evaluation and documentation of the TTVI DNA operation.

\subsection{Specific aims of this study}

To date, a thorough evaluation of the TTVI DNA response has not been published. This has led to mis-information and confusion about the impact of the DNA response. The goal of the research presented in this thesis is to provide an accurate analysis of data obtained from the TTVI and to publish the results in international forensic journals. DVI is a highly specialised area of forensics, and advances in this field rely on lessons learned from previous disasters. In particular, first-hand accounts from those involved in a DVI operation over an extended period provide an accurate insight. This research has resulted in a number of 
recommendations which will add to the continuous improvement of DVI in terms of faster identifications, strategies to resolve complex cases, improved operational management, improved policies, better resource allocation and preparedness.

The overall goal of this research is to evaluate the TTVI DNA response to the South-East Asia Tsunami. Specifically, the aims of the research are to:

1. Determine the success of DNA testing in the early stages of the TTVI operation.

2. Identify impediments that limited the TTVI DNA Team.

3. Identify solutions that were implemented by the TTVI as a response to the impediments.

4. Evaluate the effectiveness of the solutions implemented.

5. Determine how effective the DNA method was at each stage of the TTVI operation.

6. Determine where the DNA method was most effective in victim identification by exploring the number and rate of victim identifications by age and nationality.

7. Determine how DNA could be better integrated with other identifiers, while maintaining independence.

8. Provide recommendations from this research for the benefit of future DNA responses to mass fatalities.

\subsection{Progress of research linking the scientific papers}

Paper 1 explores the success of the traditional DVI approach at the TTVI, where a single primary identifier (dental, DNA, fingerprints) can establish identifications relatively quickly. Incomplete or poor quality AM and PM data prevented a large number of identifications using this strategy alone. The AM and PM data deficiencies are explored to allow understanding of the complexity of the operation and how this prevented victim identification. A new 'nearthreshold' identification strategy was implemented by the TTVI, and the outcomes of this are 
explored, including the number of identifications it assisted (by age and nationality), which scientific teams it assisted, and how it improved TTVI operational efficiencies (aims 1, 2, 3, 5, $6,7$ and 8$)$.

The second paper investigates the identification rates of adults and children at the TTVI. Preliminary analysis showed that children were being identified in significantly fewer numbers than adults. AM and PM data issues highlighted in paper 1 are expanded to specifically explore why children were more difficult than adults to identify (aims 1 and 2). Targeted strategies implemented by the TTVI DNA Team (which include the near-threshold strategy discussed in paper 1) are highlighted and analysis shows they had a significant impact on child identifications (aims 3, 4, 6, 7 and 8).

The third paper explores the impact of DNA profiling in the early, middle and late stages of the TTVI operation (aim 5 and 6) and relates identification trends back to the impediments and implementation of successful strategies discussed in papers 1 and 2. In the early stages, DNA had little success due to the lack of AM and PM DNA profiles, data management and DNA software issues (aims 1 and 2). However, once these issues were addressed (including strategies discussed in papers 1 and 2), DNA identifications increased. By October 2005 onwards, DNA profiling was the most used method of identification. The effect of victim demography (age and nationality) on identification method is explored, further highlighting issues with unavailable AM data (aims 1,2 and 8). Finally, the overall impact of DNA analysis is reported from 12 January 2005 to 16 July 2008 , at which point $90 \%$ of victims had been identified (aim 5). The results are compared with previously published TTVI DNA outcomes which reveal some misleading conclusions by other authors who have evaluated the DNA effort. 
In combination, the three papers provide a valuable record of the TTVI DNA operation from its commencement on 12 January 2005 to 16 July 2008, when $90 \%$ of victims had been identified $(3,308$ out of 3,679$)$. The research highlights impediments to DNA identifications, reveals strategies which were implemented to overcome these issues, and analyses their effectiveness post-implementation. This information provides a reliable learning tool for the forensic community and provides a number of DNA-based recommendations for the continuous improvement of DVI for future mass fatalities. 


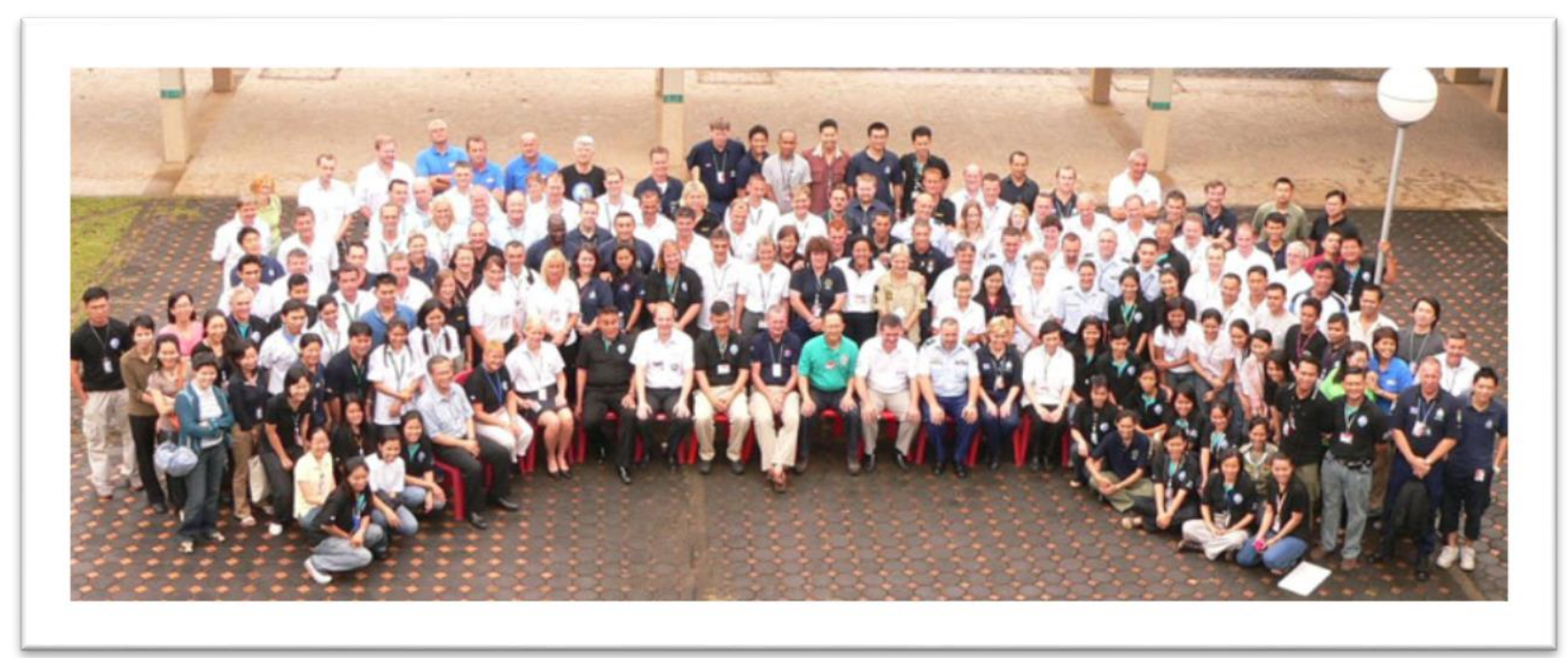


The international Thai Tsunami Victim Identification Team in Phuket, Thailand. Photo sourced from TTVI. Image freely available from the internet. 


\subsection{General Discussion and Conclusions}

Key resources for continuous improvement in DVI include records and evaluations of previous operations written by people who participated in the operation in a leadership capacity, and who had first-hand insight of their team's issues and successes. A direct account of the TTVI DNA response to the South-East Asia Tsunami also forms part of an historical record of the largest and most successful DVI operation in history. The overall goal of this research was to evaluate the TTVI DNA response to the tsunami and use the results to address current gaps in the literature from an operational and historical perspective. In doing so, the findings and recommendations are meant to form an objective and pragmatic assessment and should not be viewed as criticism of any group or individuals involved in the TTVI operation.

The outcomes of DNA testing was evaluated in the early stages of the operation, and revealed that very few identifications were achieved. The poor success of DNA could have led to the 
conclusion that DNA was not an effective identification tool for this type of disaster. However, to accurately evaluate the TTVI DNA response, it is critical to uncover the issues and complexities that were encountered. Without a thorough understanding of the limitations and impediments, any conclusions drawn merely from identification data are misleading and may lead to the misuse of DNA in future mass fatalities. The science of DNA as a laboratory-based method has been used for many decades and is sound, but how DNA is best used as a tool to identify victims of mass disaster, and how it is incorporated into a DVI operation from a management perspective, are still relatively new issues that need further exploration. This evaluation focused on the TTVI DNA response from an implementation and management perspective, rather than a scientific one. It has been written for Forensic Biologists, other scientific experts participating in a DVI, police DVI Commanders, and ultimately those responsible for the drafting and implementation of DVI plans at state, national and international levels. It is hoped that the results of this research will provide greater understanding of the strengths and limitations of DNA in a mass fatality operation and suggest ways in which DNA can be better implemented to provide faster identifications in a more resource efficient manner. On a more social level, the research aimed to address the dichotomous views held by many in relation to the use of DNA in a DVI. That is, DNA is the 'magic bullet' versus DNA has little impact and should only be used as a last resort. To achieve this, results of this research were compared to published literature, including those based on generalised views. The literature review revealed a number of misleading conclusions drawn by authors who have misrepresented the TTVI DNA operation, the sum of which has formed an inaccurate historical record of the operation, which then may lead to misuse of DNA in future disasters.

The first paper highlights the success of the traditional DVI strategy, where victims are identified rapidly using one form of forensic evidence (dental, DNA or fingerprints). In February and March $2005,93 \%$ and $87 \%$ of all identifications, respectively, were established with a single method. However, use of single methods for victim identification significantly declined 
to only $20 \%$ by December 2005 ( $p<0.0001)$. It is critical that the causes of this decline be understood to ensure adequate preparation for future disasters and to effectively use identification resources, which are often limited and expensive. The lack of accurate and complete AM and PM data for each identification method and the causes were explored, revealing issues in quality assurance, evidence collection and data management processes, and evidence deficiencies caused by the nature of the disaster.

The TTVI implemented a new 'near-threshold' identification strategy in June 2005 to overcome these issues. This new strategy targeted DNA kinship matches that fell below the reporting threshold of $99.9 \%$, and used the physical, medical, dental, and fingerprint information in a coordinated and systematic approach to either exclude the case, flag it for collection of additional AM evidence, or strengthen the case and progress it to the Reconciliation Team. The Investigation Team coordinated the process to maintain a level of independence between scientific teams, and recorded the outcomes of their investigations. The near-threshold strategy was immediately successful and resulted in a total of 111 identifications from July 2005 to December 2005. Of these identifications, 87 were adults and 24 were children. The Fingerprint Team established nearly $60 \%$ of these identifications and a combined DNA/Physical method was responsible for another $30 \%$. In addition, the strategy provided an 'end-point' for cases that were not going to be resolved without collection of additional evidence. This stopped continual re-examination of the case by experts, and allowed more complex cases to be targeted earlier in the operation, allowing faster resolution. The strategy enabled DNA to be better integrated into the DVI operation, specifically where it could not provide a stand-alone identification, but could assist by eliminating possible matches and targeting probable matches for other identification groups. Independence between teams was maintained by the flow of information and use of the Investigative Team to prevent confirmation bias. The strategy changed the standard decision-making process of experts when evaluating and handling challenging cases. Specifically, instead of experts placing a 
lower value on such cases, and in many instances ceasing work on them, they placed a high value on the cases and shared their information to help others. It is recommended that the near-threshold strategy be used alongside the traditional DVI approach when single-method identifications start to decline, to address deficiencies in AM and PM information. While DNA was the starting point in the strategy outlined, it is possible that either of fingerprints, dental, or property could be repositioned within the strategy sequence and thus provide alternative starting points. The key point of the strategy was that all groups worked together to achieve identifications that would not have been obtained by sharing information and working together in a structured, yet independent approach.'

The second paper provides the first thorough investigation of identification rates between adults and children in DVI. Approximately 500 children from over 20 nationalities were victims of the Thai tsunami. From early on in the TTVI operation there was a clear difference in the proportion of adult and child identifications. In the first 100 days, 1,211 adults were identified compared to only 78 children. To eliminate nationality as a variable, six countries with the largest number of child victims were examined (Finland, France, Germany, Norway, Sweden and Thailand). This revealed that, despite being the same nationality, adults were being identified in significantly greater proportions than children. For example, in the first 100 days, $92 \%$ of Swedish adults were identified compared to only $27 \%$ of Swedish children. Other similar results were: $89 \%$ Finnish adults versus 29\% Finnish children; $84 \%$ German adults versus $29 \%$ German children.

Given differences existed between the rate of adult and child identifications, the child category was further examined and revealed a significant difference in the average number of days it took to establish identifications of children from 0 to 16 years old $(p<0.0001)$. Children under the age of 1 took on average 195 days to be identified, compared to children aged 16, with an 
average of 130 days. On average it took 4.3 days longer to identify a child for each year they were under the age of 16 (95\% confidence interval $=2.9$ days to 5.7 days). This information demonstrates that the age of the victim could affect the length of time to repatriation, which can be used to manage expectations of child victim identification. It also draws attention to the need to prioritise AM information that is more likely to identify children.

The causes of the slower identification rates were examined, and revealed that common AM evidence that was available for adults was not available for children. These deficiencies existed across all identification methods and were causing not only the slower identification of children, but more critically, were preventing the identification of children. The TTVI recognised this risk and made identification of children a priority. In response, the TTVI DNA Team implemented a number of targeted strategies to identify children, which were discussed in this thesis (Paper 2). The outcomes of the targeted child strategies were investigated to determine whether they were responsible for the increase in child identifications. After implementation (from May 2005), the proportion of child identifications started increasing compared to adults. By June 2005 , the percentage of children identified that month with DNA was $85 \%$, compared to $15 \%$ for adults. Of the 442 children identified by 12 December 2005 , DNA identified 214 (48.4\%), fingerprints 152 (34.4\%), dental 73 (16.5\%), and physical 3 $(0.7 \%)$

This research provides a critical understanding of the complexities and different requirements for child identifications compared to adults in mass disasters, which has not been previously published. This understanding is necessary to ensure an equal opportunity for identification for victims of all age groups. The TTVI DNA Team's experience with child identifications has led to a number of recommendations, which may assist in future mass fatalities. These include using PM body length to prioritise DNA testing of children, using PM DNA samples 
from parents of missing children as references for kinship matching, targeted use of kinship matches falling below reporting thresholds, and PM-to-PM kinship matching.

The third paper draws together all of the issues, strategies and successes discussed in papers 1 and 2 for an overall evaluation of the TTVI DNA response. The impact of DNA was investigated in the early, middle and late stages of the operation and the trends during each stage were explored in detail. By the end of May 2005 (early stage), DNA had established only 15 identifications (307 fingerprints, 1,266 dental and 11 physical). A critical lack of AM and PM DNA profiles, and issues with data management and DNA software were the main causes. By the end of May 2005, 2,358 AM case files and 4,325 PM case files had been created, though only 310 AM profiles and 180 PM profiles were available to the TTVI DNA Team. Reasons for this were highlighted, and included lack of direct AM DNA evidence that was destroyed by the wave, and the large number of related victims preventing availability of suitable kinship references. Poor DNA sample selection at the initial autopsy (decomposed soft tissue), lack of experience in profiling human remains by many laboratories who also struggled with the sudden surge of samples, prevented rapid access to PM DNA profiles.

By the end of June 2005, the TTVI had access to 1,269 AM DNA profiles, 1,310 PM DNA profiles, and had systems in place which improved data management to allow automated kinship matching with DNA software. From October 2005 (late stage), DNA was the most used method of identification by the TTVI. By 12 December 2005, DNA had identified 13\% of adults (all nationalities), $33 \%$ of 10 to 16 year olds, $43 \%$ of 5 to 9 year olds, and $73 \%$ of 0 to 4 year olds. To understand how victim demography affected identification method, analysis was conducted on the six nationalities with the greatest number of missing children. The distribution of identification methods used for each nationality and age group was vastly different, demonstrating that a victim's age and nationality largely determined how successful 
each identification method was. DNA was used for only $2 \%$ of French, Finnish, German and Swedish adults combined, but was used for $30 \%$ of Thai adults. DNA was most successful for Thai children (68\% for 10 to 16 year olds, $94 \%$ of 5 to 9 year olds, and $99 \%$ for 0 to 4 year olds), and was the most used method for European children 0 to 4 years old (52\%). Analysis within the child category revealed there was a $3.9 \%$ increase in DNA identifications for each year a victim was younger than 16 years old $(p<0.0001)$. Overall, the TTVI DNA response was successful, identifying a large number of children (all nationalities) and Thai adults (both of which were flagged as priorities by the TTVI). By 16 July 2008, DNA had established $24 \%$ (799) of all 3,308 identifications, dental 40\% (1,337), fingerprints 35\% $(1,142)$ and physical $1 \%(30)$. It is acknowledged that there were differences in the speed that AM DNA profiles were provided to the TTVI by different countries. Analysis compared identification rates of adults and children within each country to remove this variable. It was evident that for many countries the adults were identified faster than children from that same country.

Understanding how victim demography affects identification methods, and how trends in each identification method change throughout each stage of a DVI operation are critical for planning a response to disasters. Such information can affect planning for collection of AM and PM material, resourcing, expectation management, and informing external communications (government agencies, family and media). Coordinating resources to target groups of victims that are more likely to yield success with a particular identification method saves time and money, and achieves the ultimate goal of returning victims home as quickly as possible.

Learning from previous disasters, having suitable response plans and appropriate resources in place, recognising each method's strengths and limitations, implementing successful identification strategies specific to victim demography and the nature of the disaster, and being prepared to respond to unexpected issues are all critical to the success of a DVI operation. 
The standard INTERPOL DVI protocol was successful at the TTVI and facilitated rapid identification of victims using a single primary method $(93.02 \%$ of victims were identified using a single method in the first full month of the DVI operation). The standard protocol provides a workflow that ensures teams work independently, avoiding possible mis-identifications from confirmation bias, and is established best-practice in all INTERPOL member countries using a DVI response team. The method has been successfully used for small and large disasters, including the 2002 Bali Bombings (Biotechnology Australia), and the WTC Disaster (Budimlija, Z. et al. (2003), and should continue to be used in all future disasters. The research presented here supports the application of the standard DVI process and use of the three primary identifiers at the TTVI, as this strategy was shown to rapidly identify the majority of victims across all nationalities.

However, it was evident from the beginning of the operation that the standard method resulted in underuse of the DNA method, compared to other methods, to the detriment of the whole operation. None of the 57 identifications made in January 2005 were assisted by DNA, and only $1 / 516$, and 2/542 were made with DNA in February and March, respectively. Paper 1 outlines the factors that contributed to the lack of AM DNA profiles, which consequently limited the capability of DNA to contribute. The combination of these two factors was unique to the Boxing Day Tsunami, though each factor had been encountered individually in other disasters. The DNA matches that were generated at the TTVI fell below the reporting threshold required for an identification without support from an additional modality. The many hundreds of 'weak' DNA matches meant that the case-specific request for targeted assessment using the standard protocol was not possible, as it would have generated an enormous volume of work due to the large proportion of likely 'false' matches. Use of the 'near identification-threshold' strategy, explored in Paper 1 allowed the DNA information to be better used by the TTVI, and 
when integrated with the other identifiers, ultimately contributed to the identification of 111 victims.

The value of the new strategy wasn't restricted to achieving identifications. One of the major benefits of the strategy was enabling systematic collation of all available evidence for each case, and the inclusion of a decision point to determine whether the case could progress without collection of additional evidence. The incorporation of such a decision point is absent in the standard DVI process, and may lead to cases being handled multiple times and by multiple teams at the TTVI. All teams would be expected to reach the same decisions, but these decisions may not necessarily be recorded or acted upon. The new decision point developed in this thesis allows accurate evaluation of a case early in the operation, facilitating collection of extra evidence and for those decisions to be recorded. Essentially, difficult cases will be flagged easily, which allows decisions to be made about the case based on combined evidence rather than on fragments of evidence spread across different identifiers.

The new strategy should not replace the standard DVI protocol. It should be used in conjunction with the standard DVI protocol if access to good quality AM or PM data is unavailable for any of the identifiers (Figure 6). The team structures should be retained from the standard approach as these are familiar to all DVI nations and prevent confirmation bias for stand-alone cases. A dual process approach could rapidly identify victims using one form of evidence, while also integrating partial information from all identifiers, providing a more holistic approach to resolving cases. The dual DVI process approach may have been useful for the 2005 Hurricane Katrina DVI operation, where there was a lack of some PM information, including fingerprints due to degradation of the remains because of the delayed body recovery phase (because priority was placed on search and rescue and owing to the large destruction zone) (Conly \& Johnston, 2005). For the Katrina operation there was also a lack of AM DNA 
from personal effects and AM dental records due to the tidal surge and hurricane damage, and because such a low percentage of the affected population had had dental treatment, precluding the use of AM dental records. In some cases there was also a lack of living close relatives that could provide AM DNA due to multiple family members perishing in the disaster. In this respect, a dual strategy could have commenced with DNA, fingerprints, or dental information, and been used to overcome the absence of the information described above.

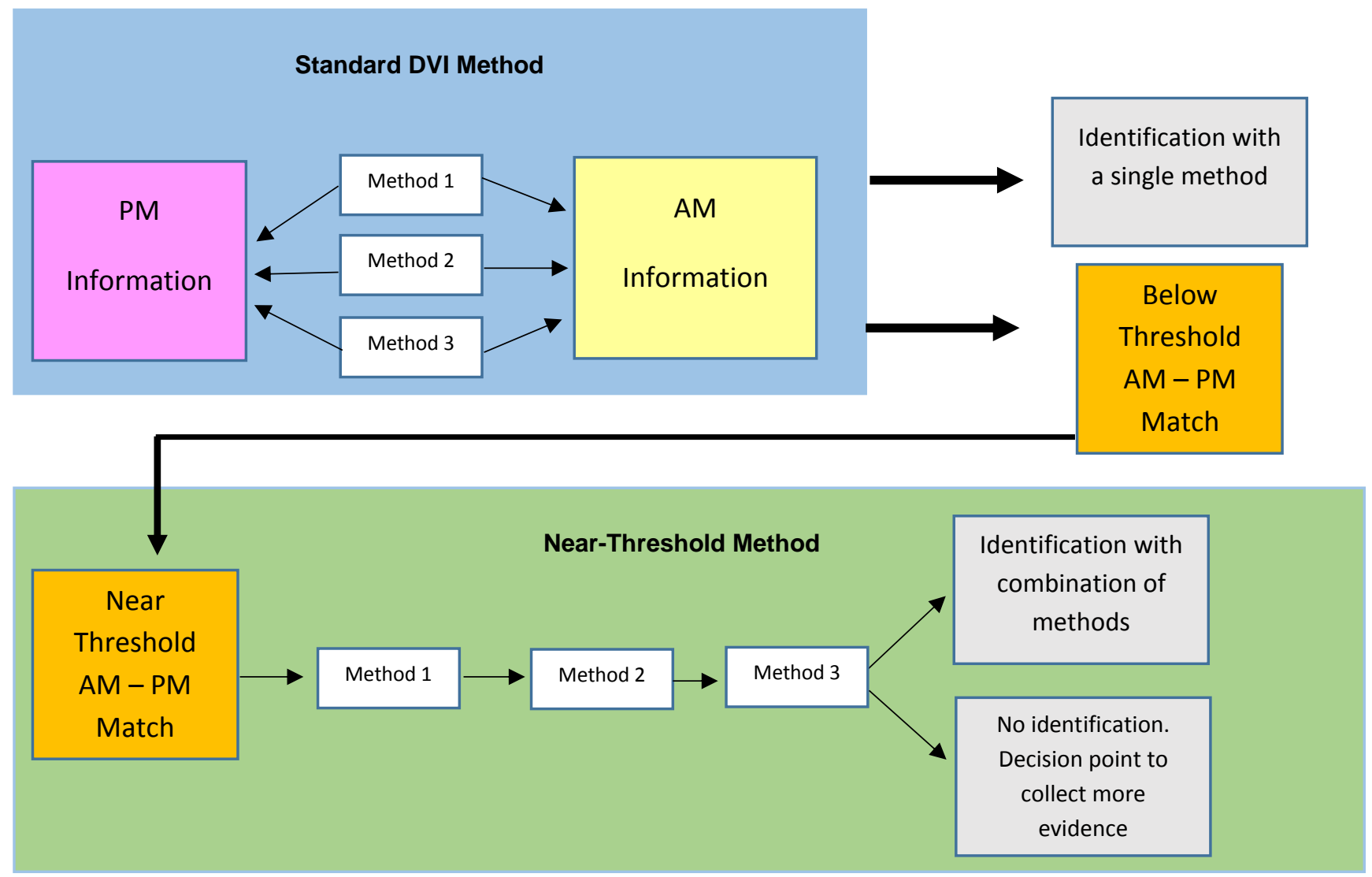

Figure 1: Incorporating the standard DVI method and the near-threshold method within a mass fatality operation.

\subsection{Future Directions}

The Boxing Day Tsunami presented experts with a previously unimaginable scenario for victim identification; this should now be considered the new benchmark for DVI preparedness. Expectations for DVI responses have also increased, with the public and government agencies 
now anticipating that forensic science can quickly and accurately identify all victims from disasters. As a result, the 'modern' DVI response needs to continue to evolve and improve to meet these demands. This thesis has highlighted some areas where future research could be targeted to address current deficiencies and improve DVI response for large or complex operations.

\subsubsection{Improving integration of DNA within the DVI operation}

Typically the DNA team is involved in the DVI operation at the AM phase to profile DNA samples collected from family and personal items, at the PM phase to profile DNA samples collected at the mortuary, and at the reconciliation phase to match AM DNA profiles to PM DNA profiles and report matches reaching a nominated identification threshold. This level of involvement (or partial integration) may limit the success of DNA methods and should be reconsidered. Effective integration of DNA into a DVI operation will depend upon a number of variables. The awareness of these variables, and when and how they should be considered, will influence the role of DNA. The disaster event, location (including country), number of victims, demography of victims, cause of the disaster, accessibility to victims and disaster site, condition of the remains, surrounding infra-structure and facilities, weather at the disaster site, and the nature of the disaster (open vs closed) are all elements that can impact on the need for DNA, and if so, how it should be used and how effective it may be. Social, religious, political, and medico-legal aspects will largely determine the goal of the operation (extent of body and body part repatriation, particularly when fragmentation is involved). The entirety of this information is not usually available at the outset of the operation, so operational decisions are often made based on prior experience and predictions. A dynamic, yet structured, decision-making process needs to be integrated into DVI management throughout key stages and phases of the operation to adjust identification strategies based on new information. Moulding the down-stream processes of a DVI response to remedy the influences of 
redundant or incorrect information may waste resources and impede victim identification. Knowing when key decision points occur throughout the life of a DVI operation, who should be involved, and what information is needed could optimise downstream responses. While particular experts may be involved in the operation, they may be mistakenly excluded from the decision making process, or not have all the necessary information, particularly for a multiagency or multi-national response.

A DVI operation is typically defined by the five INTERPOL phases; recovery, PM, AM, reconciliation, and debrief, and management structures are aligned to these phases. The phases are characterised by specific specialist tasks rather than management phases, therefore, the traditional view of a DVI operation needs to be expanded to better align with key decision points (Figure 2).

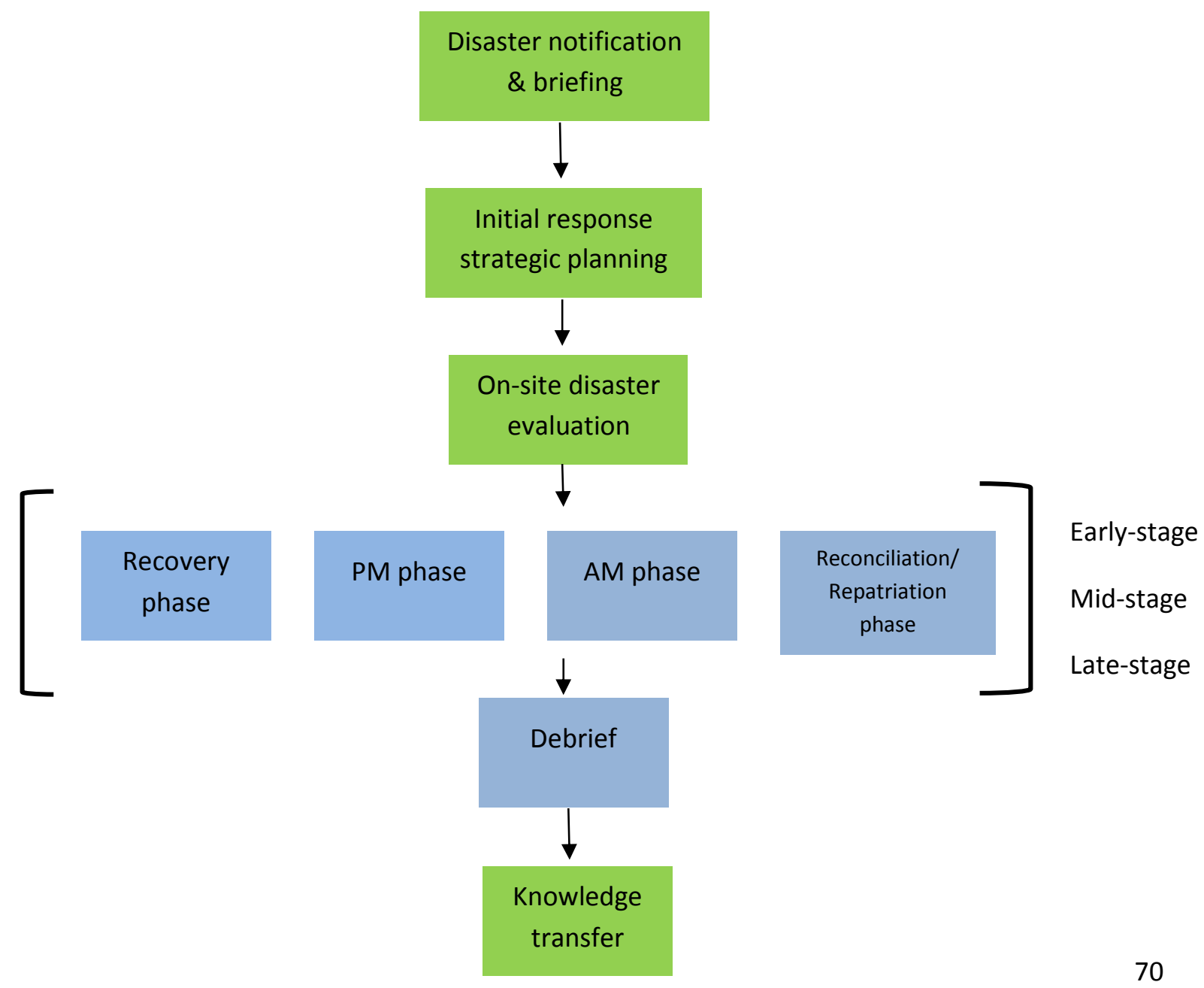


Figure 2: Stages of a disaster management response that could include decision points on identification strategies.

The disaster notification is the first source of information available to the police, and is information typically from first responders, local police, and witnesses. The information is usually incomplete, and may contain inaccurate information due to the lack of time and access to the disaster site to assess the situation thoroughly, and due to the unfolding rescue phase which takes priority. From this point information flow is rapid and frequent to the DVI Commander. Depending on the scenario and remoteness of the disaster, more complete and accurate information will be available for a formal briefing. At this point identification specialists (managers and key subject matter experts) should be notified and included in the disaster briefing, however, from experience, typically the initial briefing involves police members with a focus on the recovery phase.

Integration of a Forensic Biologist at the disaster briefing, who will then gain knowledge of the disaster variables, can help inform the next stage of the DVI; the initial response and strategic planning. This stage usually occurs at the headquarters of the lead agency responsible for the DVI response (policing agency), and involves planning deployment of the first DVI response team to the disaster site (typically within 24hrs), and preparation of a follow-on response involving the first four DVI phases. An operational command centre is usually established at the lead agency's headquarters to coordinate information, logistics and personnel movements. Photos or television images of the disaster may or not be available at this stage, and often oral reports from local authorities near the disaster site are the main source of information upon which to base decisions. What role DNA may offer, the potential reliance on DNA, and how and when DNA should be used is key information that needs consideration at this management stage. The Forensic Biologist should also start 
conveying the potential limitations and logistical requirements of a DNA response, and provide advice on the level of involvement that may be required by a Forensic Biologist in the Recovery, AM, PM, and reconciliation phases.

The main tasks of the first DVI response team during on-site stage is to evaluate the disaster and gather information from local authorities, commence the recovery phase, and prepare the nominated mortuary for the PM phase. The information is relayed to the operational command centre and includes disaster variables such as condition of the bodies and expected duration of the recovery phase. These are two key pieces of information that will inform how and when DNA is used, the potential success or limitations of a DNA response, resource requirements, DNA analysis method selection, and the expected duration of PM sample DNA analysis. If the Forensic Biologist does not receive this information, the strategic planning for the four DVI phases may reduce the level of integration and success of the DNA operation and create false expectations of how quickly and how successful DNA methods can produce identifications. Such false expectations, from the author's experience, are then relayed to the media, families of victims, and government officials. Ideally, a Forensic Biologist should be included in the first DVI response team to evaluate the disaster from a DNA perspective, communicate the above DNA-related information, and importantly, provide advice on contamination mitigation and appropriate preservation of DNA samples at the scene and mortuary. Inclusion of a Forensic Biologist at this stage is not standard, and the lack of information could delay strategic planning of the DNA response, or lead to poor decisions that delay or disrupt the DNA response.

Integration of the DNA team into the AM and PM phases (DNA sample collection) is not standard practice from the author's experience. Police traditionally collect personal items from victims' home (for example toothbrushes), or collect DNA samples from close living 
relatives of the missing person. Input is needed from the Forensic Biologist prior to the AM phase to align sample collection with the DNA testing strategy and overcome any limitations posed by the disaster variables. With the Thai tsunami, the large number of tsunami victims and the high degree of relatedness between victims increased chances of an adventitious match when comparisons were made between remains and a living family member. Typically one close relative may be sufficient to identify a missing person, however in this instance this collection strategy resulted in possible DNA matches falling below the reporting threshold. The near-threshold strategy was developed in response, and often led to police revisiting the family to collect additional DNA samples (as discussed in paper 1 Chapter 2). In cases where only highly degraded remains are available for DNA analysis (for example through incineration), mtDNA analysis may be the only method that yields results. AM collection teams should be advised at the outset of the need to collect maternal family members in this instance. Knowledge of the disaster variables and integration of the DNA team into earlier stages of the DVI operation than is currently standard practice is essential to DVI management and for increasing identification outcomes using DNA.

Better integration of the DNA team during the PM phase is also needed, specifically, to assist with DNA sample selection during autopsy at the mortuary. This task is usually performed by the Forensic Pathologist, or the Mortuary Technician. In cases where bodies are intact and show no significant signs of degradation, a Forensic Biologist is not needed for sample selection. When the body is highly fragmented, decomposed, or incinerated, however, the Forensic Biologist has the best experience to determine what portion of the remains will yield the best DNA result. A judgement can also be made on whether the remains are unsuitable for DNA testing. Obtaining the best sample will reduce the amount of repeated tests within the DNA laboratory, avoid requests for a second sample (and therefore re-examination of the body), and save time and resources. Only collecting samples suitable for DNA testing will similarly decrease the laboratory workload and ideally lead to the faster 
provision of good quality results (complete DNA profiles). This increases the chance of matching to an AM sample and reaching the reporting threshold.

The debrief phase may occur weeks, months, or in the case of the Thai tsunami, years after the completion of the DVI operation. The Forensic Biology manager is usually involved and provides feedback to the DVI Commander and representatives from other identification groups and police. Recommendations on procedural improvements are generally provided and may lead to changes in policy, training, or standard operational procedures. Knowledge transfer at the completion of a DVI operation may include presentations at conferences, publications in journals, or on the job mentoring, however, this is not a requirement and is often the decision of the individual or the organisation on how to document the operation and share information. Fatigue and post-DVI workloads may also prevent knowledge transfer. It is the author's experience that lessons learned may not be shared or lead to an improved response, with repetition of mistakes and procedural deficiencies occurring in subsequent DVIs within a jurisdiction. A formalised knowledge transfer stage needs to be incorporated into each DVI operation, and perhaps included in each jurisdiction's DVI response plan to provide opportunity for continuous improvement. Overall, DNA is typically partially integrated into the DVI response, and this limits its effective use as an identifier and results in operational-wide inefficiencies. An expansion of the current view of a DVI response (the five INTERPOL phases) to include key management stages and decision points will allow better integration of all identification methods and better opportunities to share knowledge.

\subsubsection{Analysis of AM / PM TTVI cases that led to mis-identifications}

In any DVI there is a risk of mis-identification. Due to the nature of some DVIs, quality assurance is often implemented as an operation is unfolding, rather than being in place before any work starts. This was true for the TTVI. At the TTVI the risk of mis-identification was also 
compounded by the scale and complexity of the disaster, the lack of existing infrastructure and information management systems, the varying levels of experience of staff, constantly rotating staff, difficulties with language and standard terminologies, and the situation where experts from 39 countries were used to working under different operational procedures. It has been recognised that mis-identifications prior to the TTVI occurred largely due to the reliance on visual identification of victims prior to the implementation of a formal DVI response (INTERPOL Tsunami Evaluation Working Group; Morgan, 2006). It is unclear how many of the approximately 560 bodies released by local Thai authorities were mistakes, or how many of the 1,151 bodies released by the Thai Forensic Team prior to the TTVI, identified using mainly dental, physical and property examinations were mistakes during this forty day period (Morgan, 2006). One forensic scientist guessed that the error rate of incorrectly released bodies during the visual identification phase could have been anywhere between $5 \%$ and $20 \%$ (Phuket Wan Tourism News). Certainly, the TTVI operation commenced with already existing mistakes, which may have contributed to continuing error.

A number of authors have discussed sources of error within the TTVI, however no actual numbers of incorrectly identified cases caused by TTVI processes have been reported (Holmund et al, 2006; INTERPOL Tsunami Evaluation Working Group; James,2005; Lessig et al, 2006). Anecdotal information during the first year of the operation suggests at least 12 cases occurred (seven due to errors in dental and five due to errors in fingerprints), however, this cannot be verified. It was also suggested that DNA analysis uncovered nearly all of these errors (usually after the incorrect body had already been released). Once again, this cannot be verified. Mis-identifications are costly in terms of time and resources required to detect and correct them, they affect trust of the DVI process, and have a huge emotional toll on victims' families. A thorough examination of TTVI AM and PM cases and management reports involved in mis-identifications would provide an accurate record of how many errors were made, when they were made, how they were made (flawed methods, training issues, human 
error, fatigue, IT flaws), what part of the process failed, and how better quality controls and quality assurance could be implemented in future DVI's to prevent similar errors from occurring. Analysis and discussion of quality assurance issues in DVI's and transparent reporting of findings and lessons learned needs greater attention and research overall. The INTERPOL DVI Guide is used by all member countries in a DVI, however management and jurisdictional and operational differences exist which may lead to different quality issues that can provide greater learning opportunities. The INTERPOL Standing Committee on DVI has developed 'Quality Management Guidelines' which were included in the 2014 INTERPOL DVI Guide. The guide is a welcome addition which aligns DVI operations with international quality standards, management and technical requirements commonly used by Forensic Science Laboratories and Police Agencies involved in routine criminal and coronial casework. However, DVI operations have different challenges and quality issues compared to standard forensic casework. Therefore, further research into TTVI quality issues and quality issues from other DVIs could help to improve and inform the DVI Quality Management Guidelines.

\subsubsection{Combined PM Kinship Analysis}

The TTVI DNA operation was impeded by extensive shortages in AM evidence due to the nature of the disaster, the number of related victims, and the demography of victims. Chaikunrat et al (2011) reported that only $58.1 \%$ of AM records contained DNA profiles. Large scale disasters such as floods and earthquakes can similarly prevent forensic biologists obtaining the samples they need to establish identification. From a social perspective, losing multiple family members in the one disaster prolongs identification and causes sporadic repatriation of the victims back to their loved ones. In Thailand it was common for several victims belonging to the same family to be repatriated weeks and months apart from each other. In some instances, the family preferred a group burial, so lengthy repatriation delays occurred until all family members were finally identified. 
Ideally, all biologically related victims should be identified at once, to provide rapid closure to families and a reduction in the length and cost of the DVI operation. Currently no method exists in any of the forensic sciences to enable this to occur. In addition, currently none of the three forensic methods of primary identification (dental, DNA, fingerprints) can establish identification without ante-mortem reference material (unless based on exclusionary methods in small disasters). The use of PM-PM kinship matching described in this thesis was shown to be successful, but needs further research to establish extended PM-PM kinship matching beyond parent-child pairs and methods of statistical calculations to generate a single likelihood ratio that evaluates the possibility of the victims being a listed missing family. Essentially, this could allow identification to be established for a number of related deceased without requiring any AM reference samples currently needed in traditional DNA methods.

The kinship software used for PM-PM matching at the TTVI was limited to finding up to only three related victims in one search, although a 'deceased family pedigree' could be constructed using multiple pairs and trios depending on the biological relationship to each victim. Further development of kinship software to include PM-PM algorithms for several related victims of various genetic relationships would be beneficial. Inclusion of meta-data in the kinship software analysis could assist with the construction and comparison of unknown families with missing families. Development of conservative criteria for the inclusion and exclusion of deceased individuals into a potentially statistically significant combined kinship calculation is needed. 


\subsection{Recommendations}

The analyses of the TTVI data in this research have provided a number of recommendations that are detailed in papers 1 to 3 . The recommendations are focused on improvements in DVI management and preparedness, and strategies that can be used to resolve complex cases, and increase the speed of identification. A consolidated list of recommendations is provided below.

1. For large-scale DVI operations where complete and accurate AM and PM data may not be available, a near-threshold strategy should be implemented to increase identification potential and operational efficiencies. Disasters involving children, large numbers of related deceased, or populations who may not have access to regular dental examination (who will therefore lack AM dental records) will benefit most from this strategy. The near-threshold strategy should be implemented as early as possible alongside the traditional DVI strategy. While the strategy implemented at the TTVI started with the DNA Team, it is also possible for the Fingerprint, Dental, and Property Teams to provide a starting point by provision of information from partial matches.

2. Difficulties surrounding the identification of children should be recognised at the outset of a DVI operation. Policies and procedures addressing the different issues associated with availability of AM and PM evidence from child cases should be implemented to facilitate equal identification opportunities across all victim age groups.

3. A prioritised list of child victims based on autopsy data such as body length and dental age estimation should be generated. A dedicated mortuary line should be established to triage children's remains based on the prioritised list, thereby expediting the collection and testing of child PM DNA samples. 
4. Given child identifications rely heavily on DNA, the DVI DNA Manager should provide the DNA laboratories performing PM analysis a list of prioritised PM samples from children, to facilitate rapid analysis and matching.

5. Direct sources of AM DNA, such as newborn screening cards, to identify missing children should be targeted. This will reduce the reliance on kinship reference samples when numerous family members are also victims of a disaster.

6. A field should be included on the INTERPOL AM DVI form that specifies whether other family members are missing from the same disaster (on page 9 of the AM form where the family tree information is recorded). When indicated, the AM numbers of the other missing family members should be recorded on the family tree diagram. The family tree diagram should be available electronically and in a format that can be updated as new information arises. For example, if a missing family member is identified, their PM number should be recorded on the family tree diagram (see Recommendation 7).

7. A PM DNA sample should be collected prior to releasing identified bodies. When multiple family members are also victims of a disaster, PM DNA samples from identified relatives may be critical as family references to identify their relatives, particularly children. PM DNA samples from identified victims should be included as an option in the 'Guide to AM reference samples' under the 'biological relatives' category in the INTERPOL DVI Guide (p75).

8. DNA matching software capable of PM-to-PM kinship matching should be utilised, and results compared to AM family tree information for targeted identifications. This process will aid DVI operations characterized by large numbers of related victims, particularly where children are involved. 
9. DVI communication plans should include liaison with DNA experts at the outset and at key decision points to help manage expectations, determine what samples are best to collect (and preferably be available at the mortuary site to assist), and advise throughout the operation of any unexpected impediments and resource implications.

10. The DNA Manager should prioritise establishing appropriate quality assurance procedures at the beginning of the operation, continuously review procedures and conduct regular audits of DNA samples, AM and PM data integrity and continuity, and DNA reports.

11. After a DVI, the DNA Manager and other key staff in the DNA Team should be required to write a comprehensive debrief of the DNA operation shortly after its completion. Access to relevant data (Reconciliation databases, AM and PM files) should be provided to allow an accurate and comprehensive assessment supported by quantitative data. Valuable insights, lessons learned and an accurate assessment of the operation are needed for continuous improvement of the DNA response, as a training tool, and as an historical record. 


\section{Bibliography}

Alonso, A. et al. (2005) Challenges of DNA profiling in mass disaster investigations, Croatian Medical Journal, 46:4, 40-48.

Barnes, J. (2011) The Fingerprint Sourcebook. Washington, D.C.: National Institute of Justice (NIJ). Accessed 26 December 2015. https://www.ncjrs.gov/pdffiles1/nij/225320.pdf

Beauthier, J.P, Vlack, E, Lefevre, P, and Winne, J. (2009) Mass Disaster Victim Identification: The Tsunami Experience, The Open Forensic Science Journal 2, 54-62.

Biesecker, L. et al. (2005) DNA identifications after the 9/11 World Trade Centre Attack, Science 310:1,122-1,223.

Biotechnology Australia, Accessed 27 December 2015.

http://archive.industry.gov.au/Biotechnologyonline.gov.au/human/dnaforensic.html

Budimlija, Z, Prinz, M, Zelson-Mundorff, A, Wiersema, J, Bartelink, E, MacKinnon, G, Nazzaruolo, B, Estacio, S, Hennessey, M, and Shaler, R. (2003) World Trade Centre human identification project: experiences with individual body identification case, Croat Med J 44: 3 , 259-63.

Budowle, B, Bieber, F, and Eisenberg, A. (2005) Forensic aspects of mass disasters: Strategic considerations for DNA-based human identification, Legal Medicine 7, 230-243.

Byard, R, and Winskog, C. (2010) Potential problems arising during international disaster victim identification (DVI) operations, Forensic Science, Medicine and Pathology 6, 1-2.

Calacal, G. et al. (2005). Identification of exhumed remains of fire tragedy victims using conventional methods and autosomal/Y-chromosomal short tandem repeat DNA profiling. The American Journal of Forensic Medicine and Pathology. Volume 26, 3, 285-291.

Chaikunrat, J, Pongpanitanon, P, and Petju, M. (2011) Victim Identification in the Tsunami Disaster in Thailand, Journal of Health Science 20, 897-902.

Clayton, T, Whitaker, J, and Maguire, C. (1995) Identification of bodies from the scene of a mass disaster using DNA amplification of short tandem repeat (STR) loci, Forensic Sci. Int. 76, 7-15.

Cohen, E. (2007) Tsunami and flash floods - Contrasting modes of tourism-related disasters in Thailand, Tourism Recreation Research 31(1), 21-39.

Cohen, E. (2009) Death in Paradise: tourist fatalities in the tsunami disaster in Thailand, Current Issues in Tourism 12, 183-199.

Dailey, J. (1997) Charting errors in mass disaster dental records; incidence, issues and implications. In: C. Bowers, G. Bell, Manual of forensic odontology, 3rd ed., Saratoga Springs: American Society of Forensic Odontology, 250-257. 
Daily Mail, accessed 26 December 2015, http://www.dailymail.co.uk/news/article2768227/DNA-experts-identify-remains-1-639th-victim-9-11-attacks-31-year-old-Belgianworked-North-Tower.html

Deng, Y, Yuan-Zhe, L, Yu, X, Li, L, Wu, D, Zhou, J, Man, T, Yang, G, Yan, J, Cai, D, Wang, $\mathrm{J}$, Yang, $\mathrm{H}$, Li, S, and Yu, J. (2005) Preliminary DNA identification for the tsunami victims in Thailand, Geno. Prot, Bioinfo 3:3,143-157.

De Valck, E. (2006) Major incident response: Collecting ante-mortem data, Forensic Science International 159S, S15-S19.

Donkervoort, S, Dolan, S, Beckwith, M, Northrup, T, Sozer, A. (2008) Enhancing accurate data collection in mass fatality kinship identifications: Lessons learned from Hurricane Katrina, Forensic Science International: Genetics 2, 354-362.

Ferreira, S, Kuser, H, Garrido, R, Trindade-Filho, A, Paula, K, Galvão, M, and Moraes, (2011) A. Floods and mudslides in the State of Rio de Janeiro and a plane crash in the Brazilian Amazon rainforest: A study of two different experiences in disaster victim identification (DVI), Forensic Science International: Genet Supplementary Ser. 3, e516-e517.

Fujita, K, Endo, T, Okamoto, I, Nakanishi, Y, and Yamada, M. (2010) Myanmar Migrant Labourers in Ranong, Thailand, Institute of Developing Economics Discussion Paper. www.eri.u-tokyo.ac.jp/sumatra/Abstract051202b.pdf

1949 Geneva Convention (I) for the amelioration of the condition of the wounded and sick in armed forces in the field. Accessed 26 December 2015.

http://www.icrc.org/ihl.nst/FULL/365?OpenDocument

M. Hennessey, World Trade Center DNA identifications: the administrative review process. $13^{\text {th }}$ International Symposium on Human Identification (2002). Promega, 18 June 2014 http://au.promega.com/products/pm/genetic-identity/ishi-conference-proceedings/13th-ishioral-presentations/

Hirsch C, Brondolo T, Butcher B. Report to HE Dr. Surachai, Minister of Public Health, Thailand, and Dr. William Aldis, (2005) WHO representative to Thailand World Health Organization. Assessment of victim identification operations: Thailand tsunami disaster. New York: City of New York office of Chief Medical Examiner, 11.

Holland, M, Cave, C, Holland, C, and Bille, T. (2003) Development of a quality, high throughput DNA analysis procedure for skeletal samples to assist with the identification of victims from the World Trade Centre attacks, Croat Med J 44:3, 264-72.

Holmund, G, Lodstad, I, Nilsson, N, and Lindblom, B. (2006) Experiences from DNA analysis in Sweden for the identification of tsunami victims, International Congress Series 1288, 744746.

Holmlund, G, Lodestad, I, Nilsson, H, and Lindblom, B. (2006) Experiences from DNA analysis in Sweden for the identification of tsunami victims, International Congress Series 1288, 744746.

Hsu, C, Huang, N, Tsai, L, Kao, L, Chao, C, Linacre, A, and Lee, J. (1999) Identification of victims of the 1998 Taoyuan Airbus crash accident using DNA analysis, Int $\mathrm{J}$ Legal Med. 113(1), 43-6. 
International Federation of Red Cross and Red Crescent Societies. (2013) "What We do Disaster Management” Accessed 26 December 2015. http://www.ifrc.org/en/what-we-do/ disaster-management/

INTERPOL DVI Forms, 18 June 2014 http://www.interpol.int/en/INTERPOLexpertise/Forensics/DVI-Pages/Forms

INTERPOL DVI Guide, 18 November 2014 http://www.interpol.int/Media/Files/INTERPOLExpertise/DVI/DVI-Guide.

INTERPOL Tsunami Evaluation Working Group, 18 November 2014 http://www.interpol.int/Media/Files/INTERPOL-Expertise/DVI/INTERPOL-TsunamiEvaluation-Working-Group.

James, H. (2005) Thai Tsunami Victim Identification - Overview to Date, The Journal of Forensic Odonto-Stomatology 23, 1-18.

Kahana, T, and Hiss, J. (1997) Identification of human remains: forensic radiology, J Clinical For Med 4:1, 7-15.

Kaushal, N. (2009) Fingerprints: Historical Background And Future Trends, The Internet Journal of Forensic Science Volume 4, Number 2.

Kieser, J, Laing, W, and Herbison, P. (2006) Lessons learned from large-scale comparative dental analysis following the South Asian Tsunami of 2004, Journal of Forensic Science 51, 106-112.

Kondo, T, Ohtsuji, M, and Ohshima, T. (1995) A new surgical method from the viewpoint of personal identification: a case of identification based on the presence of a metallic Z-stent, Forensic Sci Int 73:2, 101-107.

Lau, G, Tan, W.F, and Tan, P.H. (2005) After the Indian Ocean Tsunami: Singapore's contribution to the international disaster victim identification effort in Thailand, Ann Acad Med Singapore 35, 341-351.

Lay, T, Kanamori, H, Ammon, C, Nettles, M, Ward, S, Aster, R, Beck, C.R.S, Bilek, S, Brudzinski, M, Butler, R.M, DeShon, H, Ekstrom, G, Satake, K, and Sipkin, S. (2005) The great Sumatra-Andaman earthquake of 26 December 2004, Science 308, 1127-1133.

Leclair, B, Fregeau, C, Bowen, K, and Fourney, R. (2004) Enhanced kinship analysis and STR-based DNA typing for human identification in mass fatality incidents: the Swissair flight 111 disaster, J Forensic Sci 49:5, 939-53.

Lessig, R, Grundmann, C, Dahlmann, F, Rotzscher, K, Edelmann, J, and Schneider P. (2006) Tsunami 2004- a review of one year of continuous forensic medical work for victim identification, EXCLI Journal 5, 128-129.

Ludes, B, Tracqui, A, Pfitzinger, H, Kintz, P, Levy, F, Disteldorf, M, Hutt, J, Kaess, B, Haag, $\mathrm{R}$, and Memheld, B. (1994) Medico-legal investigations of the Airbus, A320 crash upon Mount Ste-Odile, France, J Forensic Sci. 39(5), 1147-52. 
Meyer, H. (2003) The Kaprun cable car fire disaster-aspects of forensic organisation following a mass fatality with 155 victims, For Sci Int 139, 1-7.

Mishra, S, Mahajan, H, Sakorikar, R, and Jain, A. (2014) Role of prosthodontist in forensic odontology: Literature review, Journal of Forensic Dental Sciences, 6:3, 154-159.

Montelius, K, and Lindblom, B. (2012) DNA analysis in disaster victim identification, Forensic Sci. Med. Pathol. 8, 140-147.

Morgan, O, Sribanditmongkol, P, Perera, C, Sulasmi, Y, Van Alphen, D, and Sondorp, E. (2006) Mass fatality management following the South Asian Tsunami Disaster: Case studies in Thailand, Indonesia, and Sri Lanka, PLoS Medicine, 809-815.

Mourning in Bali, 20 June 2014.

http://www.indo.com/bali121002 bekup/mourning4.html

Nalbant, S, Steac, S, Sieh, K, Natawidjaja, D, and McCloskey, J. (2011) Seismology:

Earthquake risk on the Sunda trench, Nature, 435:7043, 756-757.

News 24, accessed 27 August 2014.

http://www.news24.com/World/Archives/TsunamiDisaster/DNA-to-identify-tsunami-dead$\underline{20050110}$

Office of Chief Medical Examiner World Trade Centre Operational Statistics. Printed 3 May 2011

Olaisen, B, Stenersen, M, and Mevag, B. (1997) Identification by DNA analysis of the victims of the August 1996 Spitsbergen civil aircraft disaster, Nat Genet 15(4), 402-5.

Paris, R, Lavigne, F, Wassimer, P, and Sartohadi, J. (2007) Coastal sedimentation associated with the December 26, 2004 tsunami in Lhok Nga, west Banda Aceh (Sumatra, Indonesia), Marine Geology 238 (1-4), 93-106.

Perrier, M, Bollmann, M, Girod, A, and Mangin, P. (2006) Swiss DVI at the tsunami disaster: Expect the unexpected, Forensic Science International 159S, S30-S32.

Petju, M, Suteerayongprasert, A, Thongpud, R, and Hassiri, K. (2007) Importance of dental records for victim identification following the Indian Ocean tsunami, Public Health 121, 251257.

Phuket Wan Tourism News, 17 October 2008, 'Tsunami ID Cremation Mix-ups Trouble Families'. Accessed 26 December 2015. http://phuketwan.com/tourism/tsunami-id-cremationmix-ups-trouble-families/

Patrinos, G, and Ansorge, W. (2009) Molecular Diagnostics. Academic Press.

Prinz, M, Carracedo, A, Mayr, W, Morling, N, Parsons, T, Sajantila, A, Scheithauer, R, Schmitter, H, and Schneider, P. (2007) DNA Commission of the International Society of Forensic Genetics (ISFG): Recommendations regarding the role of forensic genetics for disaster victim identification (DVI), Forensic Science International: Genetics 1, 3-12.

Rai, B, and Anand, S. (2006) Role of forensic odontology in Tsunami disasters, The Internet Journal of Forensic Science, Vol 2. 
Rosa, D. The Boxing Day Tsunami and its effects on Thailand's tourism, accessed 29 August 2014

http://www.neumann.edu/academics/divisions/business/journal/review2012/rosa.pdf

Schuller-Gotzburg, P, and Suchanek, J. (2007) Forensic odontologists successfully identify tsunami victims in Phuket, Thailand. Forensic Science International 171, 204-207.

Shaler, R. (2005) Who They Were: Inside the World Trade Center DNA Story: The Unprecedented Effort to Identify the Missing, Simon and Schuster Inc., New York.

Sozer, A. (2014) DNA Analysis for Missing Person Identification in Mass Fatalities, Boca Raton (Florida): CRC Press.

Sribanditmongkol, P, Pongpanitanont, P, Porntrakulsree, N, Petju, M, Kunaratanapruk, S, Kitkailass, P, Ganjanarintr, P, and Somboonsub, N. World Health Organisation, Forensic aspect of disaster casualty management Tsunami Victim Identification in Thailand,

Accessed 18 June 2014

http://www.who.int/hac/events/tsunamiconf/presentations/2 16 forensic pongruk doc.pdf

Taylor, J. (2009) A brief history of forensic odontology and disaster victim identification practices in Australia, Journal of Forensic Odontostomatol, 27:2, 64-74.

The Sydney Morning Herald, accessed 27 August 2014. http://www.smh.com.au/news/AsiaTsunami/DNA-only-way-to-identify-most-bodies/2005/01/05/1104832179614.html

Tsokos, M, Lessig, R, Grundmann, C, and Benthaus, S. (2006) Experiences in tsunami victim identification, International Journal of Legal Medicine 120, 185-187.

TTVI Operations Thailand, accessed 18 November 2014.

http://www.who.int/hac/events/tsunamiconf/presentations/2 16 forensic kent ppt.pdf.

United States Centres for Disease Control and Prevention. (2005) Morbidity and Mortality Weekly Report, 51,16-18.

Vidoli, G, Mundorff, A. (2012) Victim fragmentation patterns and seat location supplements crash data: American Airlines Flight 587, Aviation, Space, and Environmental Medicine, 83:4, 412-417.

Watts J, and Aglionby, J. 'Long and Agonising Task to Identify Bodies', The Guardian (London), 15 October 2002.

Wright, K, Chaseling, J, Mundorff, A, Maguire, C, and Crane, D.I. (2015) DNA Identification of Child Victims of the South-East Asia Tsunami in Thailand, Unpublished manuscript.

Wright, K, Mundorff, A, Chaseling, J, Forrest, A, Maguire, C, and Crane, D.I. (2015) A New Disaster Victim Identification Management Strategy Targeting "Near Identification-

Threshold" Cases: Experiences from the Boxing Day Tsunami, Forensic Science International 250, 91-97.

Wright, K, Mundorff, A, Chaseling, J, Maguire, C, and Crane. D.I. (2015) An evaluation of the Thai Tsunami victim identification DNA operation, Forensic Science Policy \& Management: An International Journal, 6:3-4, 69-78. 
This research is based on the following papers (referred to by the numbers 1 to 3 ).

PAPER 1 A new disaster victim identification management strategy targeting "near identification-threshold" cases: Experiences from the Boxing Day Tsunami

PAPER 2 DNA identification of child victims of the South-East Asia Tsunami in Thailand

PAPER 3 An evaluation of the Thai Tsunami victim identification DNA operation 
A new disaster victim identification management strategy targeting "near identification-threshold" cases: Experiences from the Boxing Day Tsunami
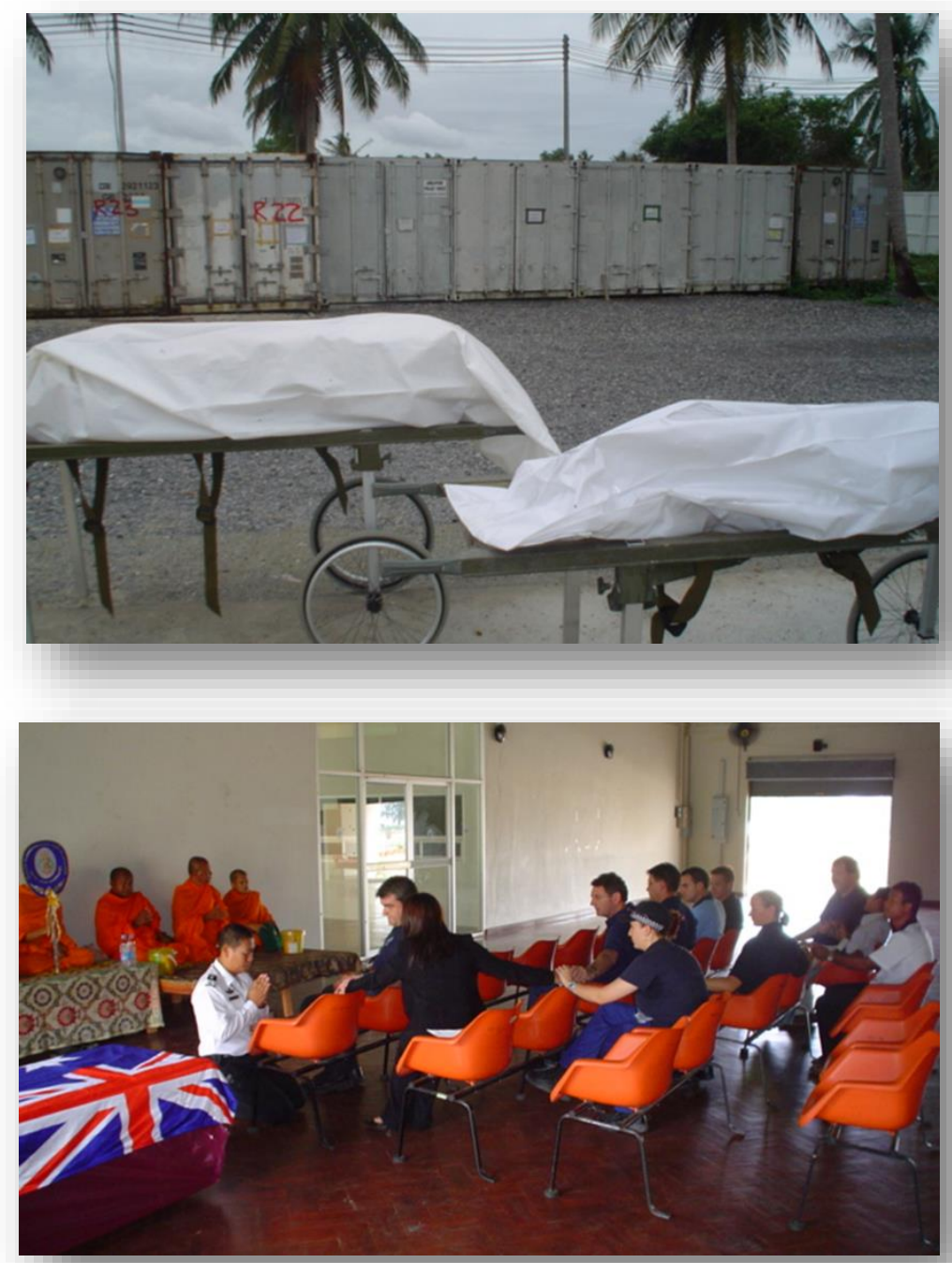

Images from Kirsty Wright 


\section{STATEMENT OF CONTRIBUTION TO CO-AUTHORED PUBLISHED PAPER}

The bibliographic details of the co-authored paper, including all authors, are:

Kirsty Wright ${ }^{a}$, Amy Mundorff ${ }^{b}$, Janet Chaseling ${ }^{c}$, Alexander Forrest ${ }^{a, d}$, Christopher Maguire ${ }^{e}$, Denis Crane ${ }^{a, f}$

a School of Natural Sciences, Griffith University, 170 Kessels Road, Nathan, Queensland, Australia 4111 ${ }^{\mathrm{b}}$ Department of Anthropology, The University of Tennessee, 250 South Stadium Hall, Knoxville, TN 37996, USA

'School of Environment, Griffith University, 170 Kessels Road, Nathan, Queensland, Australia 4111

¿Queensland Health Pathology and Scientific Services, 39 Kessels Road, Coopers Plains, Queensland, Australia 4108

e District of Columbia Department of Forensic Science, Washington DC 20024, USA

${ }^{\dagger}$ The Eskitis Institute for Drug Discovery, Griffith University, 46 Don Young Road, Nathan, Queensland, Australia 4111

\section{Keywords}

Boxing Day Tsunami, Disaster Victim Identification (DVI), Forensic Biology, Dental Age Estimation, Fingerprinting, Thai Tsunami Victim Information (TTVI) operation 


\section{Kirsty Wright (Candidate):}

Devised the near-threshold strategy while working at the TTVI in 2005 as DNA Team Leader. Presented the near threshold strategy to the TTVI Executive Committee, wrote the operational procedure and implemented the strategy with the assistance of TTVI members. Assisted in the analysis and interpretation of DNA profiles, writing and reviewing scientific statements and provision of testimony at the TTVI Identification Board. Wrote operational and quality procedures for the TTVI DNA Team. Contributed to the experimental design and research plan. Analysed and interpreted the TTVI data, performed statistical calculations and wrote the manuscript.

(Signed) (Date)

Kirsty Wright (Corresponding author of paper)

\section{Amy Mundorff (Co-Supervisor and DVI Expert):}

Provided significant contribution to the manuscript in the form of editing and redrafting sections to be more streamlined and targeted for publication.

\section{Janet Chaseling (Co-Supervisor and Forensic Statistician):}

Provided statistical advice and reviewed calculations. Contributed to the experimental design and research plan and contributed to the manuscript in the form of review and editing.

\section{Alexander Forrest (Forensic Dentist):}

Suggested the inclusion of the TTVI Dental Team to the near-threshold strategy to perform dental aging techniques on DNA kinship matches to help exclude cases.

\section{Christopher Maguire (Co-Supervisor and DVI Expert):}

Contributed to the manuscript in the form of review and editing.

\section{Denis Crane (Supervisor):}

Reviewed and provided advice on experimental design and research plan. Contributed to the manuscript significantly in the form of review and editing. (Date) 
A New Disaster Victim Identification Management Strategy Targeting "Near Identification-Threshold" Cases: Experiences from the Boxing Day Tsunami 


\section{Abstract}

The international disaster victim identification (DVI) response to the Boxing Day Tsunami, led by the Royal Thai Police in Phuket, Thailand, was one of the largest and most complex in DVI history. Referred to as the Thai Tsunami Victim Identification operation, the group comprised a multi-national, multi-agency, and multi-disciplinary team. The traditional DVI approach proved successful in identifying a large number of victims quickly. However, the team struggled to identify certain victims due to incomplete or poor quality ante-mortem and postmortem data. In response to these challenges, a new 'near-threshold' DVI management strategy was implemented to target presumptive identifications and improve operational efficiency. The strategy was implemented by the DNA Team, therefore DNA kinship matches that just failed to reach the reporting threshold of $99.9 \%$ were prioritized, however the same approach could be taken by targeting, for example, cases with partial fingerprint matches. The presumptive DNA identifications were progressively filtered through the Investigation, Dental and Fingerprint Teams to add additional information necessary to either strengthen or conclusively exclude the identification. Over a five-month period 111 victims from ten countries were identified using this targeted approach. The new identifications comprised 87 adults, 24 children and included 97 Thai locals. New data from the Fingerprint Team established nearly $60 \%$ of the total near-threshold identifications and the combined DNA/Physical method was responsible for over $30 \%$. Implementing the new strategy, targeting near-threshold cases, had positive management implications. The process initiated additional ante-mortem information collections, and established a much-needed, distinct "end-point" for unresolved cases.

\section{Introduction}


On 26 December 2004, an earthquake measuring 9.1 on the Richter Scale triggered a massive tsunami responsible for more than 280,000 deaths in thirteen countries. In Thailand 5,395 victims were recovered, including approximately 2,400 foreign tourists representing 41 nationalities $[1,2,3]$. An identification operation commenced immediately, resulting in local authorities releasing approximately 560 bodies based on visual identification by their families. Thai forensic teams released an additional 1,151 bodies, 111 of which were based on dental examination and the rest based on physical and property examination [4]. The Thai identification effort was later joined by international experts from over 30 countries working as part of the Thai Tsunami Victim Identification (TTVI) operation in Phuket, Thailand. By the commencement of the international DVI operation in January 2005, there were 3,679 unidentified bodies, approximately half of which were thought to be Thai locals [1]. The TTVI operation followed the DVI management strategy outlined by INTERPOL [5]. Plass Data's ${ }^{T M}$ 'DVI System International' was used to record, store and electronically search ante-mortem data (AM) and post-mortem data (PM) contained in INTERPOL DVI forms and an Automated Fingerprint Identification System (AFIS) was used to search fingerprints [6, 7, 8, 9].

This article examines the implementation, capabilities, and contributions of a novel identification approach executed during a complex DVI operation. A new DVI management strategy, specifically targeting cases yielding below the established DNA identification threshold, was implemented in response to the significant decline in single-modality identifications. The approach was designed to achieve positive identifications for complex cases and to identify cases lacking the necessary information to establish an identification, to request additional data collection.

\section{Background}


Typically, primary (DNA, Dental, and Fingerprints) and secondary (property and physical) identification teams work independently of each other and of police investigators. The teams search for matches between AM and PM records that reach nominated reporting criteria based on international standards and that are set by the command structure within each DVI operation [5]. The separation of the identification teams in DVI mimics the approach used by many forensic experts for criminal cases, which is designed to eliminate cognitive and confirmation bias and promote independent interpretation of forensic analysis. This was the approach used at the TTVI, with a Data Mining Team searching data for matching secondary identifiers (property and physical identifiers such as scars and tattoos).

Following the tsunami, AM records were received from 42 countries and the PM records were generated by a rotating staff from at least 30 countries as part of the TTVI mortuary operations. As seen with other DVI operations, identifications can be quickly established when accurate and complete AM and PM data are available $[10,11]$. Therefore, the traditional DVI strategy worked well, particularly during the early part of the operation. This is clearly evidenced during the months of February and March 2005, when the majority of identifications were established using a single primary method, (93.02\% and 87.26\%, respectively) (Figure 1). By April 2005, $90.18 \%(1,057$ of 1,171$)$ of the dental identifications as a stand-alone method had already been achieved. This was followed by a rapid and precipitous decline in the proportion of cases being resolved by a single primary identification method. Highlighting this drop further, overall single-modality identifications declined in the month of December 2005 to only $20.33 \%$ (12 of 59), ( $p<0.0001)$. By 19 January 2006, a combination of identification methods was necessary to establish nearly $30 \%$ of all identifications [1]. 
On 9 January 2008, a total of 3,761 AM records and 3,696 PM records had been entered into their respective databases. However, the forensic data available in the AM records was limited, with only $58.1 \%$ containing DNA evidence, $52.6 \%$ Dental evidence and $41.3 \%$ Fingerprint evidence [12]. The low percentage of AM records with forensic evidence helps explain why stand-alone methods of identification could not be used to resolve a number of cases.

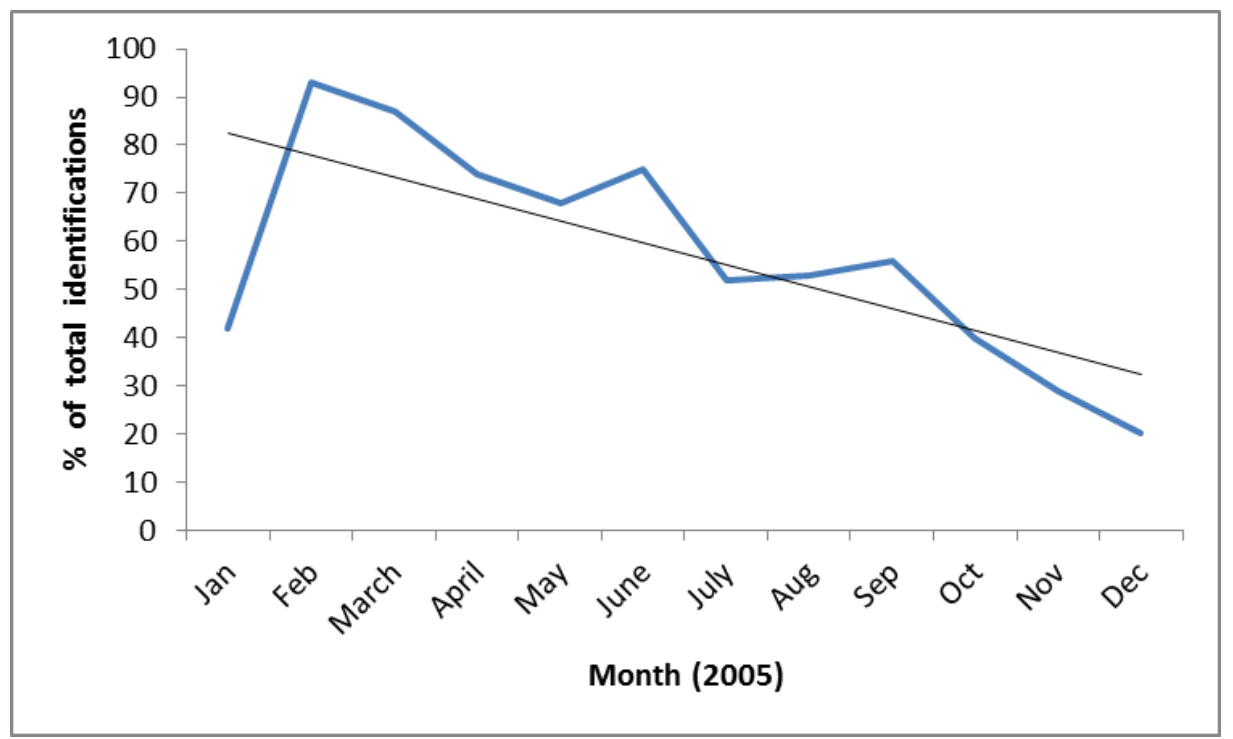

Figure 1: Percentage of total identifications each month achieved with stand-alone methods.

Missing or incomplete AM data can be attributed to a number of factors, many of which have been experienced during other DVI operations $[13,14]$. The reasons for incomplete AM data confounding identification efforts specific to this disaster include:

- Lack of AM dental records for Thai locals. Petju (2007) reported that only $18.1 \%$ of missing Thais had dental charts and only $0.8 \%$ had dental X-rays [15]. This compares to missing Europeans, of whom $94.4 \%$ had dental charts and $75.5 \%$ had dental X-rays. Of the $18.1 \%$ of Thai victims with dental records, only $7 \%$ were used to establish identity [12].

- Loss of reference samples due to the tsunami's destruction, including local AM dental records and identifying personal effects for the numerous victims on the beach at the time of the event [16]. 
- Lack of AM dental records for victims originating from Myanmar. This may be attributed to limited access to dental care or because family members were hesitant to come forward and supply AM information if their missing relative was in the country working illegally.

- Lack of DNA reference samples from family members of victims, many of whom were also victims. In some cases entire families were missing.

- Lack of fingerprint reference samples for local Thai children too young to have their fingerprints recorded on National identity cards [1].

- Difficulties in obtaining reliable AM fingerprints from missing foreign children [1].

- A 'preferential approach' to the collection of AM material adopted by many countries early in the operation. For example, some countries targeted data for dental identification; while others decided DNA would be the best method and chose not to supply fingerprint and dental data [17].

Using the standard DVI approach, investigators struggled to increase identifications beyond a certain point. Instances of incomplete data, or data compromised by data entry errors, prevented matches. Additionally, segregating the identification teams, a typical DVI strategy, led to duplicated efforts between staff rotations. Each national DVI team typically had a staff rotation between two and five weeks, where new experts would join a team, replacing those returning home. The newly rotating individuals would begin to search for possible matches among cases previously discounted within their group or discarded by another primary team because there was no mechanism in place to record confirmed exclusions. Complex cases often did not continue to progress when handed off to a new rotation and critical information was not always transferred between teams when an investigator finished a rotation. While a 'Targeted Request' form was in place, the process was not efficient or systematic and was not structured to leverage and integrate all possible information from the primary and secondary identification teams. 
Moreover, the DVI strategy was based on searching for AM and PM matches; exclusions were not consistently or systematically recorded. There was no established "end-point" for cases lacking sufficient AM data. This was a critical void in the identification process given the large number of AM cases with incomplete records (DNA $41.9 \%$, Dental $47.4 \%$ and Fingerprints 58.7\%) [12]. Although a paper-based process existed to allow an investigator to request additional AM information, this was typically limited to a single discipline on a caseby-case basis and not adequately implemented or rigorously followed-up. In effect, these cases remained in limbo and were repeatedly investigated without resolution due to their lack of identification potential.

Each team recognised cases that they categorised as a 'possible' or 'probable' match but the evidence was not strong enough to progress to the Reconciliation Board. At such a point in time, there was no formal process to direct these cases for systematic and independent comparison across other Identification Teams, to bolster existing evidence and build a stronger basis for identification. Each Identification Team had a small piece of the 'identification jig-saw puzzle’ that, when combined, may have established an identification, but operational efficiencies were not in place to allow this to happen. As a result, more complex cases lingered, still unidentified, and single-modality identifications declined. 


\section{Materials and Methods}

A more efficient system was necessary to strategically target information from cases that fell just below the reporting threshold for identification. An approach was needed that could systematically select those cases for targeted investigation. In June 2005 a new approach was tested with promising results. Twelve DNA kinship matches that were below the $99.9 \%$ reporting threshold were selected for additional investigation. Five of the targeted cases resulted in new identifications through additional fingerprint data. The following month, a new, targeted identification strategy focusing on all "near-threshold" DNA matches was formally implemented into the TTVI (see Figure 2).

Matches that could not be excluded were passed onto the next Team.

Non-excluded cases where insufficient data existed across all teams were given to Liaison Officers for collection of additional AM information.

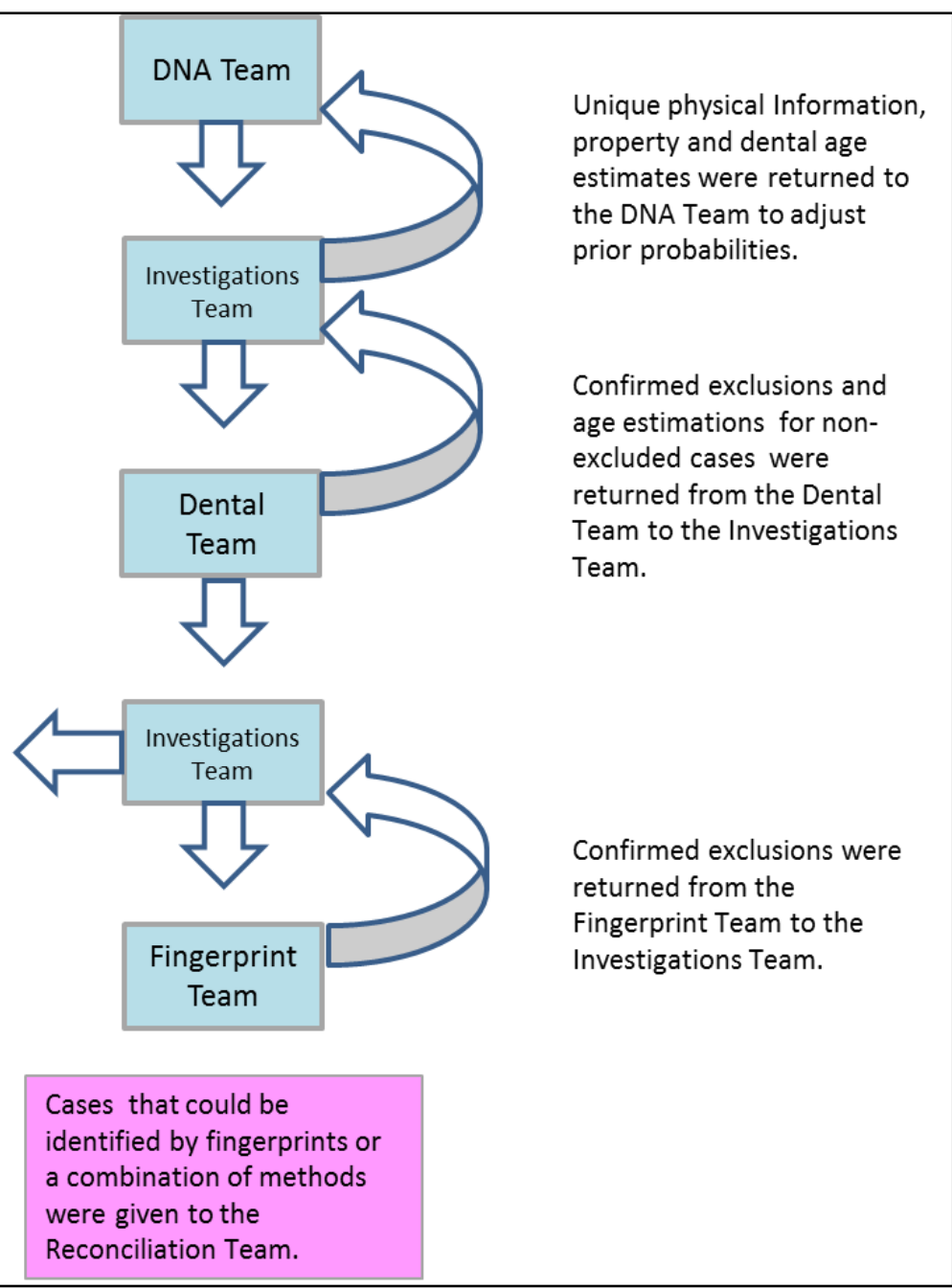

Figure 2: The near-threshold strategy used at the TTVI. 
The new approach focused on "near-threshold" DNA matches. However, this strategy could be adapted so other identification methodologies, such as dental or fingerprint analysis, could also be used to prioritize high probability matches. Cases selected for investigation were progressively filtered through analyses to exclude a match, provide strength to a weak match or to target the case for additional AM information collection. The individual elements of this strategy were as follows:

1. Defining the List to be Investigated: The DNA Team generated a daily list of "possible to probable" DNA kinship matches with a posterior probability of $90.0 \%-99.8 \%$ (the positive identification threshold was set at $99.9 \%$ ). The list was electronically uploaded to a database specifically designed for these special investigations.

2. Property and Physical Information Evaluation: The Investigations Team selected a case from the database and evaluated its associated property and physical information (e.g.; height and personal property) in order to quickly exclude cases and narrow down the list of potential matches. The Property and Physical Information Evaluation was strategically positioned as the first investigative-filter because this rapid exclusionary process reduced the workload for the succeeding team. Dental and fingerprint investigations required specific experts who, when compared to law enforcement personnel, were a limited resource at the TTVI. When exclusion was not possible, the evaluation was recorded in the database and the case was progressed to the Dental Team.

a. Concurrently, newly discovered individualizing information (e.g.; inscribed wedding ring, scars, and tattoos) was transmitted to the DNA Team to be used to further adjust the prior probabilities for that specific case. For example a uniquely inscribed wedding ring recovered from a victim could be used to reduce the prior probability from $1 / 3,000$ to $1 / 2$.

b. Potential matches were recalculated using the updated prior probabilities, which often led to the posterior probability reaching the $99.9 \%$ threshold. When 
this occurred the identification method was designated as combined 'DNA/Physical'.

3. Dental Evaluation: The next evaluation was an in-depth dental re-examination. Matches were forwarded to the Reconciliation Team and exclusions were returned to the Investigations Team. When exclusion was not possible, the case was progressed to the Fingerprint Team.

a. Again, additionally acquired data, such as dental age assessment, was transmitted to the DNA Team for adjusting prior probabilities between the adult and child sub-categories.

b. Potential matches were reassessed using the updated prior probabilities.

4. Fingerprint Evaluation: The Fingerprint Team manually compared hardcopies of AM and PM fingerprints (rather than matching with AFIS). Fingerprint analysis was intentionally placed at the end of the process to limit the number of cases necessitating a labour-intensive manual comparison. Matches were progressed to the Reconciliation Team and exclusions were returned to the Investigations Team. The Fingerprint Team also flagged cases that could not be evaluated due to insufficient AM or PM prints.

a. Cases that could not be definitively excluded, or could not be identified due to lack of AM data or poor quality data, were targeted for additional AM information collection.

5. Reconciliation: The Reconciliation Team evaluated all possible matches and assessed whether the evidence was sufficient to scientifically support identity. The Reconciliation Board took the official decision for identification.

Throughout the process, the Investigations Team managed the database, continually updating the system to reflect each subsequent evaluation. Details specific to each case were recorded in the database to track a case's progress, record exclusions, confirm identifications, and identify cases requiring additional data. The database supplemented 'DVI System International', which lacked these capabilities. The database also provided effective and efficient case management, and a means to maintain independence between teams. 
Utilizing data from multiple databases, cases processed through the near-threshold strategy were evaluated as to whether or not the process contributed to identifications. The specific databases utilized during this analysis included:

1. The 'DNA Investigations' database, created July 2005 at the TTVI, which contained new case entries through to 4 October 2005. The 'DNA Investigations' database was an Excel spreadsheet developed and maintained by the Investigations Team. It contained the AM and PM case number for the presumptive DNA kinship match, information on targeted searches that included evaluations of height, age, personal property, and dental and fingerprint comparisons. The database was used to record and track exclusions and identifications, and cases requiring additional AM data.

2. The TTVI 'AM and PM DNA Matches' database created April 2005 with entries until 23 September 2005. This was an Excel spreadsheet created and used internally by the DNA Team to record the AM and PM case number of all DNA matches, the posterior probability for the match and whether the cases progressed to the Reconciliation team via a DNA report.

3. The TTVI 'Reconciliation' database created in January 2005 with entries through to 12 December 2005 (access to the TTVI reconciliation data after 12 December 2005 was restricted, potentially underestimating the reported number of cases assisted by the near-threshold strategy). This was an Excel spreadsheet created and used internally by the Reconciliation Team to record the AM and PM number of each confirmed identification, the date the case was accepted by the Identification Board, which identification method/s were used, the age, sex and nationality of the victim.

Evaluation of the 'DNA Investigations' database revealed data entry inconsistencies among operators. Progress summaries varied in detail and instances where data field entries were ambiguous or contained no data (e.g. result or date of investigation) were noted. Therefore, sole reliance on this database was not sufficient for evaluation necessary to attribute a successful identification to the near-threshold strategy. The specific criteria outlined below, 
along with additional information from the other two databases, allowed for the evaluation of ambiguous cases for inclusion or exclusion into the data set.

To qualify as an identification that was assisted by the near-threshold strategy, the case must have been initially flagged by the DNA Team as a possible kinship match, unidentified at the time of investigation and met at least one of the following criteria:

1. Comments on the 'DNA Investigations' database indicated that one of the identification teams investigated and confirmed the possible match (either as stand-alone or part of a combined identification).

2. Comments on the 'DNA Investigations' database indicated that the case could not be excluded and was progressed for further examination by the Dental or Fingerprint Teams, and then appeared on the 'Reconciliation' database within two weeks of being investigated.

3. Comments on the 'DNA Investigations' database indicated that the AM case required further information to progress and the case was subsequently identified by this additional information.

4. Comments on the 'DNA Investigations' database indicated physical, property or dental information was used to support the DNA match, or that comments returned to the DNA Team allowed for adjusted prior probabilities leading to an identification in the 'Reconciliation' database.

Cases were not considered for inclusion in the dataset if there was insufficient information or if the DNA match reached the $99.9 \%$ posterior probability threshold before investigation.

\section{Results}


A total of 792 cases were examined as part of the new strategy. All cases were initiated for investigation because the kinship DNA matches fell just below the reporting threshold. The near-threshold strategy revealed immediate success, with 49 new identifications achieved during the first full month of implementation (Table 1). A total of 111 new identifications were established which amounts to $10.31 \%$ of all TTVI identifications during the strategy's 5 -month implementation period (23 July 2005 and 12 December 2005). Identifications were comprised of 87 adults and 24 children (16 years and under); 97 of the 111 new identifications were Thai nationals; three were Swedish nationals, two each from China, Finland and Myanmar and one each from France, Germany, Japan, Russia and the United States.

Table 1: Number of identifications assisted with the new strategy.

\begin{tabular}{cccc} 
Month (2005) & All IDs $^{\mathbf{a}}$ & New strategy IDs & \% of new strateg \\
\hline July & 227 & 1 & $0.44 \%$ \\
Aug & 185 & 49 & $26.49 \%$ \\
Sep & 167 & 25 & $14.97 \%$ \\
Oct & 228 & 26 & $11.40 \%$ \\
Nov & 211 & 8 & $3.79 \%$ \\
Dec & 59 & 2 & $3.39 \%$ \\
Total & $\mathbf{1 , 0 7 7}$ & $\mathbf{1 1 1}$ & $\mathbf{1 0 . 3 1 \%}$ \\
a IDs, identifications & & &
\end{tabular}

Even though the cases targeted for investigation under this strategy were selected because they were all just under the threshold for DNA identification, this did not preclude other modalities from establishing identifications or limit identifications to DNA combined with another method. The strategic flow developed through this process allowed other identification teams to establish new, stand-alone identifications with information not previously noted due to data quality issues. For example, the Fingerprint Team recorded 66 stand-alone identifications and contributed to another ten combined identifications (Table 2). The process 
also allowed other identification teams to provide supportive data to bolster the original DNA match. A combined DNA/Physical identification ('physical' included property and medical/autopsy information) was achieved on 35 occasions, and the remaining 10 identifications were assisted through different combinations of methods.

Table 2: Number of identifications assisted, by method, using the near-threshold strategy.

\begin{tabular}{lc} 
Method & IDs $^{\mathbf{a}}$ \\
\hline Fingerprints & 66 \\
DNA/Physical & 35 \\
Fingerprints/DNA & 3 \\
Fingerprints/DNA/Physical & 3 \\
Fingerprints/Physical & 3 \\
Fingerprints/Dental & 1 \\
identifications &
\end{tabular}

Twenty-one new identifications resulted from additional AM data collections. Part of this strategy focused on identifying cases with insufficient AM material necessary to resolve identification. Once recognized, these cases were brought to the attention of Liaison Officers who worked with police in the victim's country of origin. Where possible, requests for additional information were accompanied by specific advice on the type of AM information to collect. For example, additional family DNA reference samples may be requested to boost the kinship probability to the reporting threshold.

\section{Discussion}




\subsection{Resolution of difficult cases using the near-threshold strategy}

Thai nationals proved difficult to identify owing to the lack of AM dental records. More reliance was placed on fingerprint and DNA analysis, however, access to sufficient AM DNA reference samples was also problematic. The near-threshold strategy proved successful for cases lacking adequate AM data. The significant number of Thai victims identified under this program reflects the benefits of an alternative targeted approach.

Evaluating physical and property evidence contributed strong secondary information leading to nearly one third of the new identifications. The objective of having this analysis at the beginning of the process was to resolve near-threshold DNA cases with secondary information from physical characteristics or property to minimize the use of dental and fingerprint resources. To increase operational efficiencies, individuals with varying backgrounds could be trained to evaluate secondary identifiers (property and physical characteristics) when access to dental or fingerprint specialists was limited.

Dental comparison is only successful in rapidly identifying large numbers of victims when good quality AM and PM records are available. Individuals without sufficient AM dental records are not easily identified by this approach. For example, the Dental Team identified only $2.0 \%$ of Thais (given only $18.1 \%$ of missing Thais had dental charts and only $0.8 \%$ had dental X-rays), but identified $76.4 \%$ of Europeans and $76.5 \%$ of North Americans (who had $94.4 \%$ and $88.2 \%$ of dental charts and $75.5 \%$ and $76.5 \%$ of dental X-rays, respectively) [15]. However, the new targeted approach facilitated dental evaluation even when the AM data was limited. Key informative details, such as dental age estimates, were gleaned from the Dental Team's analyses. The PM cases involving children provided the most value in terms of accurately estimating the age of the victim due to specific dental development patterns [1]. In addition, instances of inconsistent age estimations recorded on the autopsy form, individuals too broadly nominated as either adult or child, and cases with incorrect age estimations were revealed through this evaluation. 
James (2005) has discussed specific quality issues of dental records, including ambiguous AM record collection by general dentists and occasionally police officers rather than experienced forensic dentists, a lack of AM radiographs from public clinics, poor quality AM radiographs, and poor dental examination record taking and record keeping [2]. The Dental Team found that the reproduction of original AM radiographs by photocopying, photographing, faxing or scanning, removed detail necessary for matching. Keiser reported that of 106 TTVI AM dental records examined for quality control, only $49 \%$ were accepted, with the remaining $51 \%$ returned because the data were either incomplete or of an unacceptable standard [18]. The Tsunami Evaluation Working Group reported that such reproductions were frequently flawed and stated "each step away from the original document or radiograph introduces the possibility and the probability of error, resulting in a significant waste of time and also the probability of non-identification" [p110, 1]. The PM dental records were of a higher standard than AM dental records. Keiser examined 78 PM records for quality control and determined that $92 \%$ of dental charting was considered good quality, $85 \%$ of radiographs were considered good quality and $96 \%$ of photographs were considered good quality [18].

The near-threshold strategy revealed a large number of potential fingerprint matches that were not detected by the automated AFIS system. In these instances, data quality issues prevented electronic matches. For example, poor quality AM or PM prints, inconsistencies in the relative sizes of the scanned prints, or the way in which the data were electronically processed for transfer to the TTVI from the host countries. Fingerprints were scanned at a resolution of 500 dpi before being entered into AFIS, but such resolution did not allow for electronic matching of certain finer detail, particularly as found in fingerprints from children. At that point, the software did not allow for an increase in resolution. Instead, fingerprint examiners relied on hard copy prints and a magnifying glass to manually detect the finer details needed for some matches [1]. This was not a practical approach for comparing thousands of records; therefore the Fingerprint Team relied on targeted requests from the near-threshold strategy to progress more complex cases affected by data quality issues. In addition, this strategy revealed a few 
instances where the AM fingerprints had not been uploaded to AFIS, so those cases were targeted for collection, upload and comparison.

The quality of $\mathrm{AM}$ fingerprints also varied, as some countries collecting prints in the homeland of missing foreign tourists were not aware of the quality standards needed. Another issue was the electronic transmission of AM fingerprints without an appropriate scale, rendering the prints incompatible for matching against PM fingerprints in AFIS [17].

The impact of the AM data quality issues was recognised in the INTERPOL Tsunami Evaluation Working Group report, which highlighted that speedy and successful identification can only be achieved with quality AM data relating to the missing. The group recommended 'that INTERPOL oversee the development of standard operating procedures and minimum data standards for the submission of quality ante-mortem data by foreign countries' [p96, 1].

Data quality issues were not unique to the Boxing Day tsunami DVI operation; other largescale disasters have confronted similar problems that impacted successful identifications. Hennessy examined six areas of possible quality failure in the collection of AM DNA records for the World Trade Center Attacks [19]. The six areas of possible quality failure were inaccurate data from the informants, misunderstandings between informants and interviewer, uneven DNA training for interviewers, information incorrectly recorded by interviewers, lack of data entry standardisation and handwritten interviews. He speculates that if $99 \%$ accuracy is achieved at each point of possible quality failure, then the final record will only be $94 \%$ accurate; this strongly advocates for a stringent administrative review process. Donkervoort examined the data accuracy for the collection of AM family reference DNA from Hurricane Katrina and reported on the three fields considered to be critical information for achieving DNA identification, namely: number of missing relatives, relationship of the donor to the missing relative and verification of relationship through pedigree. She reported that only $30 \%$ of the forms evaluated for the study were completely accurate [20].

\subsection{Improvements in operational efficiencies}


The near-threshold strategy introduced operational efficiencies during the mid to later stages of the TTVI operation. It is necessary to implement such management strategies, particularly when evaluating difficult cases, to minimise redundant efforts and clearly define and endpoint. Implementation of the new near-threshold strategy improved operational efficiencies by:

1. Ending redundant evaluations of the same cases within and between teams;

2. Excluding 'possible' and 'probable' DNA matches, thereby saving DNA resources;

3. Documenting the outcome of each case investigation;

4. Flagging cases that could not proceed to an identification without additional AM information, thereby establishing an end-point to the repeated evaluations;

5. Targeting the collection of additional specific AM data for individual cases;

6. Targeting 'possible' DNA matches that otherwise would not have been reported;

7. Systematically addressing data quality issues through identification of inaccurate records and collection of better quality information.

Constantly re-examining cases without reaching a resolution costs valuable time and resources, and delays the inevitable request for additional AM data necessary to achieve identification. Smaller DVI operations allow for easy liaison between identification teams and the Reconciliation Team. These targeted discussions can then lead to a request for additional AM material. This simply was not possible at the TTVI because of the large number of victims $(3,679$ by January 2005$)$ and frequently rotating personnel. The implementation of the nearthreshold strategy is a mechanism which allows for these types of liaisons to exist, even within a large-scale disaster.

Software systems used to rapidly compare large quantities of data are critical for DVIs involving high numbers of deceased. However, poor quality data may lead to a false exclusion, or worse, an incorrect identification. Dailey highlights the importance of quality control for AM and PM dental records in a DVI. He also warned against the involvement of over-confidence in inexperienced operators and negative effects of staff 'burnout' in these 
circumstances [21]. At the TTVI, AM and PM data quality issues resulted from differences in operating procedures, non-standardised terminology, inexperienced personnel, fatigue, the use of disparate databases, issues arising from the reproduction of original dental and fingerprint records, problems during electronic transfer, and manual entry errors [1, 22].

Along with incomplete data, the decline in single modality identifications was also attributed to poor data quality. A number of measures were implemented to increase data quality. These included a Quality Assurance Team at the mortuary sites; an AM and PM Data Quality Team to address data entry; and the introduction of standard operating procedures into the work practice of individual teams. A 'Final Inventory Protocol' was also undertaken at the mortuaries to re-examine unidentified victims in an attempt to detect errors, collect additional data, and validate existing information [1, 2, 9, 23].

Ultimately, implementing the near-threshold strategy resulted in swift resolution of difficult cases. Creating a process with a discrete end-point led to the targeted acquisition of additional information. In turn, this facilitated swift identifications ultimately conserving time and monetary resources. The value of a systematic end-point was recognised following the World Trade Center Human Identification Project by Biesecker et al (2005). One of their seven recommendations for future disaster management planners states, "Criteria for determining end-points should be designated early in the identification process" [p1122, 24]. Therefore, the duration of large-scale DVI operations could be considerably reduced through implementing this type of approach.

\section{Conclusions}

To maximize efficiency and identifications, a near-threshold strategy should be implemented to augment a traditional DVI approach, particularly when stand-alone identifications begin to decline. Management personnel can utilise this type of strategy to generate a target list of 
potential matches, which can be filtered through identification teams while systematically recording investigative outcomes.

The traditional DVI approach allows for rapid identification by stand-alone methods, provided that access to good quality AM and PM data is available. However, the specific characteristics of the Boxing Day tsunami (i.e.; people on the beach without personal effects, limited access to dental care, entire families' killed, and mass destruction of homes) resulted in a significant number of cases with incomplete AM data. Conversely, incidents with focused disaster locations such as the events of September $11^{\text {th }}, 2001$ (the Twin Towers, the Pentagon, a field in Pennsylvania), still allowed police to collect items from the victims' homes and family members were still available for DNA references. Similarly, following the 2002 Bali Bombings, the police were able to collect items from the victims' hotel rooms and DNA from living family members. In these disasters, it was the incomplete PM records that caused the identification difficulties due to fragmented and compromised human remains $[25,26]$. However, the bodies of the tsunami victims were mostly intact and often well enough preserved to obtain fingerprints. Petju reported that of 3,750 bodies examined, $97.4 \%(3,652)$ were considered whole bodies and only $2.6 \%$ (98) were body parts or bodies without a head [15].

For large DVI operations such as this, where complete and accurate AM or PM data is not always available, a near-threshold strategy should prove useful. Many of the successful identifications achieved through this process were the result of this strategy to identify cases requiring additional $\mathrm{AM}$ information for resolution. This approach had a mechanism in place to flag cases unable to progress with the limited information available, resulting in specific requests tailored to each case. Supplementary case-specific information necessary to adjust prior probabilities thus allowing for identification by DNA also resulted from this approach. In addition, implementation of this new strategy helped address data quality problems in both AM and PM information. More specifically, transcription errors not detected during the initial 
data entry process or problems encountered during data upload into AFIS, both of which hindered identifications.

There are many difficulties associated with large-scale DVI operations. More complex cases often necessitate the use of combined methods for identification, to complement stand-alone methods. In fact, there are recommendations that support using combined information for mass fatality identification operations [25]. Prinz et al recommends that "Especially if multiple family members are involved, DNA-based identification should whenever possible be anchored by anthropological and/or circumstantial data, a second identification modality, or multiple DNA references" [p9-10, 27]. A combined identification method can increase identification efficiencies, increase the level of confidence in identification and potentially decrease identification errors.

In summary, this article illustrates that a traditional DVI operation benefits from the concurrent implementation of a strategy targeting complex cases. Simultaneous implementation during a large-scale DVI operation can be successful while also maintaining the original organisational structure, rigid scrutiny of matches and specific identification team responsibilities. A minimum of 111 identifications were assisted by the near-threshold identification strategy during its 5month implementation period.

\section{Supplementary Material}


The four cases below are successful examples of the near-threshold strategy. Each case was initiated by the presumptive DNA match and established with the assistance of fingerprints. The targeting of the AM and PM case and the manual comparison of fingerprint records, which was part of the strategy, overcame data quality issues which prevented the match being generated in AFIS. In Cases 1 and 2 a DNA report was requested by the Investigation Team after the fingerprint match was found, and a combined identification was recorded in the Reconciliation Database. However, often the Fingerprint Team forwarded a report to the Reconciliation Team without notifying the Investigations Team or DNA Team (see Cases 3 and 4). This led to the case being recorded in the Reconciliation Database as being established only with fingerprints, despite the identification being initiated by the probable DNA match. It is reasonable to conclude that the fingerprint identifications established using the near-threshold strategy would not have occurred without the records being targeted for manual comparison.

Case 1 (Swedish adult): A possible DNA match from 'DVI-System International' was forwarded to the Investigations Team. The result of the investigation was recorded on 28 July 2005 as 'Matched. Good physical similarities. Fingerprint comparison confirmed the identification'. Six days later on 3 August the case was taken to the Identification Board and the method of identification was recorded as Fingerprints/DNA/Physical.

Case 2 (Swedish child): A DNA match with a posterior probability of $99.7 \%$ was forwarded to the Investigations Team. The result of the investigation was recorded on 30 July 2005 as 'Cannot be discounted, correct age, height and clothing. Referred to fingerprints for further examination'. On 15 August 2005 the case was accepted by the Identification Board and the method of identification was recorded as Fingerprints/DNA.

Case 3 (Thai adult): A possible DNA match was forwarded to the Investigations Team. The result of the investigation was recorded on 2 August 2005 as 'Matched. Fingerprint comparison confirms ID. Files with fingerprint section for action'. On 8 August 2005 the 
Identification Board accepted the case and the method of identification was recorded as Fingerprints.

Case 4 (Thai adult): A DNA match with a posterior probability of $99.67 \%$ was forwarded to the Investigations Team. The result of the investigation was recorded on 4 October 2005 as 'Possible DNA match (99.67\%); physical comparison shows possible match due to age, height, weight, light build, ear piercings and long black hair. Check by fingerprint section confirms identity'. The case was accepted by the Identification Board three days later and the method of identification recorded as Fingerprints.

\section{References}

[1] INTERPOL Tsunami Evaluation Working Group, 18 June 2014 http://www.interpol.int/Media/Files/INTERPOL-Expertise/DVI/INTERPOL-TsunamiEvaluation-Working-Group. 
[2] H. James, Thai Tsunami Victim Identification - Overview to Date, The Journal of Forensic Odonto-Stomatology 23 (2005) 1-18.

[3] T. Lay, H. Kanamori, C. Ammon, M. Nettles, S. Ward, R. Aster, C.R, S. Beck, S. Bilek, M. Brudzinski, R. M, R. Butler, H. DeShon, G. Ekstrom, K, Satake, S. Sipkin, The great SumatraAndaman earthquake of 26 December 2004, Science 308 (2005) 1127-1133.

[4] World Health Organisation, Forensic aspect of disaster casualty management Tsunami Victim Identification in Thailand, P. Sribanditmongkol, P. Pongpanitanont, N. Porntrakulsree, M. Petju, S. Kunaratanapruk, P. Kitkailass, P. Ganjanarintr, N. Somboonsub, 18 June 2014 http://www.who.int/hac/events/tsunamiconf/presentations/2 16 forensic pongruk doc.pdf

[5] INTERPOL DVI Guide, 18 June 2014 http://www.interpol.int/Media/Files/INTERPOLExpertise/DVI/DVI-Guide.

[6] INTERPOL DVI Forms, 18 June 2014 http://www.interpol.int/en/INTERPOLexpertise/Forensics/DVI-Pages/Forms

[7[ JP. Beauthier, E. Vlack, P. Lefevre, J Winne, Mass Disaster Victim Identification: The Tsunami Experience, The Open Forensic Science Journal 2 (2009) 54-62.

[8] G. Lau, WF. Tan, PH, Tan, After the Indian Ocean Tsunami: Singapore's contribution to the international disaster victim identification effort in Thailand, Ann Acad Med Singapore 35 (2005) 341-351.

[9] R. Lessig, C. Grundmann, F. Dahlmann, K. Rotzscher, J. Edelmann, P. Schneider, Tsunami 2004- a review of one year of continuous forensic medical work for victim identification, EXCLI Journal 5 (2006) 128-129.

[10] S. Ferreira, H. Kuser, R. Garrido, A. Trindade-Filho, K. Paula, M. Galvão, A. Moraes, Floods and mudslides in the State of Rio de Janeiro and a plane crash in the Brazilian Amazon rainforest: A study of two different experiences in disaster victim identification (DVI). Forensic Science International: Genet Supplementary Ser. 3 (2011) e516-e517.

[11] H. Meyer, The Kaprun cable car fire disaster-aspects of forensic organisation following a mass fatality with 155 victims, Forensic Science International 138 (2003) 1-7.

[12] J. Chaikunrat, P. Pongpanitanon, M. Petju, Victim Identification in the Tsunami Disaster in Thailand, Journal of Health Science 20 (2011), 897-902.

[13] Calacal, G. et al (2005). Identification of exhumed remains of fire tragedy victims using conventional methods and autosomal/Y-chromosomal short tandem repeat DNA profiling. The American Journal of Forensic Medicine and Pathology. Volume 26, 3, 285-291.

[14] B. Olaisen, M. Stenersen, B. Mevåg, Identification by DNA analysis of the victims of the August 1996 Spitsbergen civil aircraft disaster. Nature Genetics 4 (1997) 402-405.

[15] M. Petju, A. Suteerayongprasert, R. Thongpud, K. Hassiri, Importance of dental records for victim identification following the Indian Ocean tsunami, Public Health 121 (2007) 251-257.

[16] M. Perrier, M. Bollmann, A. Girod, P. Mangin, Swiss DVI at the tsunami disaster: Expect the unexpected, Forensic Science International 159S (2006) S30-S32. 
[17] E. De Valck, Major incident response: Collecting ante-mortem data, Forensic Science International 159S (2006) S15-S19.

[18] J. Kieser, W. Laing, P. Herbison, Lessons learned from large-scale comparative dental analysis following the South Asian Tsunami of 2004, Journal of Forensic Science 51 (2006) 106-112.

[19] M. Hennessey, World Trade Center DNA identifications: the administrative review process. $13^{\text {th }}$ International Symposium on Human Identification (2002). Promega, 18 June 2014 http://au.promega.com/products/pm/genetic-identity/ishi-conference-proceedings/13thishi-oral-presentations/

[20] S. Donkervoort, S. Dolan, M. Beckwith, T, Northrup, A. Sozer, Enhancing accurate data collection in mass fatality kinship identifications: Lessons learned from Hurricane Katrina, Forensic Science International: Genetics 2 (2008) 354-362.

[21] J. Dailey, Charting errors in mass disaster dental records; incidence, issues and implications. In: C. Bowers, G. Bell, Manual of forensic odontology, 3rd ed., Saratoga Springs: American Society of Forensic Odontology (1997), 250-257.

[22] R. Byard, C. Winskog, Potential problems arising during international disaster victim identification (DVI) operations, Forensic Science, Medicine and Pathology 6 (2010) 1-2.

[23] M. Tsokos, R. Lessig, C. Grundmann, S. Benthaus, Experiences in tsunami victim identification, International Journal of Legal Medicine 120 (2006) 185-187.

[24] L. Biesecker, et al., DNA identifications after the 9/11 World Trade Centre Attack, Science 310 (2005) 1,122-1,223.

[25] B. Budowle, F. Bieber, A. Eisenberg, Forensic aspects of mass disasters: Strategic considerations for DNA-based human identification, Legal Medicine 7 (2005) 230-243.

[26] Z. Budimlija, M. Prinz, A. Zelson-Mundorff, J. Wiersema, E. Bartelink, G. MacKinnon, B. Nazzaruolo, S. Estacio, M. Hennessey, R. Shaler, World Trade Center human identification project: experiences with individual body identification cases. Croat Med J. 44 (3) (2003) 25963.

[27] M. Prinz, A. Carracedo, W. Mayr, N. Morling, T. Parsons, A. Sajantila, R. Scheithauer, H. Schmitter, P. Schneider, DNA Commission of the International Society of Forensic Genetics (ISFG): Recommendations regarding the role of forensic genetics for disaster victim identification (DVI), Forensic Science International: Genetics 1 (2007) 3-12. 
DNA identification of child victims of the South-East Asia Tsunami in Thailand 


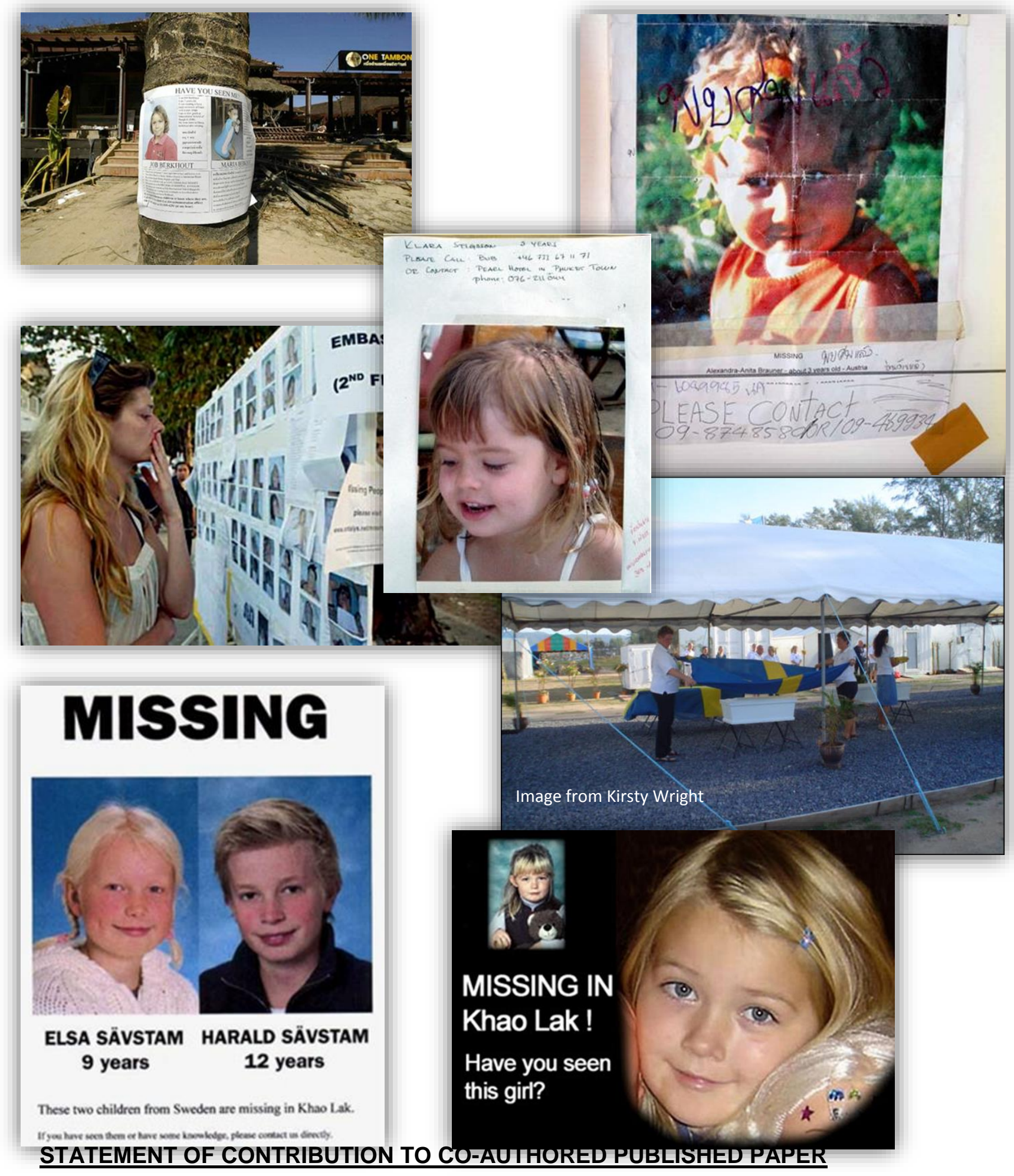

Freely available images sourced from the internet.

ored paper, including all authors, are:

Kirsty Wright ${ }^{a}$, Janet Chaseling ${ }^{b}$, Amy Mundorff ${ }^{c}$, Christopher Maguire ${ }^{d}$, Denis I. Crane ${ }^{a, e}$ 
a School of Natural Sciences, Griffith University, 170 Kessels Road, Nathan, Queensland, Australia 4111 'S School of Environment, Griffith University, 170 Kessels Road, Nathan, Queensland, Australia 4111

${ }^{\circ}$ Department of Anthropology, The University of Tennessee, 250 South Stadium Hall, Knoxville, TN 37996, USA

${ }^{d}$ District of Columbia Department of Forensic Science, Washington DC 20024, USA

eThe Eskitis Institute for Drug Discovery, Griffith University, 46 Don Young Road, Nathan, Queensland, Australia 4111

Keywords: Disaster Victim Identification (DVI); Thai Tsunami Victim Identification (TTVI) operation; Mass fatalities; Forensic Biology; South-East Asia Tsunami

\section{Statement of Joint Authorship}

\section{Kirsty Wright (Candidate):}

Devised the targeted child strategies while working at the TTVI in 2005 as DNA Team Leader. Presented the child strategies to the TTVI Scientific Group, wrote the associated operational procedures and implemented the strategies with the assistance of TTVI members. Assisted in the analysis and interpretation of DNA profiles, writing and reviewing scientific statements and provision of testimony at the TTVI Identification Board. Wrote operational and quality 
procedures for the TTVI DNA Team. Contributed to the experimental design and research plan. Analysed and interpreted the TTVI data, performed statistical calculations and wrote the manuscript.

(Signed) (Date)

Kirsty Wright (Corresponding author of paper)

\section{Amy Mundorff (Co-Supervisor and DVI Expert):}

Provided significant contribution to the manuscript in the form of editing and redrafting sections to be more streamlined and targeted for publication.

\section{Janet Chaseling (Co-Supervisor and Forensic Statistician):}

Provided statistical advice and reviewed calculations. Contributed to the experimental design and research plan and contributed to the manuscript in the form of review and editing.

\section{Christopher Maguire (Co-Supervisor and DVI Expert):}

Contributed to the manuscript in the form of review and editing.

\section{Denis Crane (Supervisor):}

Reviewed and provided advice on experimental design and research plan. Contributed to the manuscript significantly in the form of review and editing. (Date) 
DNA Identification of Child Victims of the South-East Asia Tsunami in Thailand

Keywords: Disaster Victim Identification (DVI); Thai Tsunami Victim Identification (TTVI) operation; Mass fatalities; Forensic Biology; South-East Asia Tsunami

\author{
Abstract \\ In January 2005, the Thai Tsunami Victim Identification (TTVI) operation in Phuket, Thailand \\ commenced identification of over 3,500 local and foreign tsunami victims, including
}


approximately 500 children. This study examines possible differences in identification rates between adults and children (defined as $\leq 16$ years old) during this operation. The results indicate that during the first 100 days of the operation the percentage of total adult identifications far outweighed child identifications. The younger the child, the longer the identification process would take $(p<0.0001)$. Children under the age of 1 year took an average of 195 days to identify, compared to 130 days for children aged 16 . Identification rates were extended, on average, 4.3 days for each year younger victims were than 16 .

The operation reveals numerous deficiencies in ante mortem and post mortem (PM) reference material for children, likely slowing their identification rates. In an effort to overcome these challenges, a number of targeted strategies were implemented, including an improved DNA strategy which resulted in significant and rapid increases in child identifications. These strategies included using PM body length to prioritise DNA testing of children, using PM DNA samples from parents of missing children (who had been identified by fingerprints or dental methods) as references for kinship matching, targeted use of kinship matches falling just below reporting thresholds (near-threshold identification strategy), and PM-to-PM kinship matching.

By 12 December 2005, 214 children (48.4\% of all identified children) had been identified using DNA, with 152 (34.4\%) by fingerprints, 73 (16.5\%) by dental and $3(0.7 \%)$ by physical characteristics/personal effects.

\section{Introduction}

On 26 December 2004, a 9.3 magnitude earthquake erupted in the Indian Ocean off the coast of Banda Aceh in Sumatra, triggering a massive tsunami affecting thirteen countries and killing over 280,000 people [1, 2]. Thailand reported 8,195 people as either dead or missing, many of whom were locals, lost when entire villages were swept away by the waves [1]. Approximately 2,400 victims were foreign tourists visiting popular resorts in Patong, Khao Lak, 
Krabi, and Phi Phi Island [1]. Forty nations suffered casualties in Thailand, including Sweden with 519 nationals, Germany 495, Finland 167, Switzerland 91, United Kingdom 83, Norway 77, Austria 73, and France 73 [1, 3]. Often losses involved entire families, including children. Cohen (2009) reported that nine of the ten Scandinavian families holidaying at Khao Lak beach lost children aged from three months to 15 years [4].

Approximately 500 of the victims in Thailand were children, aged 16 years or younger. The youngest child was an American boy born four days before the tsunami. Figure 1 illustrates the children's age distribution. The data for this study comprise 442 children ( 220 males and 222 females) identified by the Thai Tsunami Victim Identification (TTVI) operation up until 12 December 2005.

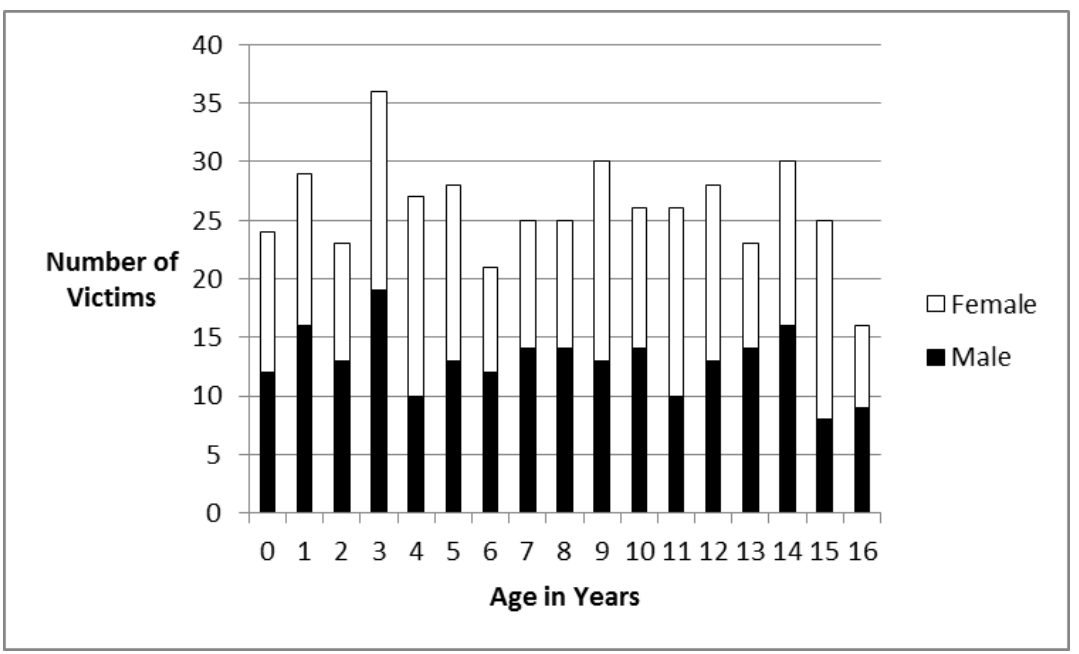

Figure 1: Age and gender distribution of 442 children who were victims of the SouthEast Asia Tsunami in Thailand (all nationalities). Source, TTVI Reconciliation Database (12 December 2005).

The effect of the disaster on local Thai families was immense, with entire villages swept away. Extended families of foreign tourists holidaying in the region also suffered large numbers of related deceased. Figures 2 and 3 represent examples of two families who lost multiple 
relatives. The type of pedigree in Figure 2 was a common scenario confronted by the TTVI operation, while the pedigree in Figure 3 was the most extreme example of multiple related fatalities.

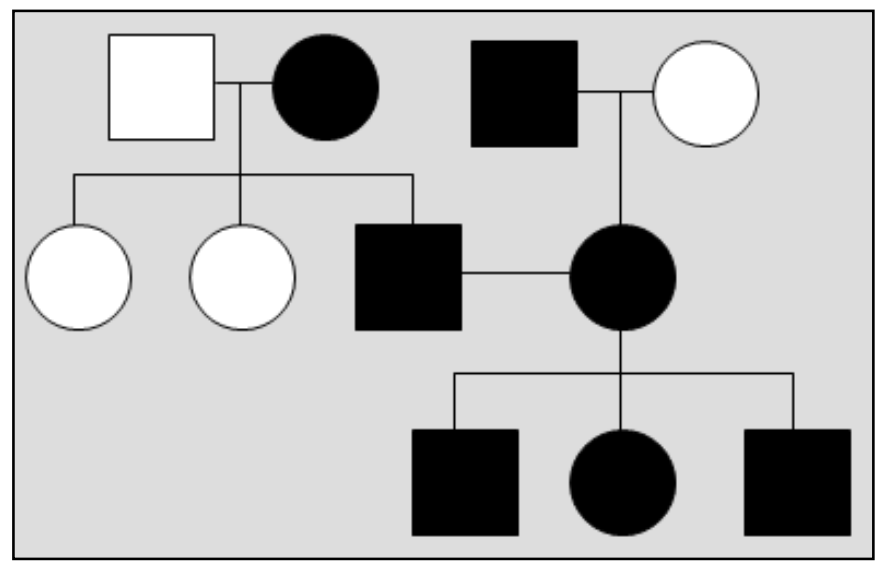

Figure 2: A family with victims across three generations. Black shapes represent tsunami victims; white shapes represent living relatives.

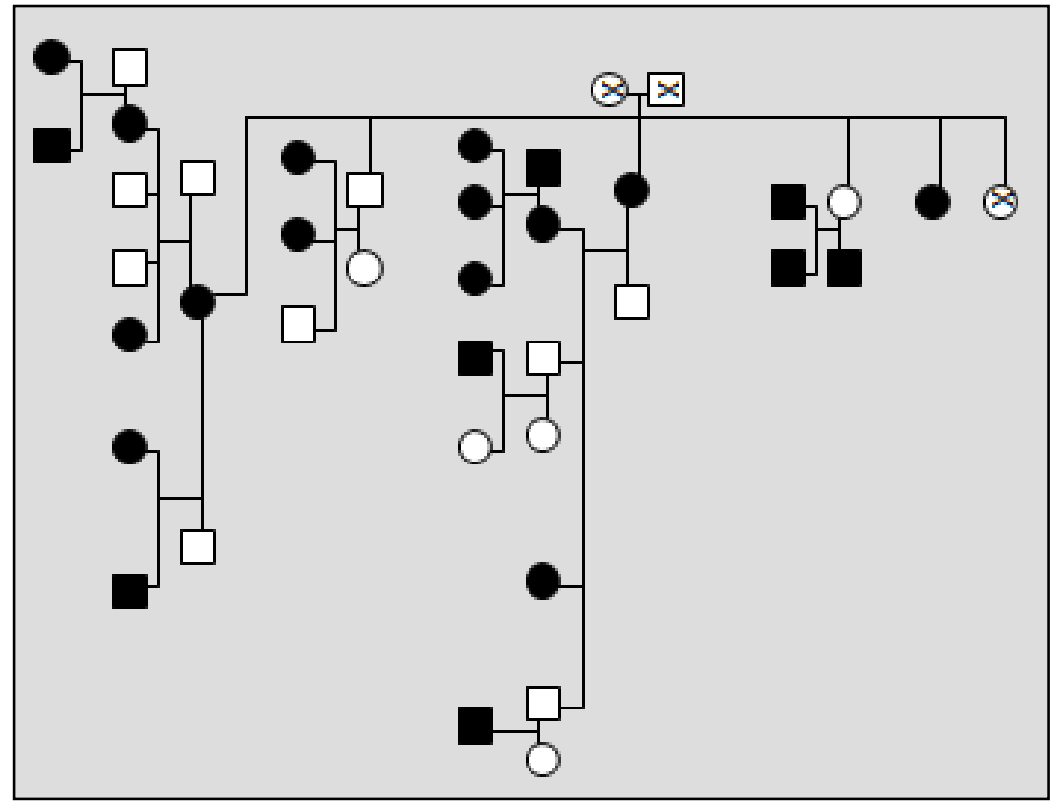

Figure 3: A local Thai family that lost twenty-two members in the tsunami. ' $X$ ' represents relatives who were deceased prior to the tsunami. Black shapes represent tsunami victims; white shapes represent living relatives. 
The high degree of relatedness among victims had not previously been encountered on this scale in a Disaster Victim Identification (DVI) operation. In addition, there was a disproportionate number of deceased children compared to other large DVI operations. By comparison, the median age of the 2,726 victims of the World Trade Center Attack in 2001 was 39 and 38 years old for males and females, respectively, and there were only three victims aged five and under, and related victims were not common [5]. Two hundred of the 202 victims of the 2002 Bali Bombings were adults, mainly in their twenties and thirties, and were unrelated. The two youngest victims of the Bali Bombing were Australian females aged 14 and 15 [6]. An example of an incident causing numerous child fatalities would be the 2001 crash of American Airlines flight 587, where 28 of the 251 (9\%) passengers killed were children 16 years or under, including multiple siblings [7]. However, as a DVI operation, AA flight 587 is not a comparable situation because it was a closed-population incident, with significantly fewer victims, and a readily available flight manifest.

This paper compares the rates of child and adult identifications and explores factors that might have contributed to the differences. It further investigates whether a difference in identification speed existed within the child category, and discusses the targeted strategies that were implemented to overcome these deficiencies. The impacts and outcomes of the targeted strategy on child identification rates are examined, followed by recommendations to guide future disaster management involving large numbers of children.

\section{Methods}

Data from the 2,871 victims who were identified during the period 12 January 2005 to 12 December 2005 were used to analyse the methods and rates of identification of adults and children 16 years and under. This period represents the early through to late stages of the TTVI operation where $78 \%$ of victims had been identified. Identifications were made beyond this point, however the authors did not have access to this information. Two records were excluded because the victims' dates of birth were unknown. Identification methods used in 
the analysis were based on the primary evidence nominated by the TTVI Reconciliation Team in the Reconciliation Database. Physical identification includes scars, tattoos, and property evidence; dental required $\mathrm{AM}$ dental records; fingerprints required $\mathrm{AM}$ data either from national databases or a personal reference sample; DNA identification required DNA from a personal item or close living relatives. More than one method of identification was entered in 891 of 2,871 records. In these instances, the first method of identification listed was used as the primary evidence in data analysis. It was standard policy for the Reconciliation Team to record first the identification method considered of most value.

\section{Results and Discussion}

\subsection{Identification rates of adults and children in the first one hundred days}

During the first 100 days of the TTVI operation (12 January 2005 to 25 April 2005) 1,289 individuals were identified. It was readily apparent that only a fraction of these identifications were children, 78 compared to 1,211 adults $(6.4 \%)$.

Table 1 examines adult-to-child identifications, from six countries with ten or more deceased children, at 50 and 100 days into the operation. For example, in the first 50 days $56.3 \%$ (218/387) of Swedish adults were identified compared to $5.2 \%(6 / 115)$ of Swedish children. After 100 days the disparity was still evident, with $91.5 \%$ (354/387) of Swedish adults identified compared to $27.0 \%(31 / 115)$ of Swedish children. Two of the six nationalities analysed, Thailand and Norway, did not follow this trend. After 100 days 3.7\% (33/893) of Thai adults and $0.6 \%(1 / 155)$ of Thai children were identified, demonstrating that both Thai adults and children were difficult to identify. The lack of AM information for Thai victims in the early phase of the operation likely contributed to their lower identification rate [1]. Conversely, a larger percentage of Norwegian children were identified in the first 50 and 100 days $(17.4 \%$ and $65.2 \%$, respectively) compared to the other nations. However, Norwegian child identification rates were still lower at 50 and 100 days compared to Norwegian adults (90.7\% at each stage). 
Table 1: Adults and children identified in the first 50 and 100 days of the TTVI operation, by country.

\begin{tabular}{|c|c|c|c|c|}
\hline Country & $\begin{array}{l}\text { Adult / } \\
\text { Child }\end{array}$ & $\begin{array}{c}\text { Victims } \\
\text { Identified }^{\text {a }}\end{array}$ & $\begin{array}{c}\% \text { ID }^{b} \text { at } 50 \\
\text { days }\end{array}$ & $\begin{array}{c}\% I^{\mathrm{b}} \text { at } \\
100 \text { days }\end{array}$ \\
\hline \multirow[t]{2}{*}{ Finland } & Adult & 109 & 67.0 & 89.0 \\
\hline & Child & 51 & 5.9 & 29.4 \\
\hline \multirow[t]{2}{*}{ France } & Adult & 49 & 28.6 & 53.1 \\
\hline & Child & 18 & 5.6 & 33.3 \\
\hline \multirow[t]{2}{*}{ Germany } & Adult & 443 & 28.5 & 84.4 \\
\hline & Child & 35 & 5.7 & 28.6 \\
\hline \multirow[t]{2}{*}{ Norway } & Adult & 55 & 90.7 & 90.7 \\
\hline & Child & 22 & 17.4 & 65.2 \\
\hline \multirow[t]{2}{*}{ Sweden } & Adult & 387 & 56.3 & 91.5 \\
\hline & Child & 115 & 5.2 & 27.0 \\
\hline \multirow[t]{2}{*}{ Thailand } & Adult & 893 & 0.5 & 3.7 \\
\hline & Child & 155 & 0.0 & 0.6 \\
\hline
\end{tabular}

a The number of identifications achieved by 12 December 2005 , ${ }^{b}$ Identified

Given the distinct difference in identification rates between adults and children, the identification rates for specific ages within the child category was explored. A similar trend in the average number of days to identify French, German, Finnish and Swedish children was found, so their data was combined and analysed further. A negative relationship was found between age and the average number of days to identify the victim $(p<0.0001)$, with children under the age of 1 year taking an average of 195 days compared to an average of 130 days for children aged 16 years (Figure 4). Identification took 4.3 days longer for each additional year the child was under the age of $16(95 \% \mathrm{Cl}=2.9$ days to 5.7 days $)$. 


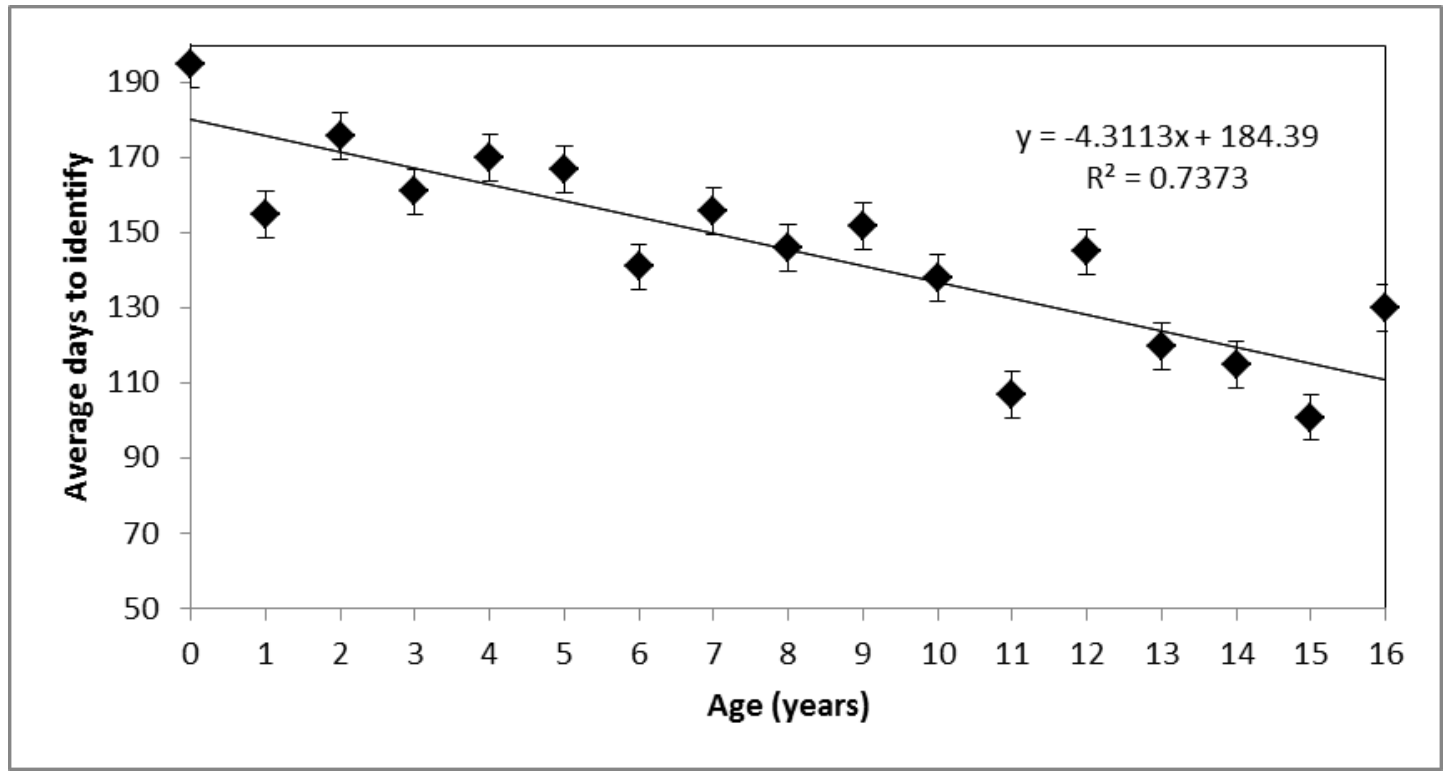

Figure 4: Average days to identify children using all methods as a function of age. Analysis based on child victims from France, Germany, Finland and Sweden.

\subsection{Factors preventing the rapid identification of children}

Each identification method encountered obstacles that prolonged or prevented the identification of children [8]. These included:

- More rapid decomposition of children compared to adults, preventing visual identification (prior to the establishment of the TTVI) [4,9].

- Lack of individualizing features associated with age, such as tattoos, surgical implants, healed fractures, distinctive scars, or body piercing $[10,11,12]$.

- Lack of identifying personal property more typical to adults, such as driver's licences, work permits, credit cards, health cards, wedding rings, and in many cases mobile phones.

- Lack of AM dental comparisons due to fewer dental restorations, and rapid change in growth and development $[13,14]$.

- Difficulty obtaining PM fingerprints of sufficient quality for the children's small hands [1]. 
- Lack of national identification cards (with associated fingerprints) for Thai individuals under the age of 16 years [3].

- Difficulties in collecting discrete AM fingerprints with reliable provenance for children. Toys, schoolbooks and other children's possessions are typically handled by multiple people [1].

- Low resolution of electronic fingerprint records (500dpi), thus obscuring the finer detail typical of children's prints [1].

- Lack of AM DNA references from parents and siblings of missing children who were also victims of the tsunami. Lack of direct sources of AM reference DNA (eg toothbrushes) that were destroyed by the wave). By January 2008, there were still only $58.1 \%$ of AM cases which contained AM DNA profiles [15].

- Initial delays surrounding DNA capability at the TTVI due to poor sampling strategies, varying experience of laboratories to obtain DNA profiles from bone samples, lack of suitable DNA kinship matching software, an underestimation of the number of family samples required for identification due to the large scale of the operation, and data management and quality issues [1].

\subsection{Strategies introduced to facilitate the identification of children}

\subsubsection{Background}

The TTVI established policies for ethical operation on 7 January 2005. The first, 'every deceased person will be treated equitably to ensure there is no discrimination based upon age, race or ethnicity' [1, p59], was implemented to ensure all victims, including children, were analysed and reported under the one standard process. Despite their best efforts, identification teams struggled with the limitations inherent in trying to identify children, leading to a growing anxiety about the lack of progress identifying child victims. Concern that a large number of children may never become identified focused attention on the lack of sufficient AM 
and PM data. In an effort to overcome these obstacles, the TTVI implemented a 'Child Investigations' Team to, prioritise the identification of children. The identification teams initiated a number of procedures to increase the collection of accurate and usable AM data for children. For example, the Fingerprint Team requested finger paintings from schools of missing children. Similarly, the DNA Team devised a number of targeted strategies which are outlined below. These strategies were designed to increase the number of AM and PM profiles available for comparison, and provide targeted information for other identification methods to utilise which may then lead to identification.

\subsubsection{Using PM body length to prioritise DNA sample-testing from children}

Initially, testing post-mortem DNA samples from child-victims was not a priority over other bone samples. This was likely due to not having a mechanism in place to discriminate adult samples from those potentially belonging to children. Similarly, because post-mortem DNA samples were anonymous, DNA laboratories processing the samples were not aware of which ones may relate to a child, preventing their prioritization through analysis.

In mid-April 2005, the DNA Team developed a plan to prioritize DNA samples belonging to children. This decision was taken to expedite the return of DNA profiles belonging to children in order to create a separate group of child cases. This allowed the DNA Team to adjust the prior probability for the child subgroup from $1 / 3,000$ to $1 / 500$ in statistical calculations of kinship matches (500 was the approximate number of deceased children). Utilizing the PM forms in PlassData's ${ }^{T M}$ DVI System International, the DNA Team generated a list of cases defined by a body length of $148 \mathrm{~cm}$ or less. It was anticipated that nearly all of the missing children would be on this list, and therefore the DNA Team focused on the shipping and analysing of these specific bone samples. Within two weeks 181 bone samples believed to be from children were sent to DNA laboratories for prioritised testing. Analysis, matching and final reporting were further prioritised once the DNA Team at the TTVI received the profiles. By July 2015 over 
half of the prioritised samples had been profiled by the laboratories and their results returned to the TTVI.

\subsubsection{Alternative sources of reference DNA}

Attempts to identify children were repeatedly characterised by weak kinship matches unable to reach the reporting threshold nominated by the TTVI (i.e. 99.9\%). This was due, in part, to unavailable DNA reference samples from close relatives who also died in the tsunami. Direct sources of AM DNA (eg toothbrushes) were swept away by the tsunami. A similar lack of reference DNA was encountered for the Hurricane Katrina operation. Nearly $80 \%$ of Louisiana flooded, destroying personal items containing DNA, and there were a number of related victims which limited availability of kinship references [16].

For the TTVI operation it was not possible to identify many of the children without either additional AM DNA reference samples or a new strategy to leverage kinship matches. Conventional sources of additional AM DNA were not easily attainable (as discussed above), necessitating an alternate approach to identify children through DNA matching. Since many adults had been quickly and easily identified during the early months of the operation (by April 20051,060 adults were identified), and many of these adults were also known to be parents of missing children, the DNA Team devised a strategy in early August 2015 to better utilize identified PM samples. This strategy facilitated DNA identifications for children from a single family with multiple victims, and for children with numerous extended family members also killed by the tsunami.

Early policies prevented implementing this kind of strategy. For example, when a victim was identified by a method other than DNA, their post-mortem DNA sample was not sent for testing or further analysis was curtailed. This resulted in identified adults without DNA profiles available for kinship matching with other, unidentified, related remains. This policy was designed to save resources and prioritise DNA testing of samples from unidentified remains. 
However, the policy did not account for the extreme number of related victims as a result of this disaster. The case files from victims identified by modalities other than DNA were not screened for additional missing relatives. By ascertaining this information, a limited number of 'identified' PM DNA samples could have been sent for testing, availing their profile for kinship matching. Therefore, the DNA Team lacked information essential to identify children.

Similarly, it was difficult to confirm relatedness among victims given the absent AM data. The INTERPOL AM data collection forms had no specific fields to record relatedness among missing victims or family tree diagrams. The Family and/or Donor Reference Collection (FDRC) form used during the Hurricane Katrina DNA operation included a family tree diagram and information about other family members that died in the disaster. Donkervoort (2008) suggests this information could assist with data accuracy and streamlining identifications, however the FDRC had not been developed in time for use at the TTVI [16].

The DNA Team identified nearly 1,000 AM cases where no direct source of DNA was available, and no family tree existed. At the request of the DNA Team, a family tree was created for each victim and uploaded into PlassData's ${ }^{T M}$ DVI System International. A family tree detailed: family members who were also victims of the tsunami, the family member's identification status and PM number if identified, which living family members were under consideration as family references, and the unique AM number allocated to each tsunami victim within the family. Family tree information was continuously updated as new identifications were established. Post-mortem DNA profiles of identified victims were entered into the AM file (INTERPOL AM Form, E4 page) of their missing relatives. Bone samples from identified individuals with missing relatives were retrieved from the mortuary and submitted for DNA testing. The coordinated approach of developing family trees allowed identified victims with missing relatives, particularly their own children, to be used as DNA references for kinship matching. 


\subsubsection{Use of a near-threshold identification strategy}

In July 2005, another formalised strategy, similar to the one developed by the DNA Team focusing on "near-threshold" identifications, was implemented to target the most challenging identifications, including those involving children [8]. Initially, PM case files from children were re-examined for documentation of unique characteristics or physical evidence. Since there was a limited number of missing children, and their AM files could be further grouped into smaller groups by age, AM and PM files could easily be compared for similarities using physical evidence, property, and dental findings. However, AM data were severely limited and the team needed another approach to progress these cases. Building on the successful program targeting near-threshold identifications, a list of kinship matches falling below the reporting threshold of $99.9 \%$ was generated for children. These cases were passed to the Fingerprint Team for manual comparison of AM and PM prints. Manual comparison overcame the lack of fine ridge detail available in electronic records which had prevented automated matching. By December 2005 the strategy was credited with facilitating 24 identifications of children [8].

\subsubsection{PM sample kinship matching}

The family tree data revealed the extent of missing related victims. Typically, kinship matching software searches for matches using an AM-to-PM algorithm. In August 2005, the DNA Team developed a kinship-matching algorithm for unidentified PM DNA profiles. The PM-to-PM kinship matching algorithm aggregated post mortem samples possibly belonging to related family members. A direct PM-to-PM match approach was used during the World Trade Center Human Identification project, to aggregate unidentified fragments with the same DNA profile, even if that profile had not yet been associated with a particular victim. When the profile was eventually matched to a victim, the entire group of fragments was linked to the identification 
[17]. The PM-to-PM approach taken at the TTVI identified kinship relationships among unidentified remains, some reaching the reporting threshold of $99.9 \%$. Familial combinations included parent-child pairs, two parents and one child, and one parent and two children. This was clear evidence that there were groups of closely related, unidentified, victims - valuable information worthy of additional investigatory efforts. Using a list of suspected kinship associations, the DNA Team generated associated family trees for the unidentified related deceased victims. Investigators then compared a "family tree group" to AM records of family units, searching for similarities. Similarities between physical/property information and a postmortem record instigated a targeted request to the Fingerprint and Dental Teams. In many instances, at least one adult family member was identified through this process. The PM sample from the newly identified adult could then be used to identify related children (as per 3.3.3). Once one individual from a family tree unit was identified, the other related deceased were putatively identified, followed by additional targeted comparisons that progressively enabled identification using DNA kinship analysis.

\subsection{Outcomes of targeted child identification strategies}

This section compares the rate of child identifications as the post-mortem interval increased (150, 200, 250 and 300 days into the operation). The targeted strategies were examined to determine if they had contributed to changes in the rate of child identifications.

The DNA Team introduced a number of targeted strategies increase the number and quality of $A M$ and PM DNA profiles available for comparison and facilitate identification of children beginning mid-April 2005, approximately 100 days after the TTVI operation commenced. By the end of May 2005, there were still only 310 AM DNA profiles and 180 PM DNA profiles available for comparison (all ages). This number rapidly increased by the end of June to 1,269 AM DNA profiles and 1,310 PM DNA profiles. The increased number of DNA profiles during this period was due to the targeted sampling and analysis of child cases and resolution of issues involving processing of PM DNA samples (additional laboratories were contributing to the effort and the success rate of laboratories were increasing with experience and submission 
of better samples). The data in Figure 5 demonstrate an increase in the percentage of childto-adult identifications from 100 days, until the identification percentages almost equalised (the total data is until 12 December 2005).

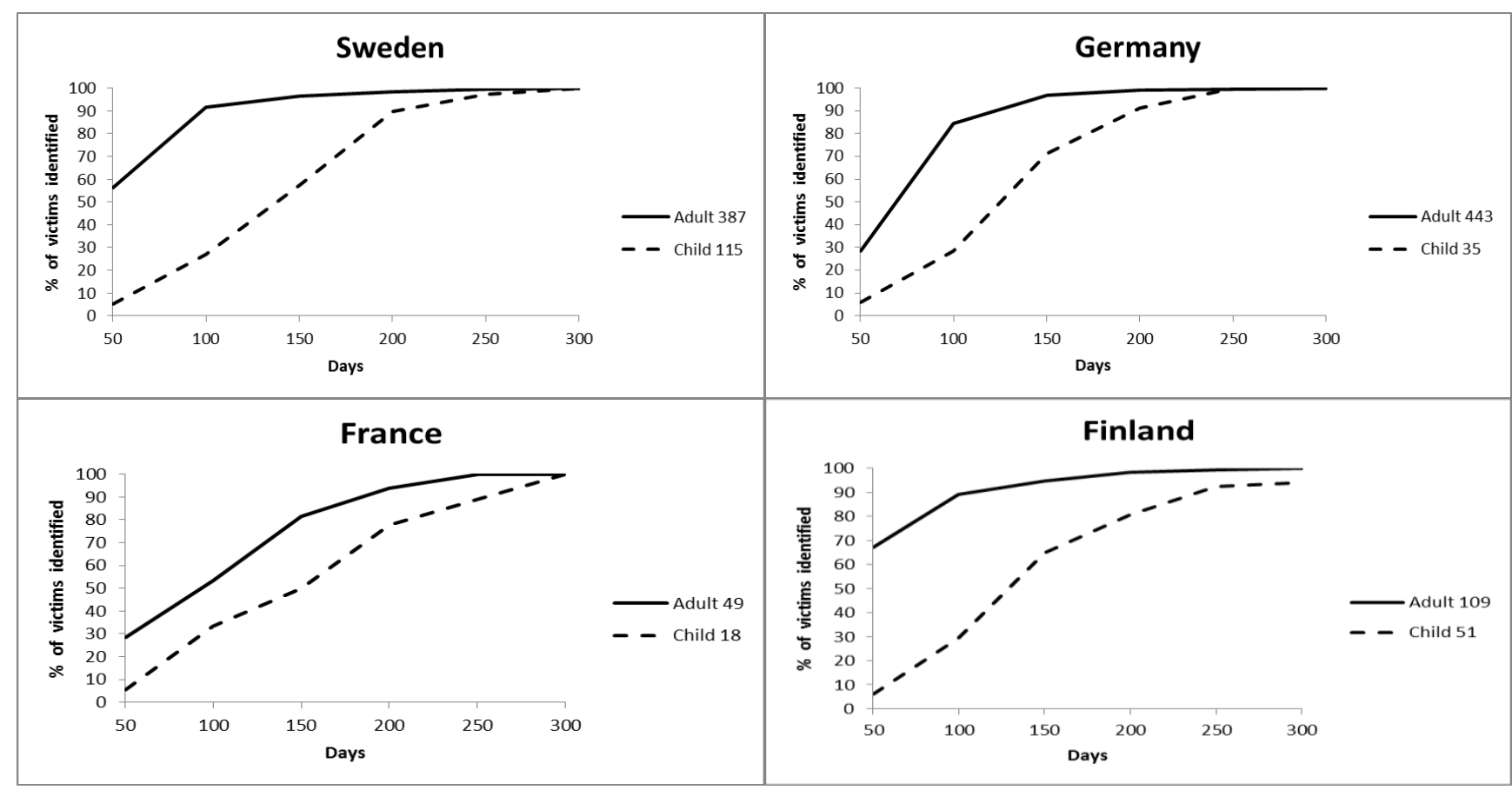

Figure 5: Examples by country showing marked increases in child identifications following implementation of targeted child identification strategies at approximately 100 days into the operation, and near concordance between adult and child identification rates by day 300 . The 'Adult' and 'Child' totals are the number of identifications established by 12 December 2005.

Figure 6 illustrates the monthly percentage of DNA-based adult and child identifications against the percentage of child and adult identifications using all methods. The graph illustrates an increase in the percentage of child identifications using DNA compared to the percentage of adult identifications using DNA following implementation of strategies targeting unidentified children (mid-April 2005). This indicates that the targeted child strategies were in part responsible for the increase in child identifications. Despite the lack of DNA profiles in May 2005 (310 AM and 180 PM all ages), there was a rapid increase in children identified by DNA, which was sustained throughout the year and improved as more DNA profiles were available for comparison and DNA kinship matching software was implemented. Prior to this, children identified by DNA were limited. For example, none of the child identifications in 
January or February $2005(n=10)$, were established through DNA. During March and April 2005 , only $2.9 \%$ and $2.6 \%$ of all identified children were established using DNA. However, this number increased to $15.1 \%$ in May (8/53 children), $45.2 \%$ in June (14/31 children), $84.8 \%$ in July (50/59 children), $88.7 \%$ in August (37/42 children), $82.4 \%$ in September $(15 / 18$ children), $95.7 \%$ in October (45/47 children), $96.1 \%$ in November (49/51 children) and 100\% in December (14 children).

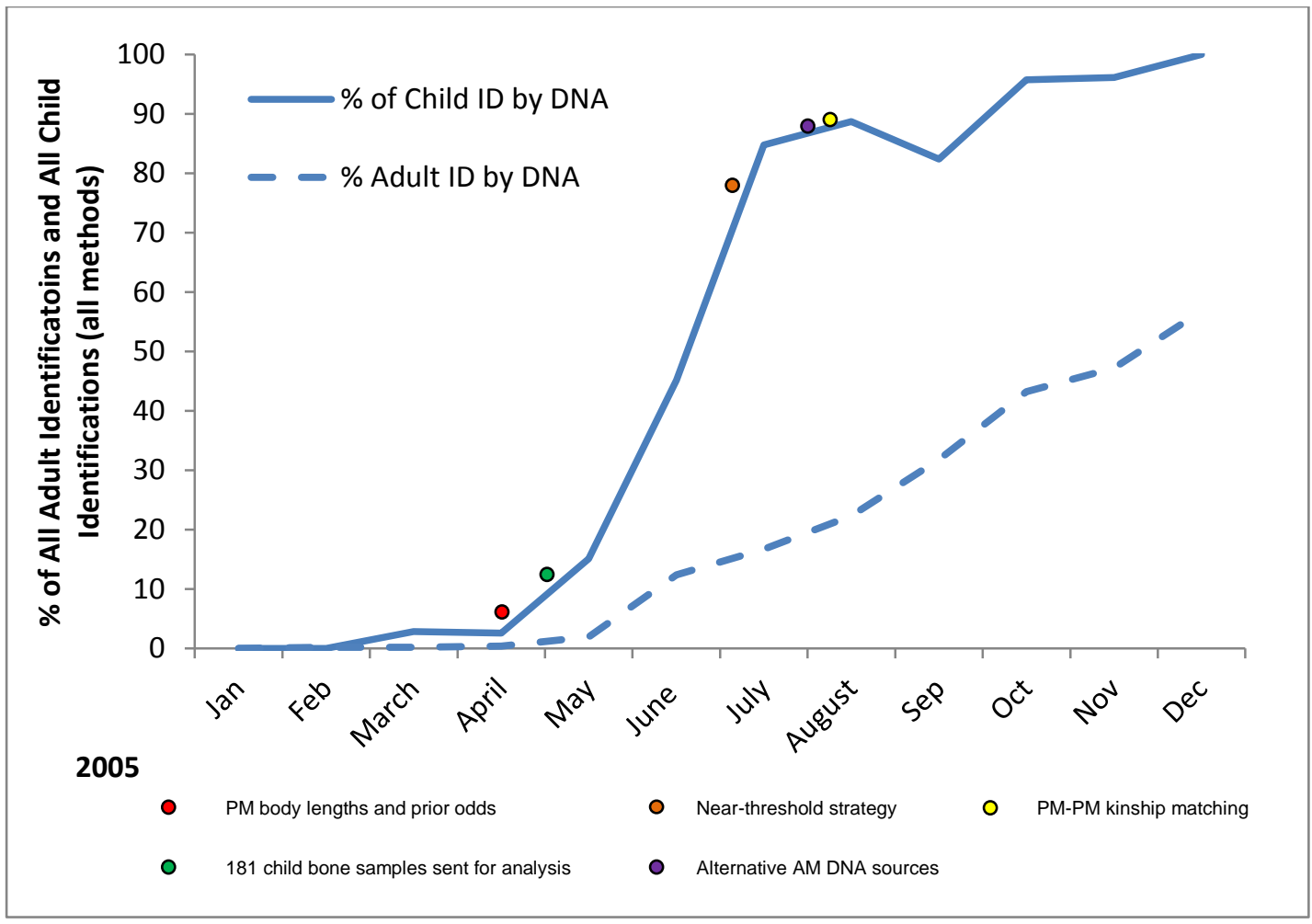

Figure 6: Percentage of child and adult identifications established using DNA from percentage of total child and adult identifications throughout the first year of the TTVI operation (all nationalities and all methods). Targeted DNA strategies were introduced from mid-April 2005.

It is difficult to assess which child strategies had the most impact. Figure 6 strongly indicates that the prioritisation of sampling and DNA analysis of child PM cases targeted by using PM body length had an immediate impact on child identifications. As previously discussed, other methods could not identify many child cases; therefore these results suggest that expediting PM DNA analysis for children will increase success. It can be assumed that child cases with sufficient AM DNA references benefited from the return of PM DNA profiles. A total of 22 (out 
of 84) children were identified in May and June. In July and August the strategies that were implemented focused on increasing the quantity of child AM DNA references, and strategies to resolve complex cases without sufficient AM DNA references. From July to December 2015, 210 children were identified using DNA methods (out of 231 children identified using all methods). The large numbers of child identifications during this period could be attributed to the combination of all targeted child strategies: return of remaining PM DNA profiles, increased child AM DNA profiles, and strategies to resolve complex cases (near-threshold and PM-PM kinship matching).

Whether the same number of child identifications would have been achieved without the strategies is difficult to prove. Certainly the faster return of child PM DNA profiles increased the speed of child identifications. First-hand experience of the author working on the child cases at the TTVI, and anecdotal evidence from other scientists and investigators working in the DNA Team and Reconciliation Team, suggests that the targeted strategies were crucial. The percentage of adult identifications shown in Figure 6 could also be used as a rough indication of what the percentage of child identifications with DNA may have looked like without the targeted strategies.

Figure 7 further illustrates the success of the targeted DNA strategies compared with other methods. The data demonstrate a distinct change in identification methods for children before and after implementing a child-focused identification approach. By July 2005, through to December 2005, DNA was the predominant method used to identify children. In total, 214 children were identified by DNA, 152 by fingerprints, 73 by dental, and 3 by physical characteristics. Chaikunrat et al (2011) analysed TTVI data until 9 January 2008 and reported that DNA identified 346 victims (0 to 19 years of age), or $53.1 \%$ of 652 victims in that age group [15]. 


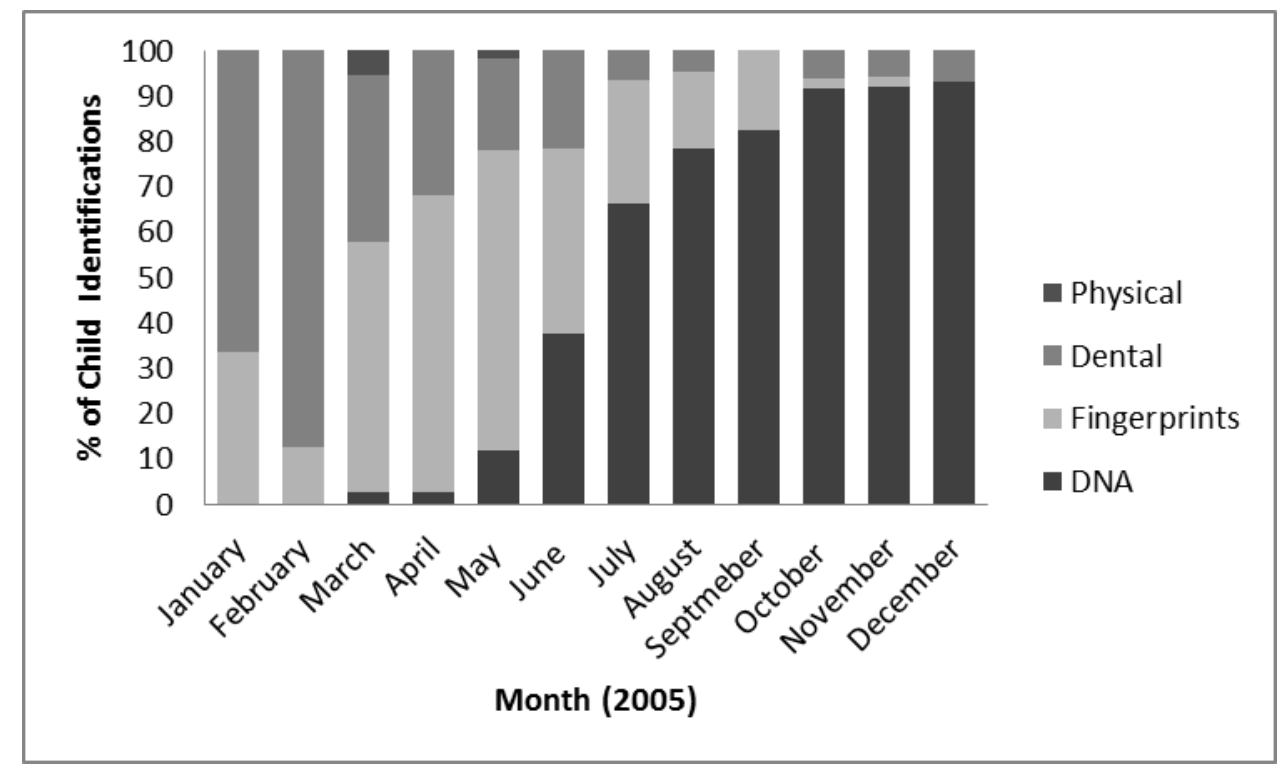

Figure 7: The percentage of total child identifications established each month by each method (all nationalities).

\subsection{Recommendations to facilitate the identification of children in mass disasters}

Based on experience at the TTVI following the South-East Asia Tsunami, early implementation of procedures directly focused on identifying children is beneficial when a significant number of child victims are involved. The following proposed recommendations are designed to guide future DVI managers challenged by large numbers of unidentified children.

\section{$\underline{\text { Recommendation } 1}$}

Recognising that children may be more difficult to identify than adults, policies and procedures addressing the differences should be implemented to facilitate equal identification opportunities.

\section{$\underline{\text { Recommendation } 2}$}

A prioritised list of children based on autopsy data such as body length, and dental age estimation should be generated. If possible, a dedicated mortuary line to triage children's remains should be established thereby expediting the collection and testing of their PM DNA samples. 


\section{$\underline{\text { Recommendation } 3}$}

DNA laboratories should be provided with a list of prioritised PM samples from children, to facilitate rapid analysis and matching.

\section{$\underline{\text { Recommendation } 4}$}

Direct sources of ante-mortem DNA, such as newborn screening cards, to identify missing children should be targeted. This reduces the reliance on kinship reference samples when numerous family members are also victims.

\section{$\underline{\text { Recommendation } 5}$}

A field should be included on the INTERPOL AM DVI form that specifies whether other family members are missing from the same disaster (on page 9 of the AM form where the family tree information is recorded). When indicated, the AM numbers of the other missing family members should be recorded on the family tree diagram. The family tree diagram should be available electronically and in a format that can be updated as new information arises. For example, if a missing family member is identified, their PM number should be recorded on the family tree diagram (see Recommendation 6).

\section{$\underline{\text { Recommendation } 6}$}

Prior to releasing identified bodies, it should be ensured that a post-mortem DNA sample was collected. When multiple family members are also victims, PM DNA samples from identified individuals will be integral as family reference samples to identify their relatives, particularly children. PM DNA samples from identified victims should be included as an option in the 'Guide to AM reference samples' under the 'biological relatives' category in the INTERPOL DVI Guide [p75, 10].

\section{$\underline{\text { Recommendation } 7}$}


A near-threshold strategy should be established specifically for children, to conclusively exclude identification or facilitate identifications supported by a combination of methods.

\section{$\underline{\text { Recommendation } 8}$}

DNA matching software capable of PM-to-PM matching should be utilised and resulting kinship matches compared to AM family tree information for targeted identifications. This process will aid DVI operations characterized by large numbers of related victims, particularly where children are involved.

\subsection{Conclusion}

The DVI operation in Phuket, Thailand following the South East Asia Tsunami highlights the challenges associated with large numbers of deceased children, particularly when related family members are also missing. Initially, children proved more difficult to identify than adults because the methods used to identify adults were not as successful in identifying children. In response, new procedures including using PM body length to prioritise DNA testing of children, using PM DNA samples from parents of missing children as references for kinship matching, targeted use of kinship matches falling just below reporting thresholds, and PM-to-PM kinship matching were introduced to overcome these obstacles. In combination, these strategies increased the number and rate of identifications for child victims of the tsunami. DVI preparedness can be significantly improved through the awareness of the different identification challenges for adults and children. Understanding these challenges and incorporating this knowledge by management is crucial when developing AM and PM collection strategies, operational policies, communication policies for families and the media, and allocating resources. 


\section{References}

[1] INTERPOL Tsunami Evaluation Working Group, 18 June 2014 http://www.interpol.int/Media/Files/INTERPOL-Expertise/DVI/INTERPOL-TsunamiEvaluation-Working-Group

[2] T. Lay, H. Kanamori, C. Ammon, M. Nettles, S. Ward, R. Aster, C.R, S. Beck, S. Bilek, M. Brudzinski, R. M, R. Butler, H. DeShon, G. Ekstrom, K, Satake, S. Sipkin, The great Sumatra-Andaman earthquake of 26 December 2004, Science 308 (2005) 1127-1133.

[3] E. De Valck, Major incident response: Collecting ante-mortem data, Forensic Science International, 159S (2006) S15-S19.

[4] E. Cohen, Death in Paradise: tourist fatalities in the tsunami disaster in Thailand, Current Issues in Tourism 12 (2009) 183-199.

[5] United States Centres for Disease Control and Prevention. Morbidity and Mortality Weekly Report. September 11, 2002 / 51 (Special Issue);16-18).

[6] Mourning in Bali, 20 June 2014 http://www.indo.com/bali121002 bekup/mourning4.html

[7] G. Vidoli, A. Mundorff, Victim fragmentation patterns and seat location supplements crash data: American Airlines Flight 587. Aviation, Space, and Environmental Medicine, 83(4) (2012) 412-417.

[8] K. Wright, A. Mundorff, J. Chaseling, A. Forrest, C. Maguire, D.I. Crane, A New Disaster Victim Identification Management Strategy Targeting "Near Identification-

Threshold" Cases: Experiences from the Boxing Day Tsunami. Forensic Science International 250 (2015) 91-97.

[9] O. Morgan, P. Sribanditmongkol, C. Perera, Y. Sulasmi, D. Alphen, E. Sondorp, Mass fatality management following the South Asian tsunami disaster: Case studies in Thailand, Indonesia, and Sri Lanka, Plos Medicine (2006) Open Access http://www.plosmedicine.org/article/info:doi/10.1371/journal.pmed.0030195

[10] INTERPOL DVI Guide 2014, 27 February 2015 http://www.interpol.int/es/INTERPOL-expertise/Forensics/DVI-Pages/DVI-guide

[11] T. Kondo, M. Ohtsuji,T. Ohshima, A new surgical method from the viewpoint of personal identification: a case of identification based on the presence of a metallic Z-stent. Forensic Sci Int 73(2) (1995) 101-107.

[12] T. Kahana, J. Hiss, Identification of human remains: forensic radiology. J Clinical For Med 4(1) (1997) 7-15.

[13] H. James, Thai Tsunami Victim Identification - Overview to Date, The Journal of Forensic Odonto-Stomatology 23 (2005) 1-18.

[14] P. Schuller-Gotzburg, J. Suchanek, Forensic odontologists successfully identify tsunami victims in Phuket, Thailand. Forensic Science International 171 (2007) 204-207. 
[15] J. Chaikunrat, P. Pongpanitanon, M. Petju, Victim identification in the tsunami disaster in Thailand, Journal of Health Science 20:6 (2011) 897-902.

[16] S. Donkervoort, S. Dolan, M. Beckwith, T. Northrup, A. Sozer, Enhancing accurate data collection in mass fatality kinship identifications: Lessons learned from Hurricane Katrina. Forensic Science International: Genetics 2 (2008) 354-362.

[17] R. Shaler, Who They Were: Inside the World Trade Center DNA Story: The Unprecedented Effort to Identify the Missing. 2005. Simon and Schuster Inc., New York.

JM. Conly, \& BL. Johnston, Natural disasters, corpses and the risk of infectious disease. Canadian Journal of Infectious Diseases and Medial Microbiology 16:5 (2005) 269-270. 


\section{An evaluation of the Thai Tsunami Victim Identification DNA operation}
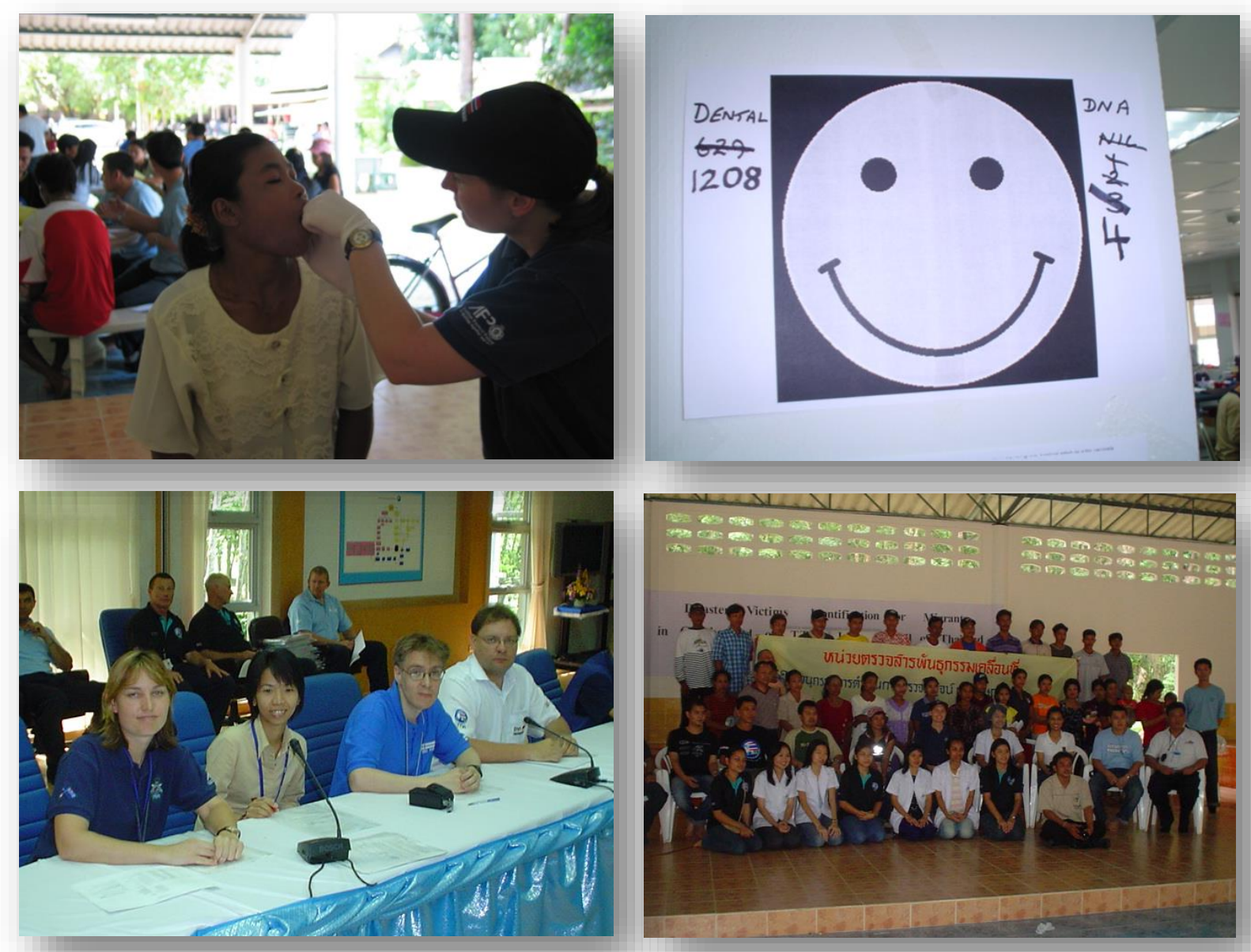

Images from Kirsty Wright 


\section{STATEMENT OF CONTRIBUTION TO CO-AUTHORED PUBLISHED PAPER}

The bibliographic details of the co-authored paper, including all authors, are:

Kirsty Wright ${ }^{a^{*}}$, Amy Mundorff ${ }^{b}$, Janet Chaseling ${ }^{c}$, Christopher Maguire ${ }^{d}$, Denis Crane ${ }^{a, e}$

a School of Natural Sciences, Griffith University, 170 Kessels Road, Nathan, Queensland, Australia 4111

${ }^{\mathrm{b}}$ Department of Anthropology, The University of Tennessee, 250 South Stadium Hall, Knoxville, TN 37996, USA

'School of Environment, Griffith University, 170 Kessels Road, Nathan, Queensland, Australia 4111

${ }^{d}$ District of Columbia Department of Forensic Science, Washington DC 20024, USA

eThe Eskitis Institute for Drug Discovery, Griffith University, 46 Don Young Road, Nathan, Queensland, Australia 4111

Keywords: South-East Asia Tsunami, Disaster Victim Identification (DVI), Forensic Biology, Mass fatalities, Thai Tsunami Victim Information (TTVI) operation 


\section{Statement of Joint Authorship}

\section{Kirsty Wright (Candidate):}

Responsible for managing the daily operation of the TTVI DNA Team, including identifying and resolving critical issues limiting DNA identification (with the assistance of TTVI DNA Team members) and reporting to the relevant groups in TTVI command. Assisted in the analysis and interpretation of DNA profiles, writing and reviewing scientific statements and provision of testimony at the TTVI Identification Board. Wrote operational and quality procedures for the TTVI DNA Team. Contributed to the experimental design and research plan. Analysed and interpreted the TTVI data, performed statistical calculations and wrote the manuscript.

(Signed) (Date)

Kirsty Wright (Corresponding author of paper)

\section{Amy Mundorff (Co-Supervisor and DVI Expert):}

Provided significant contribution to the manuscript in the form of editing and redrafting sections to be more streamlined and targeted for publication.

\section{Janet Chaseling (Co-Supervisor and Forensic Statistician):}

Provided statistical advice and reviewed calculations. Contributed to the experimental design and research plan and contributed to the manuscript in the form of review and editing.

\section{Christopher Maguire (Co-Supervisor and DVI Expert):}

Contributed to the manuscript in the form of review and editing.

\section{Denis Crane (Supervisor):}

Reviewed and provided advice on experimental design and research plan. Contributed to the manuscript significantly in the form of review and editing. (Date) 
An Evaluation of the Thai Tsunami Victim Identification DNA Operation 


\section{Abstract}

The Thai Tsunami Victim Identification (TTVI) operation was the largest disaster victim identification operation in history, involving 3,679 unidentified victims from 42 countries, and police and forensic scientists from over 30 countries. This paper evaluates the DNA response to the 26 December 2004 South-East Asia Tsunami, measuring its impact at different stages of the operation. Only 15 identifications were established through DNA analysis during the first 5 months of the operation, compared to 307 by fingerprints, 1,266 by dental and 11 by physical analysis. Critical obstacles, such as available ante-mortem (AM) and post-mortem (PM) DNA profiles, data management challenges and automated DNA matching issues were impeding the DNA response. Recognizing and resolving the key issues hindering DNA identification resulted in increased DNA identifications during the middle and late stages of the operation.

Consideration of victim demographics was also crucial to understanding the impact of different identification methods during the DVI operation. At the TTVI, DNA identifications were found to be primarily dependent on victim age and nationality, proving more successful in identifying children than adults, and for Thais than Europeans. A large proportion of children from all nations were identified by DNA matching (33\% of 10 to 16 year olds, $43 \%$ of 5 to 9 year olds, and $73 \%$ of 0 to 4 year olds), while only $13 \%$ of total adult identifications were supported though DNA analysis. Similarly, while DNA was necessary to identify only $2 \%$ of adults from Finland, France, Germany and Sweden combined, DNA was responsible for $30 \%$ of Thai adult identifications. By 16 July 2008, 3,308 victims were identified: 799 (24\%) by DNA, 1,337 (40\%) by dental, 1,142 (35\%) by fingerprint and $30(1 \%)$ by physical characteristics.

\section{Introduction}


After the devastating South-East Asia Tsunami of 26 December 2004, it was estimated that 8,195 people were either dead or missing in Thailand [1]. Of the 5,395 victims initially recovered, 2,280 were foreign tourists from 41 countries and approximately 3,000 were Thai nationals $[1,2,3]$. In response to this disaster the Thai Tsunami Victim Identification (TTVI) operation was formed on 12 January 2005, comprising police and scientific specialists from over thirty countries. To date, this is the largest disaster victim identification (DVI) operation in history. The TTVI was led by the Royal Thai Police and processes were established consistent with INTERPOL DVI Guidelines [4]. Mortuary operations ensued at four sites: Wat Yang Yao; Wat Bang Muang; Mai Kao; and Krabi, however the Krabi site was later consolidated at Mai Kao. Property Operations, Command and Administration, and the Information Management Centre (IMC) were located in Phuket [1, 2, 5].

The IMC was separated into an 'AM/PM Section' and a 'Reconciliation Section'. The DNA Team was initially part of the AM/PM Section, but later moved to the Reconciliation Section after the DNA sample collection phase concluded in the middle stages of the operation. The DNA Team was responsible for developing standard operating procedures and implementing processes to identify the victims. The DNA Team was also accountable for managing the incoming ante-mortem (AM) and post-mortem (PM) DNA profiles from outside laboratories, matching DNA profiles, and providing evidence and testimony to the Reconciliation Team and 'TTVI Identification Board'. In addition, DNA Team members operated within the Mai Kao Mortuary collecting PM samples to ship to several international DNA laboratories.

At the outset of the operation, high expectations were placed on the DNA Team by staff at the TTVI, nations desperate to repatriate their citizens, and the international media at large. Anticipation spread to the international community through TV and newspaper. Headlines such as 'DNA to identify tsunami dead' and 'DNA only way to identify most bodies', falsely 
raised expectations that the DNA process would be relatively quick and easy, while largely ignoring the potential of other identification methods $[6,7]$. Sentiments were further fuelled by previous DVI operations, such as the 11 September 2001 World Trade Center (WTC) attack and the 2002 Bali Bombings, which both relied heavily on DNA to establish identifications (91\% and $70 \%$, respectively) [8, 9]. The DNA response to these incidents was seen by some as a new benchmark and created the belief that DNA was the 'best' (fastest and most accurate) identification method for DVI. These expectations expressed only weeks after the tsunami, and before its true scale and complexity were understood, overlooked the reality of previous incidents. For example, two months into the WTC operation, DNA had established only 10 of the 193 identifications. A DNA-only approach could never realise such expectations, nor were the circumstances such that a DNA-only approach was realistic.

Some researchers have questioned whether the TTVI DNA operation failed, under-performed, or had little impact on the identification of tsunami victims $[10,11,12]$. However, to date, few empirical studies have evaluated the TTVI DNA response to the South-East Asia Tsunami [1, $13,14,15]$. Therefore, the following analysis was conducted to evaluate the outcome of the TTVI DNA operation. This study aimed to determine a) the effectiveness of DNA analysis at different stages of the operation, and b) identify where DNA analysis contributed to victim identification when other methods were unsuccessful.

\section{Methods}

Identification data were derived from the TTVI Reconciliation database from 12 January 2005 to 12 December 2005 ( $78 \%$ of victims had been identified). Analysed data include the victim's sex, age, and nationality, along with the date and method/s of identification. Multiple identification methods were recorded in 891 of 2,871 cases. TTVI policy dictated identification methods were entered into the database according to their significance in establishing each 
identification, with the most significant method listed first. For the cases identified by multiple methods, only the first method was considered in the following analyses. In addition, further analyses, using updated information (dated 16 July 2008), focus on identification method only (victim nationality, age and sex were not available). The 2008 information comprised data from the 3,308 $(90 \%)$ identified victims (371 were still unidentified). Identifications were made beyond this point, however the authors did not have access to this information. Given the data in this research comprised $90 \%$ of identifications, it was considered sufficient for analysis and from which to draw valid conclusions and recommendations.

This paper's designation of the TTVI operation stages ('early', 'middle', and 'late') are based on the volume of available AM and PM evidence, the complexity of cases, and the number of identified versus unidentified victims. Typically the early stage of a DVI operation is characterised by a large number of unidentified victims, and availability of varying quantities of $\mathrm{AM}$ and PM evidence for each method (dental records are received in large volumes, available fingerprint records are slightly fewer, and DNA profiles are few in number). A large quantity of 'simple' cases are established during this stage, usually by a single method (typically by dental methods, and to a lesser extent fingerprints). The middle stage usually involves the collation of a majority of $\mathrm{AM}$ and $\mathrm{PM}$ evidence for all methods, and a significant reduction in the initial number of unidentified victims (a third to one half are normally identified in the early stage). Cases become increasingly difficult to identify, an often rely upon multiple methods. Dental success declines rapidly and is replaced by fingerprint and DNA methods. The late stage involves a relatively small number of unidentified victims, however they are the most complex to identify, and often these cases are resolved by DNA. This stage is usually the longest, lasting months or even years for large disaster operations.

\section{Results and Discussion}

\subsection{DNA identifications compared to conventional identification methods}


Large DVI operations typically exhibit common identification rate patterns, with the more conventional methods such as fingerprint and dental matching coming online weeks or months before DNA. Ante-mortem fingerprints and dental records can be relatively easy to access in certain circumstances (e.g.; military records, government identification cards). With readily available data, AM and PM matching can begin as soon as bodies are processed through the mortuary. Conversely, managerial and technical issues must be addressed before DNA analysis can be utilized, which may be a lengthy process. From a managerial perspective, questions may include whether a jurisdiction has adequate in-house capacity or outside vendor laboratories must be contracted. Cost and available monetary resources are other considerations. Technically, appropriate PM DNA samples must be collected. This will be determined in part by the processing laboratory's capabilities (some can test blood and soft tissue but not bone or teeth), the experience of the mortuary staff to collect the best samples for DNA, and will also be determined by the post-mortem interval and condition of the remains [16]. Other technical and logistical concerns include access to temporary refrigeration or freezer storage for the samples, shipping regulations, and establishing a clear missing persons total in order to develop the requisite probability statistical thresholds.

Therefore, while DNA is seen to be slower than other methods of identification, the different methods actually complement each other well. Identification by DNA analysis becomes a more viable option around the same time conventional methods have been exhausted. Figure 1 illustrates this pattern for the TTVI operation. Only 15 DNA identifications had been established during the early stage of the operation, compared to 307 by fingerprints, and 1,266 by dental evidence. In this early stage, $95 \%$ of all dental identifications were achieved, while only $31 \%$ of all fingerprint identifications had been established, and DNA identifications were just beginning to reach double digits. Taking the three most dominant methods into consideration, dental analysis achieved large numbers of identifications quickly, in the early stage of the TTVI operation; fingerprints contributed a steady number of identifications 
throughout the early, middle and late stages of the operation; and DNA contributed most in the middle and late stages. These outcomes highlight the importance of recognising methodological trends across operational stages, and their impact on operational planning and resource allocation.

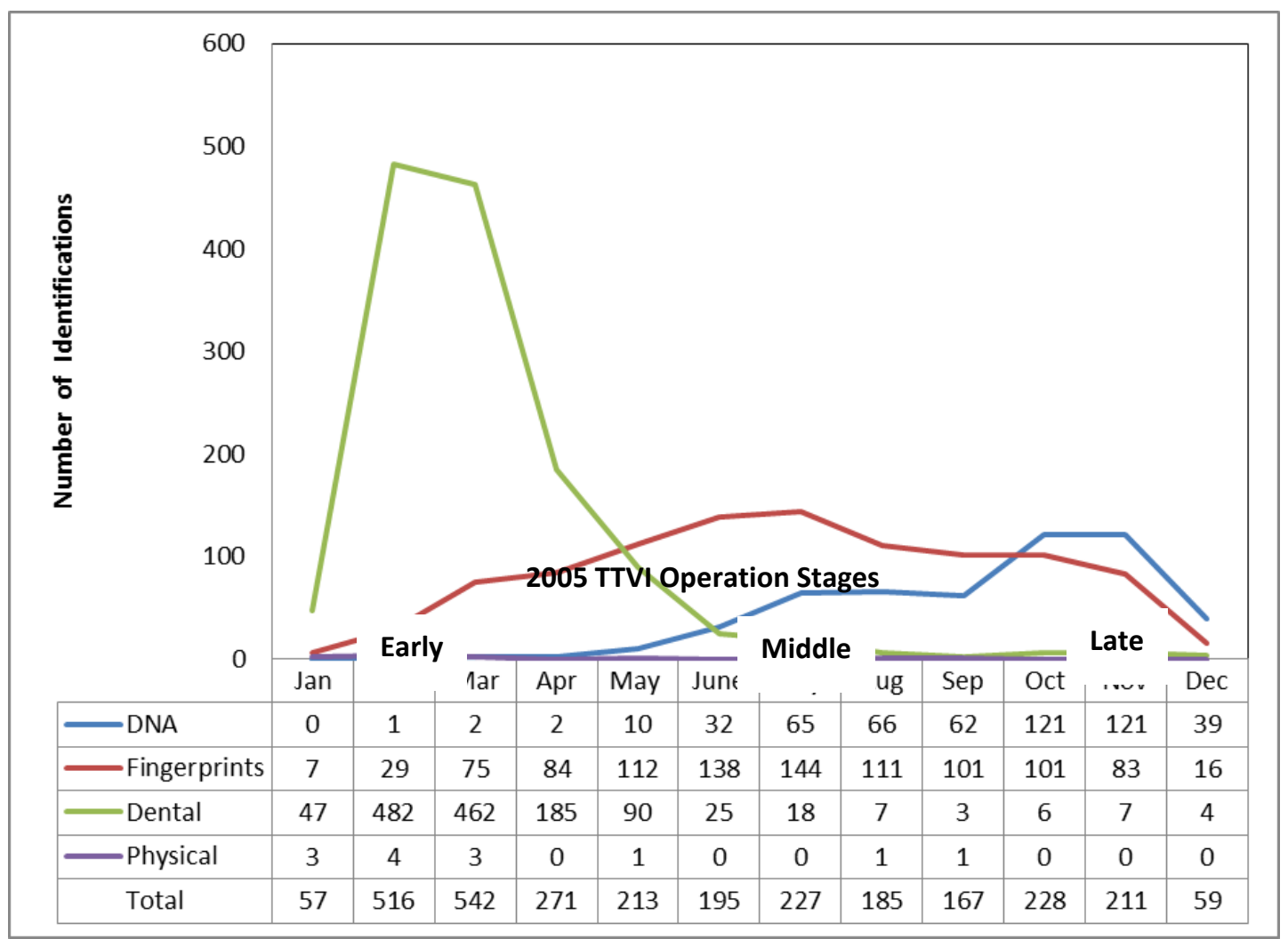

Figure 1: Identifications by month and by method during the early, middle and late operational stages.

Furthermore, the TTVI identification rates by method and month mirror those following the World Trade Center DVI operation. Conventional methods of identification dropped significantly around the $28^{\text {th }}$ week, concurrent with a sharp and sustained increase in DNA identifications [17]. The similarities between the two incidents indicate identification rates by methodology follow trends dictated by external circumstances and context. Identifying these patterns will allow future DVI managers to use this knowledge when coordinating AM and PM collections, establishing timelines, and managing expectations, both internal to the operation and to external parties including families, media and government agencies. 


\subsection{Critical elements necessary for DNA identifications}

In a DVI operation, three elements are critical to establishing identifications by DNA: AM DNA profiles (either direct or indirect), PM DNA profiles, and associated DNA matching software. The DNA Team was limited in their access to all three. By the end of May 2005, there were 2,358 AM cases and 4,325 PM cases (including duplicate records and body parts) logged into the system, yet the TTVI had only received 310 AM DNA profiles (13\%) and there were only 180 PM DNA profiles (4\%) available for comparison.

Numerous reasons have been cited for the lack of AM DNA profiles [18]. For example, the nature of the disaster limited available sources of direct DNA reference samples when the wave swept away personal items. It was common for two or more victims to be from the same family, and many instances where more than ten victims were from the same family. This significantly limited the availability of appropriate kinship references, which prevented numerous cases from reaching the nominated statistical threshold for a kinship match. Severely limited AM DNA material on such a large scale presented new challenges to forensic experts. To address these limitations, TTVI personnel responded by implementing strategies focusing on the lack of conventional AM DNA sources $[18,19]$. Other solutions included DNA profiles directly submitted by individual countries after obtaining and testing blood cards from newborn screening tests [20]. By the end of June 2005, the TTVI had access to 1,269 AM DNA profiles, 1,310 PM partial and complete DNA profiles.

Although bodies were processed through the mortuaries quickly and steadily, PM DNA profiles were slow to return. In part, this was due to administrative issues discussed above. In addition, the earliest PM tissue samples were collected from victim remains prior the TTVI's inception. Too often theses samples were of poor quality, due to tissue degradation. Furthermore, the immediate decision to sample teeth proved difficult for laboratories with limited experience 
testing such samples. To address these issues, 1,723 bodies at the Mai Kao mortuary were re-examined. Re-examination also included re-sampling of sections of mid-shaft femur for DNA analysis. Along with additional DNA sampling, the re-examination process, named the 'Final Inventory Protocol', was designed to identify and correct errors in the PM database and detect deficiencies in PM evidence [2, 14]. The Final Inventory Protocol was completed in May 2005 and PM DNA profiles began to increase in numbers the following month, attesting to the program's successful implementation.

In the early stages of the operation, complication's managing vast quantities of data, limited mass DNA profile comparisons. In particular, the TTVI needed an improved data management system to allow automated kinship matching with DNA software. Eventually, appropriate systems were in place and from July 2005, the DNA Team was producing larger numbers of identifications (See Figure 1).

By 12 December 2005, DNA enabled 521 of the 2,871 identifications (18.1\%), dental 1,336 (46.5\%), fingerprints 1,001 (34.9\%) and physical 13 (0.5\%), with 808 bodies still unidentified. Figure 2 illustrates the differences in identification method success rates for victim age categories. Dental comparison was most successful for identifying adult victims, $(2,429$ individuals, 52\%). Children were more successfully identified by DNA, which was responsible for $33 \%$ of 10 to 16 year olds, $43 \%$ of 5 to 9 year olds and $73 \%$ of children 0 to 4 years (see additional analysis by age in section 3.3).

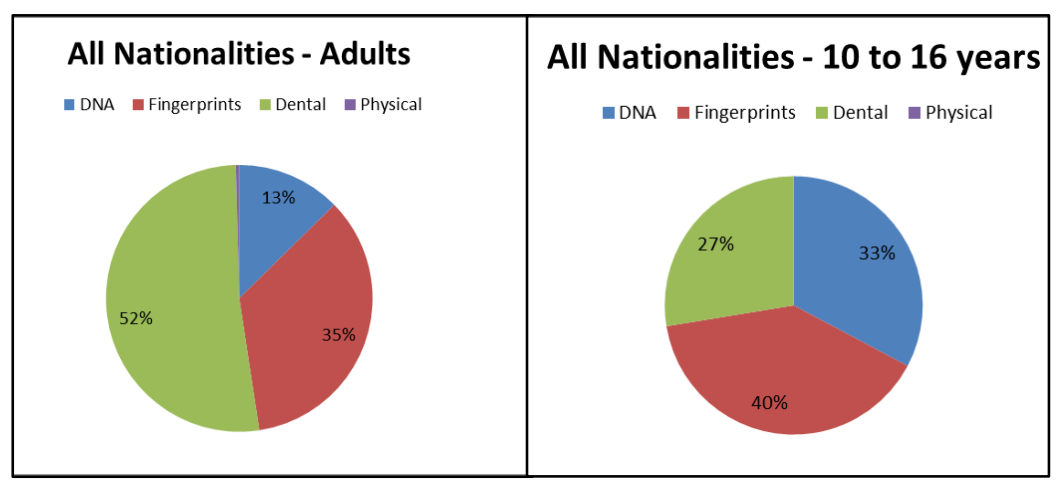




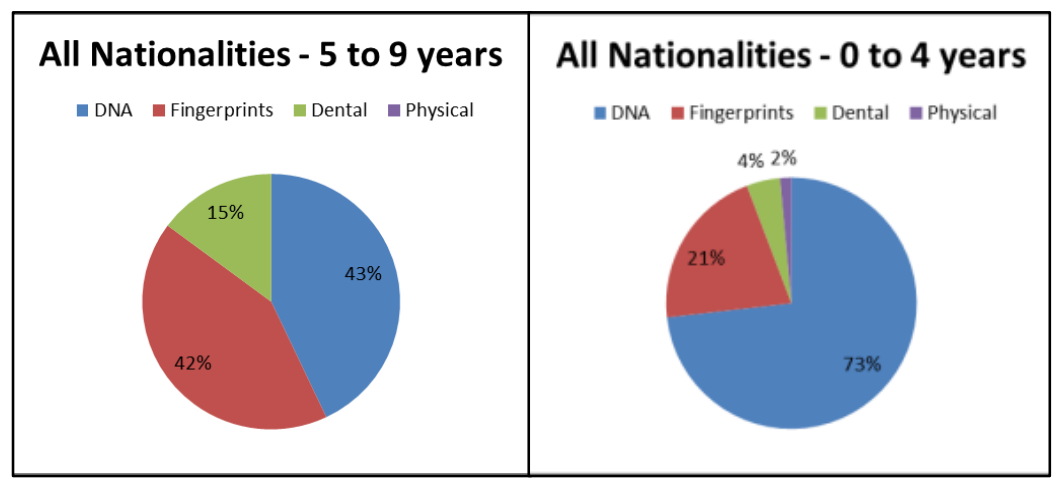

Figure 2: Identification by method and age category (data until 12 December 2005).

As seen with previous large-scale DVI operations, DNA eventually replaced conventional identification methods in the late stage of the operation. By October 2005, identifications by other methods were exhausted and DNA was relied on for the project's duration. Analysis of the TTVI Reconciliation data revealed that during the operation's later stages, between 12 December 2005 and 16 July 2008, 278 of the 487 (57\%) identifications were established by DNA comparison.

\subsection{DNA identifications by nationality and age}

The unique demographics of the tsunami victims in Thailand influenced the success rates of different identification methods and challenged management operations at the TTVI. Three circumstantial factors effected victim demography: the scale of the incident, the locations where the waves caused the most destruction, and the event's timing. More specifically, the disaster struck the beaches of popular tourist resorts, crowded with families from all over the world vacationing during the holiday season. While multi-story hotels are also present in the area, many resorts house tourists in small low-set bungalows, which were obliterated by the destruction. In addition, the killer waves began coming ashore shortly after 0930, when families were already gathering on the beaches. Together, these dynamics created the unique victim demographics in Thailand; a large number of related victims, of varying ages, both local 
and multi-national, and from disparate socio-economic backgrounds. These factors significantly affected all aspects of the TTVI DVI operation, but in particular, the role DNA played as an identification method for different nationalities and age groups.

Data from nationalities with more than ten deceased children were analysed to determine what methods were used most for each nationality and age group (refer to Table 1). Finland, France, Sweden and Germany had similar results when comparing the distribution of identification methods, therefore the data were combined into adult and child identifications. Dental was the most prevalent method used to identify adults (90\% of 988 identifications) within this group. Fingerprints and DNA analysis contributed to a small minority of the group's identifications, $8 \%$ and $2 \%$, respectively. Norwegian adults followed a similar pattern: dental $98 \%$ (53 out of 54 ), fingerprints $2 \%$ ( 1 out of 54 ), and DNA analysis $0 \%$ (Figure 3 ). Deviating from this trend were Thai victim identifications. While only $2 \%$ of Thai adults were identified by dental comparison (15 out of 886$)$, the vast majority were identified by fingerprints (68\%, 603 out of 886$)$, followed by DNA analysis (30\%, 266 out of 886$)$.

Table 1: Number of adults and children identified at 12 December 2005.

\begin{tabular}{l|llllll}
\hline Country & Finland & France & Germany & Norway & Sweden & Thailand \\
\hline Adults & 109 & 49 & 443 & 55 & 387 & 893 \\
Children & 51 & 18 & 35 & 22 & 115 & 155 \\
\hline
\end{tabular}

\begin{tabular}{|l|l|}
\hline Norway Adult & Thailand Adult \\
\hline & \\
\hline $98 \%$ & \\
\hline
\end{tabular}




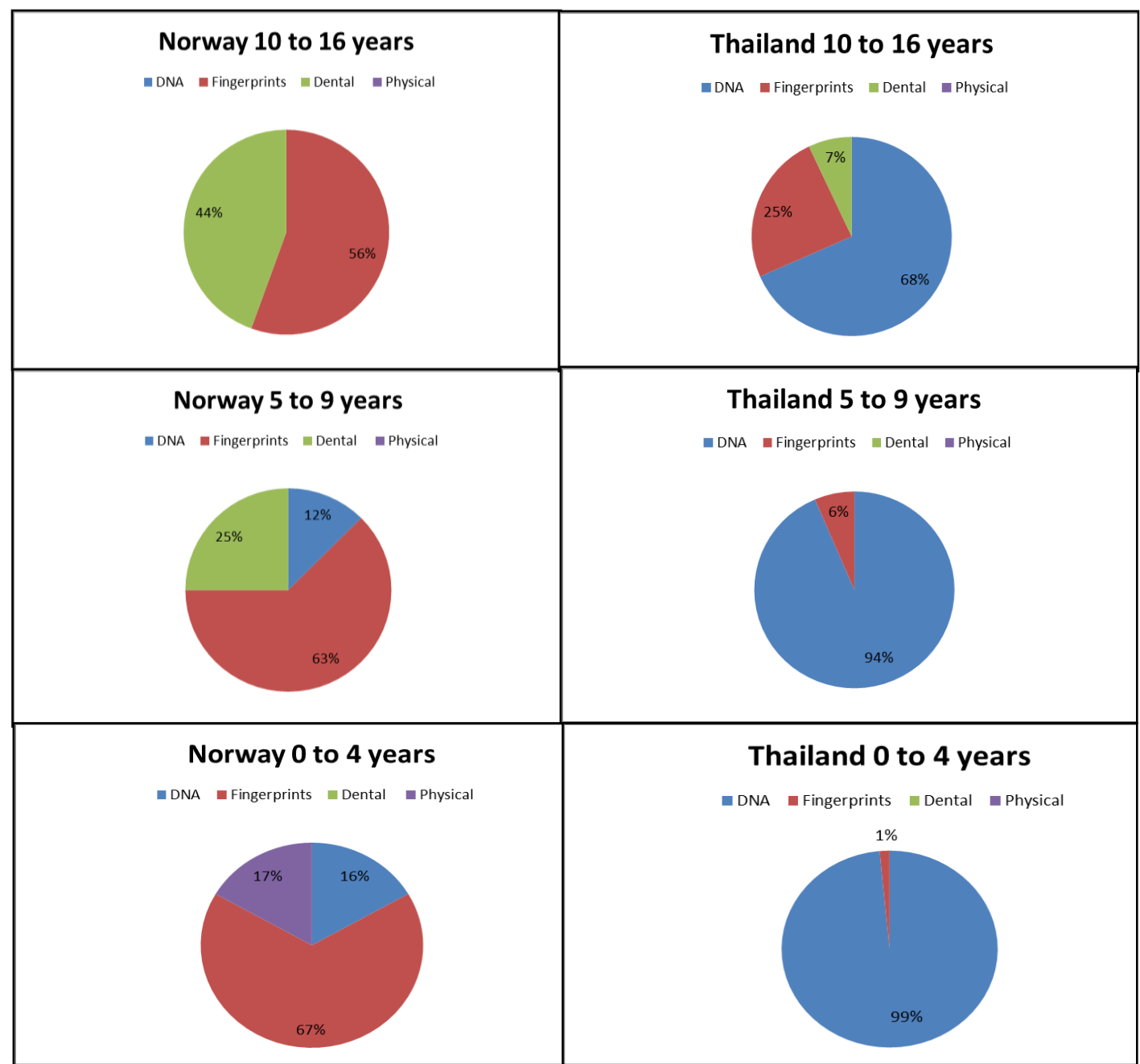

Figure 3: Methods used to identify victims from Norway and Thailand in four age categories.

Reliance on different identification methods varied dramatically between children's age ranges. When examining the Finish, French, Swedish and German child identifications, dental methods were most useful for identifying children $10-16$ year olds (35\% or 32 out of 92$)$. In addition, dental identification rates decreased as the age of the victim decreased, evidenced by a drop to $19 \%$ for $5-9$ year olds ( 14 out of 75 ), and $10 \%$ for children $0-4$ years (5 out of 52 ). In contrast, fingerprints were most useful for children 5 to 9 years (53\%, 40 out of 75$)$, and DNA was most successful for children 0 to 4 years $(52 \%, 27$ out of 52$)$. 
Once again, a deviation from the dominant trend is seen among Thai victims when compared to other nationalities. DNA proved significantly more successful identifying Thai children (39 out of 57 for $10-16$ years, 29 out of 31 for $5-9$ years, and 66 out of 67 for $0-4$ years), although, as seen previously, its success decreased as the victim's age increased. Identifications of Norwegian children presented another departure from previous patterns. Instead of dental or DNA, fingerprint matching was the most successful method of identification for Norwegian children and was responsible for identifying 5 out of 9 victims aged 10-16 year, 5 out of 8 victims aged 5-9 years, and 4 out of 5 victims aged 0-4 years.

The varying reliance on different identification methods, based on victim demographics (specifically, age and nationality), is an outcome resulting from the type, quality, and completeness of available AM material, and each nationality's number of victims and how quickly their AM evidence was made available to the TTVI. For example, although the tsunami's waves decimated tourist's personal effects on their possession, as well as those left in destroyed low-lying bungalows, law enforcement agencies in their home countries still had opportunity to collect AM evidence at their homes, schools and work places, which were unaffected. In stark contrast, AM evidence was difficult to avail from local Thai victims whose homes were also destroyed. The success of the dental method for non-Thai adult victims can largely be explained by the rapid availability of AM dental records (it was reported that $94.4 \%$ of missing Europeans had AM dental charts and $75.5 \%$ had AM dental X-rays), and availability of PM dental records (only $2.6 \%$ of PM cases did not provide dental evidence) [21]. Comparatively, identification of Thai victims relied heavily on DNA, due to the paucity of available AM dental records (only $18.1 \%$ of missing Thais had AM dental charts and $0.8 \%$ had AM dental X-rays) [21]. The success of fingerprint identifications for Norwegian children compared to those for other European children accords with superior AM fingerprint collection by Norwegian Police; in contrast, obtaining AM fingerprints for children was flagged as a difficulty by all other nationalities [1]. The Norwegian fingerprint success rate is particularly 
evident in the 0 to 4 year age category: 67\%, compared to $36 \%$ Finland, France, Sweden, and Germany combined. Norwegian AM fingerprint collection methods should be investigated further to improve international procedures and increase identification potential for children.

Rates of child identifications by DNA were further analysed. A significant relationship was found between DNA identification and decreasing victim age $(p<0.0001)$ (Figure 4). DNA identifications increased 3.9\% for each yearly age group from birth to age 16 (95\% confidence interval $2.9 \%$ to $4.9 \%)$. The specific challenges associated with the identification of children, and the strategies implemented by the TTVI DNA Team to target child identifications, have been previously reported [19].

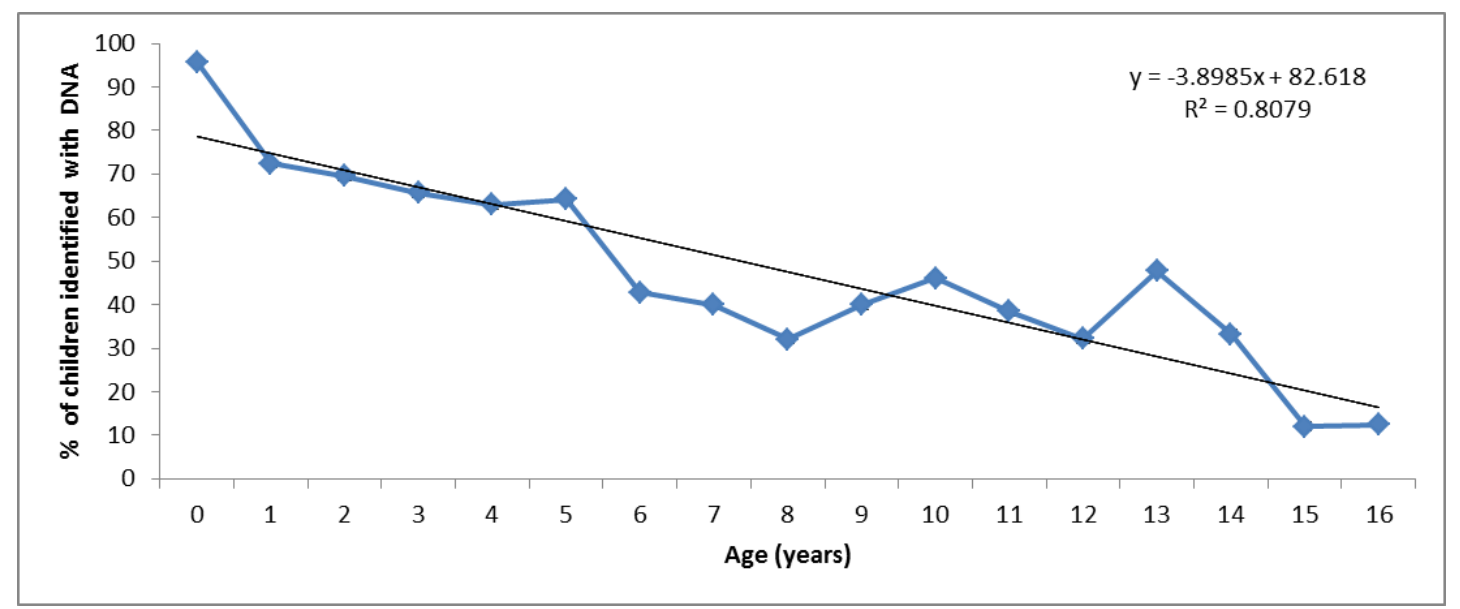

Figure 4: Percentage of victims identified with DNA between 0 to 16 years old across all nationalities.

Overall, the data show that DNA analysis was the most useful method of identification for children (48\%, 213 out of 440 combined nationalities) and Thai adults (30\%, 266 out of 886$)$. DNA was the least used identification method for non-Thai adults $(13 \%, 307$ out of 2,429$)$. The data also demonstrate that the effects of victim age and nationality on method success can be masked if not evaluated separately. This may lead to incorrect conclusions about the effectiveness (or presumed ineffectiveness) of any specific method. Additionally, there may be managerial consequences to misinterpreting data patterns, such as missing an opportunity 
to prioritize one method over another during different stages of an investigation. This in turn affects AM data collection practices, resource requirements and allocation.

\subsection{Previous evaluations of the TTVI DNA operation}

The outcomes of the TTVI DNA operation have not always been clearly reported in the past. There are papers which only reported the TTVI outcomes in the early stage of the operation when DNA was experiencing limited success $[22,23]$. Failure to provide an explanation of the impediments causing this, or to provide an updated report in the later stage of the operation, unquestionably leads to the incorrect impression that the TTVI DNA operation was not successful, and/or that the identification potential of DNA analysis in mass fatalities is limited. More concerning are those papers that have made statements such as DNA 'proved to be a relatively unimportant method of identification' for Thai tsunami victims at the TTVI $[10,12]$. Such comments have been cited unchallenged in literature as recently as 2014 (a literature review of dental identification in mass fatalities) [24].

In 2011 Chaikunrat et al evaluated victim identification in the Thai Tsunami and reported that of the 5,009 identifications (including 1,618 identified before the TTVI), the most used method of identification was physical (32.3\%) and the least used was DNA (16.0\%) [13]. In this paper the authors commented that 'DNA identification should not be considered as a first-line method of identification, but rather should only be implemented when physical, fingerprint, and dental methods have been unsuccessful' [13, p901). Similar recommendations have been made by Rai, Hirsch and Morgan [10,11, 12]. While physical or 'visual' identification was used to identify 1,618 bodies before the TTVI operation; it was not an accurate method and led to misidentifications. Delaying the use of DNA in a disaster until all other methods are exhausted would lead to long delays in identification of victims from certain demographics (for example children and adults with limited access to dental care), creating unnecessary identification bias 
against some population groups. Given DNA analysis is an expensive and time consuming identification method to implement in a disaster, a specific rather than general use is needed. A better approach is to evaluate victim demography and target DNA at the beginning of an operation for those groups where dental and fingerprint methods are historically least successful. Triaging these victims at the mortuary (for example using body lengths to help identify children) will enable their DNA samples to be sent for analysis in the first days and weeks of a disaster, enabling DNA to be more effective in the early stage of the operation.

The true value of the TTVI DNA operation was also under-reported due to a policy that was implemented (with some exceptions) at the end of April 2005 which required all DNA reports reaching the nominated reporting threshold to be accompanied by an AM-PM physical and property report. This was one of many quality controls that were introduced because of the large volume of DNA data being sent to the TTVI from 42 laboratories (producing AM and PM DNA profiles) and the concern of data transfer errors causing mis-identification. As a result of the above TTVI policy, no mis-identifications resulted from DNA evidence. By 16 July 2008, 35 identifications were reported using only DNA as evidence (764 identifications were reported using DNA and physical evidence). No published reports or literature have disclosed this as the reason why only 35 of 3,308 cases were established with DNA evidence alone. Without this explanation, it could appear that DNA success was limited. Further confusing the impact of the DNA method, in 2006 Perrier reported that for 3,000 identifications reported at the TTVI, dental contributed to $73 \%$, fingerprints $24 \%$ and DNA $3 \%$ [25]. This analysis of TTVI victim identification methods is significantly at odds with TTVI data and once again, the underreporting of DNA utilisation may have led to confusion and speculation of its failure within the operation.

\section{Conclusions}


The primary aim of this research was to evaluate the effectiveness of the TTVI DNA response at each stage of the operation, and to determine where DNA methods had greatest impact. Availability of AM and PM DNA profiles and suitable data management and DNA software systems were limited until July 2005. These issues were created by a complex combination of factors that included the scale and nature of the disaster, victim demography, initial TTVI management policies, and logistics.

Importantly, the lack of DNA success in the first 6 months was also due to a lack of preparedness. However, no laboratory could have anticipated or prepared for the large volume of PM sample analysis suddenly required by the TTVI (3,241 PM samples had been sent to several laboratories by June 2005). In addition, many forensic laboratories have limited experience with bone and tooth samples, so the initial months of the TTVI operation also involved a large component of capability development. One important lesson from this exercise for future disasters is the need for individual nations to evaluate and quantify their surge capacity to process large volumes of DNA samples from human remains. Capability development across a number of laboratories, with additional options for outsourcing to international laboratories specialising in PM case work is recommended. A similar recommendation was provided by the INTERPOL Tsunami Evaluation Working Group who stated: 'It is recommended that INTERPOL makes an inventory of accredited laboratories prepared and skilled to perform DNA analysis of post mortem samples and deliver results according to the requirements stated [p136, Recommendation 68, 1]. Given large disasters may often result in a multi-jurisdictional or multi-national response, it is essential to have established standard formats for DNA profile transfer and appropriate automated systems for data management and profile comparison (direct and kinship). The use of disparate databases, manual data configuration, and transcription should be avoided. 
The identification of Thai adults and children from all nations proved challenging for all identification methods, and was flagged as a priority by the TTVI. This research shows that DNA analysis was critical for their identification, and without its use many of those victims would have remained unidentified. When evaluating the contribution of the DNA method across the entire operation, it can be concluded that this method had a significant impact and met operational expectations.

Understanding victim demography, the impediments and requirements for each identification method and how they affect method impact at each stage of a DVI operation is critical for planning and resourcing mass disasters. Accurate evaluations of previous disasters, which include the elements above, are an important source of information for the forensic community and provide an opportunity for continuous improvement. This paper provides a reliable analysis of the TTVI DNA operation which identified $30 \%$ of Thai adults, $33 \%$ of 10 to 16 year olds, $43 \%$ of 5 to 9 year olds and $73 \% 0$ to 4 year olds (all nationalities) by December 2005, and by July 2008 was responsible for the identification of $24 \%$ of all victims. 


\section{References}

[1] INTERPOL Tsunami Evaluation Working Group, 18 November 2014 http://www.interpol.int/Media/Files/INTERPOL-Expertise/DVI/INTERPOL-Tsunami-

Evaluation-Working-Group.

[2] H. James, Thai Tsunami Victim Identification - Overview to Date, The Journal of Forensic Odonto-Stomatology 23 (2005) 1-18.

[3] T. Lay, H. Kanamori, C. Ammon, M. Nettles, S. Ward, R. Aster, C.R, S. Beck, S. Bilek, M. Brudzinski, R. M, R. Butler, H. DeShon, G. Ekstrom, K, Satake, S. Sipkin, The great SumatraAndaman earthquake of 26 December 2004, Science 308 (2005) 1127-1133.

[4] INTERPOL DVI Guide, 18 November 2014

http://www.interpol.int/Media/Files/INTERPOL-Expertise/DVI/DVI-Guide.

[5] TTVI Operations Thailand, 18 November 2014

http://www.who.int/hac/events/tsunamiconf/presentations/2 16 forensic kent ppt.pdf.

[6] News 24, 27 August 2014

http://www.news24.com/World/Archives/TsunamiDisaster/DNA-to-identify-tsunami-dead$\underline{20050110}$

[7] The Sydney Morning Herald, 27 August 2014

http://www.smh.com.au/news/Asia-Tsunami/DNA-only-way-to-identify-mostbodies/2005/01/05/1104832179614.html

[8] Office of Chief Medical Examiner World Trade Centre Operational Statistics. Printed 3 May 2011 
[9] J Watts and J Aglionby, 'Long and Agonising Task to Identify Bodies', The Guardian (London), 15 October 2002.

[10] Hirsch C, Brondolo T, Butcher B. Report to HE Dr. Surachai, Minister of Public Health, Thailand, and Dr. William Aldis, WHO representative to Thailand World Health Organization. Assessment of victim identification operations: Thailand tsunami disaster. New York: City of New York office of Chief Medical Examiner; 2005. p. 11

[11] O. Morgan, P. Sribanditmongkol, C. Perera, Y. Sulasmi, D. Van Alphen, E. Sondorp, Mass fatality management following the South Asian Tsunami Disaster: Case studies in Thailand, Indonesia, and Sri Lanka, PLoS Medicine (2006) 809-815.

[12] B. Rai, S, Anand, Role of forensic odontology in Tsunami disasters, The Internet Journal of Forensic Science (2006) Vol 2.

[13] J. Chaikunrat, P. Pongpanitanon, M. Petju, Victim identification in the tsunami disaster in Thailand, Journal of Health Science 20:6 (2011) 897-902.

[14] R. Lessig, C. Grundmann, F. Dahlmann, K. Rotzscher, J. Edelmann, P. Schneider, Tsunami 2004- a review of one year of continuous forensic medical work for victim identification, EXCLI Journal 5 (2006) 128-129.

[15] P. Schuller-Götzburg, J. Suchanek, Forensic odontologists successfully identify tsunami victims in Phuket, Thailand, Forensic Science International 171 (2007) 204-207.

[16] A. Sozer, DNA Analysis for Missing Person Identification in Mass Fatalities. Boca Raton (Florida): CRC Press 2014.

[17] R. Shaler, Who They Were. New York (New York): Free Press 2005.

[18] K. Wright, A. Mundorff, J. Chaseling, A. Forrest, C. Maguire, D.I. Crane, A New Disaster Victim Identification Management Strategy Targeting "Near Identification-

Threshold" Cases: Experiences from the Boxing Day Tsunami. Forensic Science International 250 (2015) 91-97.

[19] K. Wright, J. Chaseling, A. Mundorff, C. Maguire, D.I. Crane, DNA Identification of Child Victims of the South-East Asia Tsunami in Thailand. 2015 Unpublished manuscript.

[20] G. Holmlund, I. Lodestad, H. Nilsson, B. Lindblom, Experiences from DNA analysis in Sweden for the identification of tsunami victims, International Congress Series 1288 (2006) 744-746.

[21] M. Petju, A. Suteerayongprasert, R. Thongpud, K. Hassiri, Importance of dental records for victim identification following the Indian Ocean tsunami, Public Health 121 (2007) 251-257.

[22] P. Sribanditmongkol, P. Pongpanitanont, Forensic aspect of disaster casualty management tsunami victim identification in Thailand, 23 December 2014 http://www.who.int/hac/events/tsunamiconf/presentations/2 16 forensic pongruk doc.pdf

[23] M. Tsokos, R. Lessig, C. Grundmann, S. Benthaus, Experiences in tsunami victim identification, International Journal of Legal Medicine 120 (2006) 185-187.

[24] S. Mishra, H. Mahajan, R. Sakorikar, A. Jain, Role of prosthodontist in forensic odontology. Literature review, Journal of Forensic Dental Sciences, 6:3 (2014) 154-159

[25] M. Perrier, M. Bollmann, A. Girod, P. Mangin, Swiss DVI at the tsunami disaster: Expect the unexpected, Forensic Science International 159S (2006) S30-S32. 
